\title{
Estimativas do consumo de sódio no Brasil, revisão dos benefícios relacionados à limitação do consumo deste nutriente na Síndrome Metabólica e avaliação de impacto de intervenção no local de trabalho
}

Flávio Sarno

Tese apresentada ao Programa de Pós Graduação em Nutrição em Saúde Pública para obtenção do título de Doutor em Ciências

Área de concentração: Nutrição em Saúde Pública

Orientador: Professor Titular Carlos Augusto Monteiro

São Paulo 
É expressamente proibida a comercialização deste documento, tanto na sua forma impressa como eletrônica. Sua reprodução total ou parcial é permitida exclusivamente para fins acadêmicos e científicos, desde que na reprodução figure a identificação do autor, título, instituição e ano da tese/dissertação. 


\section{DEDICATÓRIA}

AOS MEUS AVÓS: Gennaro Sarno, João Bessa, Rachele Antonia Colicigno Sarno, Rosa Helena Pimentel Bessa.

AOS MEUS PAIS: Antonio Luiz Sarno e Elza Bessa Sarno.

À MINHA TIA: Maria da Glória Bessa.

Todos começaram suas vidas com dificuldades, porém com esperanças e vontade de construir.

Minha chegada até aqui está embasada e só foi possível depois de décadas de dedicação, esforços e renúncias destas pessoas.

Portanto, este momento e este trabalho pertencem e são dedicados a elas. 


\section{AGRADECIMENTOS}

Ao Professor Titular Carlos Augusto Monteiro.

Deve-se ao professor Carlos o mérito de nos orientar a estudar o tema consumo de sódio, vislumbrando com antecedência o aumento das discussões em torno desta questão.

À Professora Doutora Patrícia Constante Jaime.

A professora Patrícia nos acolheu prontamente em seu grupo de pesquisa, onde pudemos desenvolver trabalhos conjuntos que contribuíram muito com o resultado final da tese.

\section{À Professora Titular Sandra Roberta G. Ferreira.}

Agradecemos a professora Sandra pelo voto de confiança para participarmos de seus projetos de trabalho. O aprendizado obtido nestas participações e discussões foi parte muito importante da elaboração desta tese.

Aos membros da banca: Profa. Dra. Dirce Marchioni, Dra. Lenise Mondini, Profa. Titular Maria Zanella e Profa. Dra. Maria Gondim Peixoto.

As sugestões e correções das professoras acrescentaram qualidade e contribuíram muito com o trabalho final.

Aos amigos Daniel Bandoni e Rafael Claro

Começamos e terminamos juntos a pós-graduação. Amigos de todas as horas, estiveram sempre prontos a nos ajudar e a partilhar seus conhecimentos.

Aos amigos de pesquisa Renata Levy, Bettina Brasil, Kelly Bombem, Adriana Pellogia, Iramaia Figueiredo, Natalia Okada e Lais Peccia

Ajudaram muito em vários momentos da confecção da tese: coleta de 
dados, reuniões e discussões das análises dos dados dos artigos que compõem esta tese.

À Regina

Esteve sempre pronta a nos ajudar em todos os processos que envolveram as pesquisas e o doutorado.

Aos funcionários do Departamento de Nutrição

Agradecemos a todos que sempre foram atenciosos com nossas solicitações.

Enfim, esta tese é fruto da colaboração e participação de todos, que em vários momentos sugeriram, opinaram, corrigiram, ou seja, tornaram este trabalho melhor.

Agradeço a todos vocês! 


\section{EPÍGRAFE}

\section{Os cegos e o elefante}

Poema de John Godfrey Saxe (1816 - 1887). Baseado em uma parábola indiana (tradução livre).

Eram seis homens da Índia, muito inclinados a aprender, que foram ver o elefante. Embora todos eles fossem cegos, que cada um, por meio de observação, pudesse satisfazer a sua mente.

O primeiro aproximou-se do elefante e caiu contra o seu lado mais amplo e robusto. Imediatamente começou a berrar: "Valha-me Deus! Mas o elefante é muito parecido com uma parede!"

O segundo, sentindo sua presa, chorou, "O que temos aqui é muito redondo e liso e afiado? Para mim, isto está claro: esta maravilha de elefante é muito parecido com uma lança!"

O terceiro aproximou-se do animal e tomou sua tromba a contorcer-se dentro de suas mãos. Assim, corajosamente falou: "Eu vejo o elefante e é muito parecido com uma cobra!"

O quarto esticou a mão ansiosa e sentiu o joelho. "Com o que mais é parecida este maravilhosa besta? Está bastante claro: o elefante é muito semelhante a uma árvore!"

O quinto, que teve a chance de tocar na orelha, disse: "O homem cego pode dizer com o que isto se assemelha mais. Quem pode negar o fato de que esta maravilha de elefante é muito parecido com um abanador!"

O sexto mal havia começado a apalpar a besta e apodera-se da cauda balançante, que caíra dentro do seu alcance: "Eu vejo o elefante e é muito parecido com uma corda!"

E assim, esses homens da Índia discutiram alto e longamente, cada um com suas próprias opiniões, demasiadas firmes e fortes. Embora cada um estivesse, em parte, correto todos estavam errados!

\section{Moral da história:}

Assim, frequentemente como em guerras teológicas, os disputantes, eu suponho, fechados em suas absolutas ignorâncias sobre o que cada um quis dizer, tagarelam sobre um elefante que nenhum deles viu! 


\section{RESUMO}

Sarno F. Estimativas do consumo de sódio no Brasil, revisão dos benefícios relacionados à limitação do consumo deste nutriente na Síndrome Metabólica e avaliação de impacto de intervenção no local de trabalho. São Paulo; 2010. [Tese de Doutorado. Faculdade de Saúde Pública da Universidade de São Paulo].

Introdução: O consumo excessivo de sódio tem se associado com vários efeitos prejudiciais à saúde, como aumento da pressão arterial (PA) e doença cardiovascular. Objetivos: Os objetivos da tese foram avaliar a disponibilidade de sódio no Brasil, analisar os efeitos de dietas com teores reduzidos de sódio em indivíduos com Síndrome Metabólica (SM) ou resistência à insulina $(\mathrm{RI})$ e avaliar o impacto de uma intervenção que promoveu a redução da adição de sal aos alimentos. Sujeitos e métodos: A tese está composta de três artigos. O primeiro deles avaliou as aquisições de alimentos e bebidas realizadas pelos domicílios na Pesquisa de Orçamento Familiar de 2002/2003 do Instituto Brasileiro de Geografia e Estatística. O segundo artigo revisou a literatura de forma sistemática acerca dos ensaios clínicos realizados em adultos entre anos de 2004 e 2008. E o último artigo avaliou o impacto de uma intervenção, baseada no modelo ecológico de promoção de saúde, na redução da adição de sal nos alimentos consumidos por trabalhadores de empresas da cidade de São Paulo. Resultados: A quantidade diária de sódio disponível para consumo nos domicílios brasileiros foi de 4,7 g per capita e para uma ingestão diária de $2.000 \mathrm{kcal}$. A maior parte do sódio disponível para consumo proveio do sal de cozinha e de condimentos à base desse sal (76,2\%). A fração proveniente de alimentos processados com adição de sal representou 9,7\% do total de sódio no quinto inferior da distribuição da renda per capita e $25,0 \%$ no quinto superior. A restrição no consumo de sódio associou-se ao aumento da $\mathrm{RI}$ em dois artigos e à diminuição em três outros. Em sete dos nove artigos, uma dieta com teor reduzido de sódio determinou redução da 
PA e em dois artigos ocorreram efeitos adversos em marcadores da SM. Nas análises multivariadas, homens (IRR $=0,51)$ e aqueles considerados normotensos (IRR $=0,61)$ alocados no grupo intervenção no momento final apresentaram taxas menores de adição de sal ao prato quente. Conclusões: $O$ consumo de sódio no Brasil excede largamente a recomendação máxima para esse nutriente. A maioria dos estudos da revisão sistemática mostrou efeitos benéficos da restrição moderada de sódio da dieta, associada ou não a outras modificações nutricionais ou ao aumento da atividade física. A intervenção realizada no ambiente de trabalho reduziu a taxa de relato de adição de sal no prato quente entre trabalhadores do sexo masculino e entre aqueles categorizados como normotensos.

Descritores: Cloreto de Sódio; Sódio na Dieta; Brasil; Dieta Hipossódica; Síndrome Metabólica; Resistência à Insulina; Redução da adição de sal; Ambiente de Trabalho. 


\begin{abstract}
Sarno F. Estimativas do consumo de sódio no Brasil, revisão dos benefícios relacionados à limitação do consumo deste nutriente na Síndrome Metabólica e avaliação de impacto de intervenção no local de trabalho. [Estimates of sodium consumption in Brazil, review of benefits related to limiting the consumption of this nutrient in the Metabolic Syndrome and assessment of impact of intervention at the workplace.] São Paulo (Br); 2010. [Tese de Doutorado. Faculdade de Saúde Pública da Universidade de São Paulo].
\end{abstract}

Introduction: The excess of sodium consumption has been associated with several adverse health effects, such as increased of blood pressure (BP) and cardiovascular disease. Objectives: Evaluate the availability of sodium in Brazil, analyze the effects of diets with reduced sodium content in subjects with Metabolic Syndrome (MS) or insulin resistance (IR) and evaluate the impact of an intervention which promoted the reduction of adding salt to foods. Subjects and Methods: The thesis is composed of three articles. The first one assessed the food and beverage purchases made by households in the Household Budget Survey of 2002/2003, by the Brazilian Institute of Geography and Statistics. The second article reviewed the literature in a systematic way about clinical trials performed in adults between the years 2004 and 2008. And the last paper assessed the impact of an intervention, based on the ecological model of health promotion, in reducing the added salt to foods consumed by employees of Sao Paulo based companies. Results: The daily amount of sodium available in Brazilian households was $4.7 \mathrm{~g}$ daily per person for $2,000 \mathrm{kcal}$ intake. Most of the sodium available for consumption comes from the salt and salt based seasonings $(76.2 \%)$. The fraction derived from processed foods with added salt represented $9.7 \%$ of total sodium intake at the bottom of per person income distribution and $25.0 \%$ at the top fifth. The restriction in sodium intake was associated with increased IR in two articles and the decrease in three others. In seven of the 
nine articles, the salt intake restriction had caused decreased in BP and in two articles have occurred adverse effects on markers of MS. In multivariate analysis, men $(I R R=0.51)$ and those considered normotensive $(I R R=0.61)$ allocated in the intervention group at the final moment had lower rates of salt addition in the hot meal. Conclusions: The results indicate that sodium intake in Brazil far exceeds the maximum recommended intake for this nutrient. Most studies have shown beneficial effects of a diet with moderate sodium restriction, with or without other nutritional modifications or increased physical activity. The intervention carried out at the workplace reduced the reporting rate of salt addition in the hot meal by male workers and those categorized as normotensive.

Descriptors: Sodium Chloride; Sodium, Dietary; Brazil; Diet, SodiumRestricted; Metabolic Syndrome, Insulin Resistance; Reduction of added salt; Workplace. 


\section{APRESENTAÇÃO}

Esta tese está composta por introdução, objetivos, três artigos e resultados e conclusões finais.

$\mathrm{Na}$ introdução são levantados os aspectos gerais sobre o tema em estudo (sal e sódio). A seguir são apresentados os objetivos da tese.

Os três artigos procuraram responder aos objetivos da tese e estão apresentados de forma independente, cada um com suas respectivas introduções, objetivos, métodos, resultados, conclusões e referências.

Ao término, são apresentados os resultados e conclusões finais que buscaram aglutinar, tanto os resultados obtidos nos artigos, quanto as informações apresentadas na introdução e os consensos existentes na literatura sobre consumo de sal e sódio. 


\section{ÍNDICE GERAL}

Índice Geral

Página

1. INTRODUÇÃO. 18

1.1 História do sal. 18

1.2 Consumo de sódio - métodos de aferição..................... 19

1.3 Produção e consumo de sal no mundo e no Brasil....... 21

1.4 Sal e saúde................................................................. 25

1.4.1 Sódio e Pressão Arterial.................................... 25

1.4.2 Sódio e Síndrome Metabólica............................. 26

1.4.3 Sódio e Doença Cardiovascular......................... $\quad 27$

1.5 Intervenções e consumo de sódio.................................. 28

1.5.1 Ambiente de Trabalho...................................... 28

1.5.2 Redução do consumo de sódio.......................... 29

1.5.3 Dieta DASH................................................... $\quad 30$

1.6 Controvérsias ........................................................... 31

2. OBJETIVOS

2.1 Objetivos específicos................................................ 34

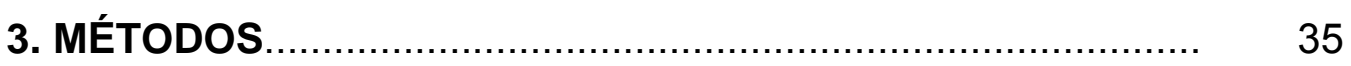

4. PRIMEIRO ARTIGO.......................................................... 36

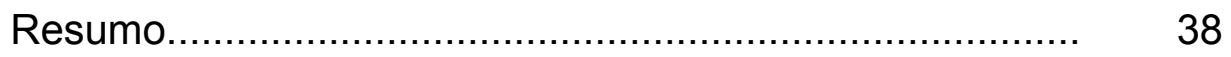

Abstract............................................................... 40

Introdução e objetivos....................................................... 41

Métodos............................................................. 42

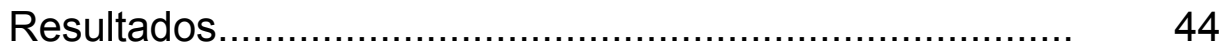

Discussão e Conclusões..................................................... 46

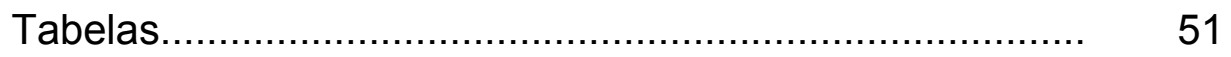

Referências.............................................................. 54

5. SEGUNDO ARTIGO .............................................................. 5

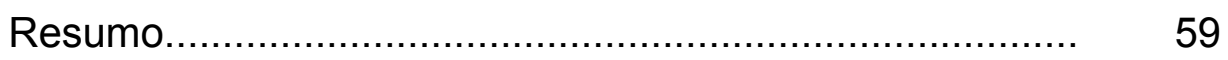

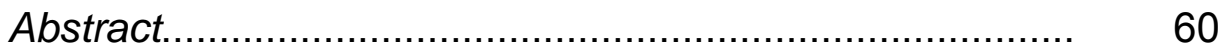


Introdução e objetivos........................................................ 61

Métodos................................................................ 66

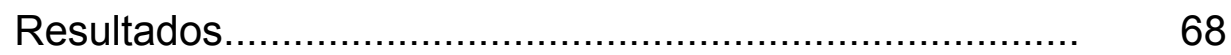

Discussão e Conclusões.................................................. 70

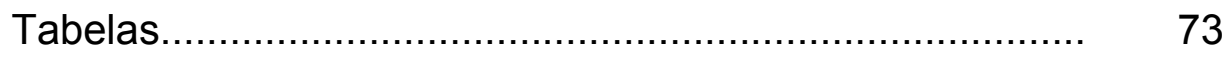

Referências............................................................. 77

6. TERCEIRO ARTIGO

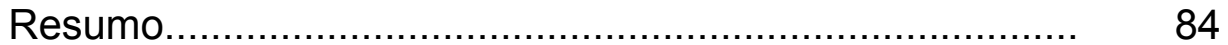

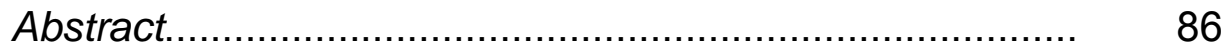

Introdução e objetivos................................................... 88

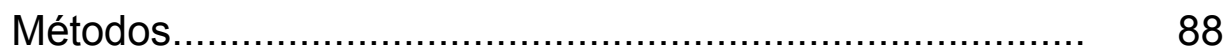

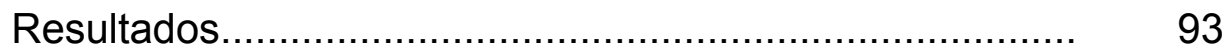

Discussão e Conclusões.................................................. 94

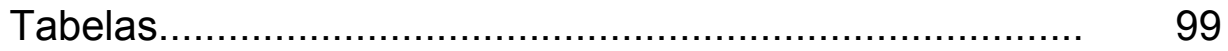

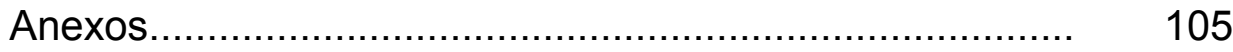

Referências.................................................................... 120

7. RESULTADOS E CONCLUSÕES FINAIS............................... 123

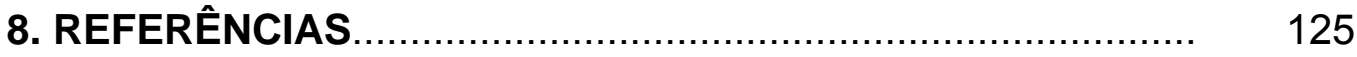

9. CURRÍCULO LATTES: Professor Titular Carlos Augusto

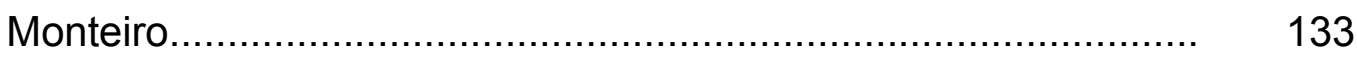

10. CURRÍCULO LATTES: Flávio Sarno................................... 135 
LISTA DE TABELAS E ANEXOS

Índice

Página

1. INTRODUÇÃO

Gráfico 1. Estimativa da produção mundial de sal, de 22 acordo com países selecionados. 2007 a 1998.

Tabela 1. Estimativas de consumo de sódio no Brasil, 24 segundo estudos selecionados.

\section{PRIMEIRO ARTIGO}

Tabela 1. Disponibilidade domiciliar de energia e de sódio,

decorrente da aquisição de alimentos, segundo macrorregião e situação urbana ou rural do domicílio. Brasil, 2002/03.

Tabela 2. Disponibilidade domiciliar de energia e de sódio, 52 decorrente da aquisição de alimentos, segundo quintos crescentes da distribuição de renda domiciliar per capita. Brasil, 2002/03.

Tabela 3. Distribuição (\%) da disponibilidade domiciliar de sódio, decorrente da aquisição de alimentos, em quintos crescentes da distribuição da renda domiciliar per capita, segundo grupos de alimentos. Brasil, 2002/03.

\section{SEGUNDO ARTIGO}

Tabela 1. Artigos incluídos na revisão de acordo com autor,

ano de publicação e segundo características das populações submetidas às intervenções.

Tabela 2. Artigos incluídos na revisão de acordo com autor, ano de publicação e segundo características das intervenções.

Tabela 3. Artigos incluídos na revisão de acordo com autor, ano de publicação e segundo características das intervenções, diferenças avaliadas e resultados e 
conclusões principais.

\section{TERCEIRO ARTIGO}

Tabela 1. Características dos participantes antes e após a

intervenção e segundo grupo de alocação. São Paulo, 2006-2007.

Tabela 2. Frequências (\%) e intervalos de confiança de 100 95\% (IC 95\%) do hábito de adicionar sal aos alimentos antes e após a intervenção, de acordo com as características dos participantes e segundo grupo de alocação. São Paulo, 2006-2007.

Tabela 3. Frequências (\%) e intervalos de confiança de 102 95\% (IC 95\%) do hábito de adicionar sal no prato quente antes e após a intervenção, de acordo com as características dos participantes e segundo grupo de alocação. São Paulo, 2006-2007.

Tabela 4. Razão da taxa de incidência (IRR) dos 104 participantes pertencentes ao grupo intervenção no momento final, segundo as variáveis do estudo. São Paulo, 2006-2007.

Anexo 1. Manual.

Anexo 2. Mini álbum seriado.

Anexo 3. Cartazes ou fundos de bandeja, banners e frases para serem veiculadas por meio da mídia da empresa.

Anexo 4. Fôlder e Filipeta.

Anexo 5. Comitê de Ética. 


\section{LISTA DE ABREVIAÇÕES E SIGLAS}

DASH - Dietary Approaches to Stop Hypertension - Abordagem dietética para controle da hipertensão arterial

DCNT - Doenças Crônicas não Transmissíveis

DCV - Doença Cardiovascular

DM - Diabetes Mellitus

EGIR - European Group for the Study of Insulin Resistance - Grupo

Europeu para o estudo da resistência á insulina

EUA - Estados Unidos da América

HA - Hipertensão Arterial

HAS - Hipertensão Arterial Sistêmica

HDL - High Density Lipoprotein - Lipoproteína de Alta Densidade

HOMA - Homeostatic Model Assessment - Modelo de Avaliação de Homeostase

IBGE - Instituto Brasileiro de Geografia e Estatística

IDF - International Diabetes Federation - Federação Internacional de Diabetes

LDL - Low Density Lipoprotein - Lipoproteína de Baixa Densidade

NCEP - National Cholesterol Education Program - Programa Nacional de Educação em Colesterol

NHANES - National Health and Nutrition Examination Survey - Inquérito Nacional em Saúde e Nutrição

OMS - Organização Mundial da Saúde

PAS - Pressão Arterial Sistólica

PAD - Pressão Arterial Diastólica

PAT - Programa de Alimentação do Trabalhador

PCR - Proteína C Reativa

POF - Pesquisa de Orçamentos Familiares

SM - Síndrome Metabólica

TG - Triglicerídeos

UAN - Unidade de Alimentação e Nutrição 


\section{EQUIVALÊNCIAS}

$1.000 \mathrm{mg}$ de sal $\approx 400 \mathrm{mg}$ de sódio $\approx 17,4 \mathrm{mmol}$ de sódio

$1 \mathrm{mmol}$ de sódio $=23 \mathrm{mg}$ de sódo 


\section{INTRODUÇÃO}

\subsection{História do sal}

Sódio, usualmente encontrado nos alimentos na forma de cloreto de sódio ou sal, é um nutriente essencial para manutenção de várias funções fisiológicas do organismo: transmissão nervosa, contração muscular, manutenção da pressão arterial e equilíbrios de fluidos e ácido básico. Apesar disso, adicionar sal à dieta não é necessário, pois a quantidade necessária para repor as perdas do nutriente é próxima do conteúdo já existente nos alimentos in natura. Além disso, o organismo apresenta alta capacidade de conservar sódio e perdas importantes do mineral só ocorrem em situações não usuais, como na sudorese prolongada.(1)

O hábito de acrescentar sal aos alimentos ocorreu apenas com a introdução da agricultura, cerca de 10.000 anos atrás. Antes disso, e por vários milhões de anos, os ancestrais dos seres humanos consumiram uma dieta que continha quantidades bastante pequenas de sal. Seu uso era desconhecido dos povos, geralmente nômades, que viviam da caça e da coleta de alimentos, tanto que antigos idiomas não possuem uma palavra para sal.(2)

Uma dieta da era paleolítica compreendendo, em bases energéticas, aproximadamente dois terços de alimentos de origem vegetal e um terço de origem animal, fornecia cerca de $0,8 \mathrm{~g}$ de sódio por dia. Para cada 1.000 Kcal ingeridas, nossos ancestrais consumiam em torno de 0,3 $\mathrm{g}$ de sódio, em comparação com $1,9 \mathrm{~g}$ dos dias atuais.(3)

Há cerca de 5.000 anos, os chineses descobriram que o sal podia ser utilizado na preservação dos alimentos, o que permitiu o estoque de alimentos, reduziu a necessidade dos povos de migrar e ajudou na fixação permanente de grupos de indivíduos e no desenvolvimento de comunidades.(4) Porém, a adição de sal causou elevação do consumo de sódio, para um maquinário renal ainda geneticamente fixado no período de nossos antepassados, ou seja, não preparado para excretar as grandes 
quantidades de sódio consumidas.(5) A adição de sal aos alimentos durante os períodos Neolítico e Industrial causou um aumento de cerca de $400 \%$ na ingestão de sódio.(6)

Com o advento da refrigeração, o sal não necessitava mais ser utilizado como conservante e sua ingestão começou a decair. Entretanto, o consumo de sal voltou a aumentar com a elevação da ingestão de alimentos processados com adição de sal, estando atualmente entre 9 e $12 \mathrm{~g}$ por dia na maioria dos países.(4)

No passado, o sal influenciou profundamente o pensamento, a cultura e o estilo de vida humano de uma forma que atualmente não pode mais ser devidamente apreciada, agora que se tornou uma substância facilmente disponível. O "ouro branco" era motivo de discussão de altas autoridades, de forma comparável ao que o petróleo representa nos dias de hoje.(2)

O sal está associado com saúde: as expressões latinas para saúde e saudável, salus e salubris, são derivadas de sal. Em muitas culturas foi o equivalente de dinheiro, como na Roma antiga onde os soldados e os oficiais eram reembolsados na forma de um salarium, a partir do qual a palavra salário é derivada. Na África, já foi trocado por ouro na proporção de um para um.(2)

O sal desempenhou também um papel central na economia de muitas regiões, o que está muitas vezes refletido nos nomes de diversas localidades. Foi utilizado como base para tributação e monopólios foram praticados em muitos Estados. O sal esteve também no foco de conflitos como, por exemplo, na Revolução Francesa e na Guerra da Independência da Índia.(7)

A importância do sal na cultura humana pode ser resumida nas palavras de Ritz: "ainda hoje, talvez subconscientemente, o sal não se tornou uma substância emocionalmente neutra devido, pelo menos em parte, aos resquícios de seus profundos significados simbólicos anexados ao longo de milênios."(2)

1.2 Consumo de sódio - métodos de aferição 
Os métodos atualmente disponíveis para avaliação de consumo de sódio podem ser utilizados isoladamente ou em conjunto: avaliação da alimentação (questionário de frequência alimentar, diário alimentar, recordatório alimentar de $24 \mathrm{~h}$ e análise por meio de duplicatas de consumo), marcação do sal com lítio, pesagem do sal consumido, disponibilidade (aquisição) de alimentos e de sal e dosagem de sódio em urina de 8 h, 24 h ou em amostra isolada.(8-11)

Porém, a avaliação acurada do consumo de sódio pela população permanece uma tarefa difícil de ser realizada. As várias metodologias existentes apresentam limitações que se devem, em parte, às diversas fontes de sódio encontradas na alimentação. Apesar de que mais de $90 \%$ do sódio consumido provenham do sal (cloreto de sódio), este se encontra distribuído entre a ocorrência natural nos alimentos e sua adição durante o processamento, no preparo dos alimentos e à mesa. A quantidade de sódio presente na água representa uma fração não significativa de consumo do mineral.(12)

Grande parte da dificuldade em se estimar o consumo de sódio por meio de inquéritos alimentares se deve à fração do consumo total de sal adicionada à mesa ou no preparo dos alimentos, que em várias populações, inclusive a brasileira, é a fração responsável pela maior parte do consumo de sódio.(13)

Resultados variados têm sido obtidos na estimativa do consumo de sódio, tanto com a utilização de vários tipos diferentes de questionários, quanto de métodos tradicionais de avaliação alimentar. $(8,14,15) \mathrm{A}$ revisão dos questionários de frequência alimentar desenvolvidos no Japão para avaliar ingestão de sódio mostrou coeficiente de correlação mediano de 0,33 nos estudos de validação.(16)

A excreção urinária de sódio de $24 \mathrm{~h}$ é recomendada pela Organização Mundial da Saúde como o melhor método para estimar o consumo de sódio.(17) O método captura cerca de $86 \%$ do sódio ingerido (18), porém o procedimento de coleta necessita de alta adesão do participante para o recolhimento completo da urina do período. Além disso, 
utilizado isoladamente, o método não possibilita informações sobre as diversas fonte de sódio da alimentação e devido à necessidade de se obter todas as micções das $24 \mathrm{~h}$, restringe a avaliação do consumo de sódio àquele realizado dentro do domicílio. Assim, faz-se necessário avançar em formas mais convenientes de avaliar comportamentos de ingestão, bem como estimar impactos de intervenções relacionadas ao consumo de sal.(19) A escolha da melhor estratégia para análise do consumo de sódio depende não só das limitações e vantagens de cada método, mas também dos recursos disponíveis e das características de consumo de sal da população em estudo.

\subsection{Produção e consumo de sal no mundo e no Brasil}

A indústria do sal se refere apenas aos produtores ou também a toda cadeia de distribuição para os consumidores finais. A estrutura desta indústria difere geograficamente, refletindo diversas condições econômicas, políticas e culturais. Em alguns sistemas, podem ser pequenas empresas familiares e, em outros, grandes aglomerados internacionais que operam em diversos continentes. Além disso, através da história, muitos governos têm sido os proprietários das instalações de produção de sal, refletindo a importância estratégica do produto.(20)

Maior produtor tradicional de sal do mundo, os EUA foram superados em 2006 pela China. Combinados, os países representam cerca de $40 \%$ da produção total de sal do mundo, estimada em 257 milhões de toneladas métricas em 2007. O Brasil apresenta uma produção estável desde 1998 e é o oitavo maior produtor de sal do mundo, com 6,9 milhões de toneladas métricas (Gráfico 1).(21) 
Gráfico 1. Estimativas da produção de sal, de acordo com países selecionados. 2007 a 1998.

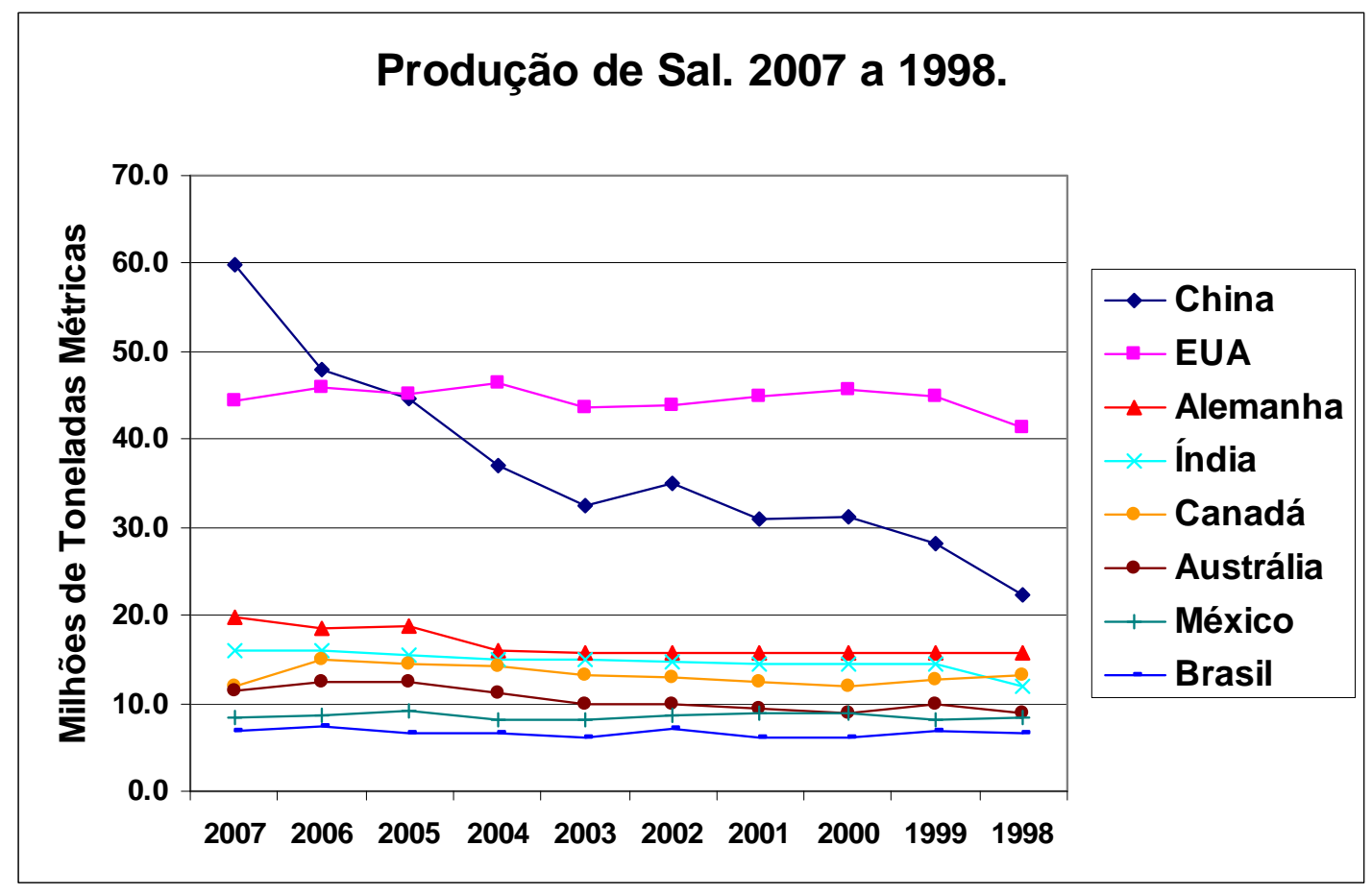

Recente revisão dos estudos que avaliaram o consumo de sódio em diversos países demonstrou que na maioria das populações o consumo do mineral encontra-se acima de $100 \mathrm{mmol}$ por dia $(2,3 \mathrm{~g})$ e, em particular na China e Japão, a ingestão média esteve acima de $200 \mathrm{mmol}$ por dia (4,6 g).(22)

No Brasil, os primeiros estudos sobre consumo de sal datam da década de 70 do século passado. A partir da análise do gasto mensal ou aquisição de alimentos, estimou-se que a disponibilidade domiciliar de sódio foi de 5,9 g em 1971-1972 para uma aquisição de 2.000 kcal.(23) Em outros estudos, levando-se em conta diferenças de amostragem e metodologia de avaliação de consumo de sódio, observou-se que o consumo variou entre $3,1 \mathrm{~g} \mathrm{e} \mathrm{4,9} \mathrm{g} \mathrm{mmol} \mathrm{por} \mathrm{dia} \mathrm{(tabela} \mathrm{1).}$

Em relação à procedência do sódio, existem diferenças importantes quando são comparados países desenvolvidos e em desenvolvimento. Nos primeiros, estima-se que a maior parte do sódio consumido pelos indivíduos provenha de alimentos processados pela indústria. Já nos países em 
desenvolvimento, a maior parte do sódio consumido é proveniente do sal de cozinha e de condimentos à base desse sal adicionados no preparo dos alimentos ou à mesa.(24) 
Tabela 1. Estimativas de consumo de sódio no Brasil, segundo estudos selecionados.

\begin{tabular}{|c|c|c|c|c|c|}
\hline Referências & $\begin{array}{c}\text { Ano da } \\
\text { pesquisa }\end{array}$ & $\mathrm{n}$ & $\begin{array}{c}\text { Metodologia de avaliação do } \\
\text { sódio }\end{array}$ & $\begin{array}{c}\text { Características } \\
\text { da amostra }\end{array}$ & $\begin{array}{l}\text { Sódio } \\
\text { g / dia }\end{array}$ \\
\hline $\begin{array}{c}\text { Sarno e cols., } \\
\text { 2009.(13) }\end{array}$ & $2002-2003$ & $\begin{array}{c}48.470 \\
\text { domicílios }\end{array}$ & $\begin{array}{l}\text { Quantidade de alimentos } \\
\text { adquiridos }\end{array}$ & Brasil & $4,7^{*}$ \\
\hline \multirow{2}{*}{$\begin{array}{l}\text { Claro e cols., } \\
\text { 2007.(23) }\end{array}$} & $1971-1972$ & 10.418 & $\begin{array}{c}\text { Gasto Mensal com aquisição } \\
\text { dos alimentos }\end{array}$ & Cidade de São Paulo & $5,9^{*}$ \\
\hline & $1998-1999$ & 7.980 & $\begin{array}{l}\text { Quantidade de alimentos } \\
\text { adquiridos }\end{array}$ & Cidade de São Paulo & $4,5^{*}$ \\
\hline \multirow{2}{*}{$\begin{array}{l}\text { Moraes e cols., } \\
\text { 2000.(25) }\end{array}$} & \multirow{2}{*}{$1990-1992$} & 27 & \multirow{2}{*}{ Urina noturna } & $\begin{array}{c}\text { Com história familiar de } \\
\text { HAS }\end{array}$ & 3,1 \\
\hline & & 130 & & $\begin{array}{c}\text { Sem história familiar de } \\
\text { HAS }\end{array}$ & 3,1 \\
\hline \multirow{2}{*}{$\begin{array}{l}\text { Molina e cols., } \\
\text { 2003.(26) }\end{array}$} & \multirow{2}{*}{$1999-2000$} & 764 & \multirow{2}{*}{ Urina noturna } & Homens & 4,9 \\
\hline & & 899 & & Mulheres & 4,3 \\
\hline \multirow{2}{*}{$\begin{array}{c}\text { Michelia e Rosa, } \\
\text { 2003.(27) }\end{array}$} & \multirow{2}{*}{$2000-2001$} & 31 & Urina de $24 \mathrm{~h}$ & 6 a 17 anos & 3,4 \\
\hline & & 188 & Urina noturna & 6 a 17 anos & 3,1 \\
\hline $\begin{array}{c}\text { Pavan e cols., } 1997 . \\
\text { (28) }\end{array}$ & $1997^{* *}$ & 370 & Questionário alimentar & & 4,0 \\
\hline
\end{tabular}




\subsection{Sal e saúde}

O consumo excessivo de sal tem se associado com vários efeitos prejudiciais à saúde. Foram observadas evidências da associação entre alto consumo de sódio e doença cardiovascular, acidente vascular cerebral, hipertrofia ventricular esquerda, independentemente ou associadas com a elevação da pressão arterial. Além disso, outros agravos incluem neoplasia de estômago, doença e calculose renal, osteoporose, asma e obesidade.(4)

\subsubsection{Sódio e pressão arterial}

Vários estudos têm sido conduzidos e, quase todos eles, apoiam o conceito de que o consumo de sal é um importante fator no aumento da pressão arterial da população. Tal conceito está embasado em pesquisas com diversos delineamentos, desde estudos em animais, de genética humana, de migração, com sociedades não aculturadas, até estudos observacionais e de intervenção.(4) Estima-se que $30 \%$ da hipertensão arterial possa ser atribuída ao consumo excessivo de sal (29), sendo o restante constituído por genética, excesso de peso e diminuição do consumo de potássio, entre outros fatores.

Por outro lado, a resposta da pressão arterial frente a modificações no consumo de sódio não é homogênea na população. Existem indivíduos que apresentam tendência maior ou menor para queda ou aumento da pressão arterial frente a reduções ou suplementações de sal, fenômeno este conhecido como sensibilidade ao sal.

Utilizando-se o método proposto por Weinberger e colaboradores ${ }^{a}$, $51 \%$ e $33 \%$ dos indivíduos com hipertensão arterial e $26 \%$ e $58 \%$ dos indivíduos normotensos foram classificados como sensíveis ou resistentes

\footnotetext{
a Aferição das diferenças de pressões arteriais médias observadas antes e após a administração intravenosa de dois litros de solução salina a 0,9\% em 4 h e antes e após a depleção de sódio da dieta (10 mmol por um dia), associada à administração de furosemida (3 doses de $40 \mathrm{mg}$ ). A sensibilidade ao sal foi definida quando da obtenção de uma diferença de $10 \mathrm{mmHg}$ ou mais entre as situações de carga e depleção de sal e a resistência ao nutriente por uma diferença igual ou menor de $5 \mathrm{mmHg}$. Os indivíduos restantes foram classificados como apresentando resposta indeterminada.
} 
ao sal, respectivamente.(30) Além da hipertensão arterial, são reconhecidos outros determinantes da sensibilidade ao sal, como etnia negra, maior idade (31) e histórico de baixo peso ao nascimento (32). Além disso, fatores genéticos (33), disfunções renais hereditárias ou adquiridas (34) e dieta (1, 35) influenciam as modificações da pressão arterial frente às variações no consumo de sal.

\subsubsection{Sódio e Síndrome Metabólica}

A Síndrome Metabólica consiste de uma complexa inter-relação entre fatores de risco para doença cardiovascular, como alteração do metabolismo da glicose, aumento da pressão arterial e dos níveis de triglicérides, diminuição da HDL colesterol e obesidade (particularmente adiposidade central). Embora a patogênese da Síndrome Metabólica não esteja completamente estabelecida, seus múltiplos componentes estão conectados possivelmente à resistência à insulina.(36)

Estresse oxidativo, disfunção endotelial, sistema renina angiotensina aldosterona ativado, aumento de mediadores inflamatórios e apnéia do sono obstrutiva têm sido propostos como fatores associados à hipertensão arterial na síndrome metabólica, atuando por meio da hiperatividade simpática, vasoconstrição, aumento de líquido intravascular e diminuição da vasodilatação.(37)

Além disso, o excesso de ingestão de sódio e alterações na manipulação do mineral levando à sua retenção são conceitos fisiopatológicos básicos da hipertensão arterial. A insulina apresenta um efeito antinatriurético, estimulando a reabsorção renal de sódio. Este efeito é claramente mantido e, talvez aumentado, em indivíduos com resistência à insulina, representando um papel importante no desenvolvimento da hipertensão arterial e, possivelmente, da sensibilidade ao sal nestes estados.(38)

Dessa forma, a restrição do consumo de sódio como forma de diminuir os níveis de pressão arterial tem sido recomendada não apenas nos 
casos de hipertensão arterial, mas também nos estados onde a doença se associa com a resistência à insulina, como na Síndrome Metabólica.(39)

O papel da dieta e dos nutrientes na ocorrência e no desenvolvimento da Síndrome Metabólica não estão estabelecidos de forma definitiva e, de forma geral, nenhum componente individual da alimentação pode ser considerado totalmente responsável pela associação entre dieta e Síndrome Metabólica. É a qualidade global da dieta que parece oferecer proteção contra a síndrome e seus componentes.(40)

\subsubsection{Sódio e Doença Cardiovascular}

Cerca de $54 \%$ dos acidentes vasculares cerebrais e $47 \%$ da doença cardíaca isquêmica podem ser atribuídas à elevação da pressão arterial, perfazendo um total de $13,5 \%$ de todas as mortes e $6,0 \%$ da morbidade ocorridas em 2001 globalmente.(41) Existe uma relação contínua e progressiva entre pressão arterial e doença cardiovascular, iniciando em níveis pressóricos de $115 \times 75 \mathrm{mmHg}$, fazendo com que, na maioria dos países, cerca de $80 \%$ dos adultos se encontrem sob risco de doença cardiovascular.(42)

As evidências que apoiam a redução da ingestão de sal como ação de saúde pública para prevenção da doença cardiovascular têm sido convincentes.(43) Revisão sistemática e síntese por meta-análise dos estudos prospectivos publicados entre 1966 e 2008 e com seguimentos que variaram entre 3,5 a 19 anos demonstraram que o maior consumo de sal está associado com aumento do risco de ocorrência de acidente vascular cerebral (23\%) e doença cardiovascular (14\%).(44) Bibbins-Domingo e colaboradores (45) contabilizaram reduções anuais de dezenas a centenas de milhares no número de casos de doença cardiovascular, acidente vascular cerebral, infarto do miocárdio e mortes por todas as causas pela diminuição para 3 gramas por dia no consumo de sal pela população, resultados que se equiparam aos que podem ser obtidos nas reduções do tabagismo, obesidade e níveis de colesterol. 
Os efeitos da redução do consumo de sal na pressão arterial e na doença cardiovascular puderam ser observados no estudo de intervenção Trials of Hypertension Prevention, Phases I and II (TOHP I e II). No primeiro ensaio, os participantes foram seguidos por 18 meses e no segundo por 36 meses. Comparados com o grupo controle, o grupo intervenção obteve redução do consumo de sal de 1,9 g e 2,5 g por dia, com queda de 1,7 / 0,8 $\mathrm{mmHg}$ na pressão arterial aos 18 meses e 1,2 / 0,7 mmHg aos 36 meses, respectivamente. Dez a quinze anos após, os indivíduos originalmente alocados no grupo que obteve redução no consumo de sal apresentaram $25 \%$ a $30 \%$ menor incidência de eventos cardiovasculares.(46)

\subsection{Intervenções e consumo de sódio}

\subsubsection{Ambiente de trabalho}

Várias razões indicam o ambiente de trabalho como um dos locais adequados para intervenções promotoras de saúde. Em primeiro lugar, proporcionam acesso a um importante segmento da população (adultos jovens e de meia idade), cuja abordagem seria dificultada de outra forma. No Brasil existem cerca de 50 milhões de trabalhadores empregados (47) e um indivíduo adulto chega a passar um terço do seu dia no local de trabalho, fazendo, ao menos, uma grande refeição durante sua jornada laboral. Em segundo lugar, o ambiente de trabalho permite o acesso continuado aos funcionários e programas de intervenção podem ser oferecidos continuamente. Este contacto intenso pode facilitar mudanças nos hábitos e comportamentos dessa população.(48)

Finalmente, o ambiente de trabalho pode propiciar intervenções de diferentes níveis - individual, ambiental e organizacional -, permitindo uma maior sustentação das mudanças favoráveis obtidas. Em nível individual, as intervenções podem utilizar várias estratégias e ferramentas educacionais; no ambiente, há possibilidade de se aumentar as oportunidades e reduzir as barreiras para comportamentos saudáveis $e$, do ponto de vista 
organizacional, mecanismos de suporte podem reforçar e encorajar ações positivas para saúde.(49)

Em revisão do estado da arte dos programas de promoção de saúde no local de trabalho, Goetzel e Ozminkowski identificaram os seguintes fatores que tornariam estes programas eficazes: a) Integrar os programas nas operações centrais das empresas; b) direcionar as abordagens para componentes individuais, ambientais, políticos e culturais; c) abordar vários problemas de saúde em simultâneo; d) criar programas para fazer face às necessidades específicas da população; e) procurar alcançar altas taxas de participação; f) avaliar rigorosamente os resultados e g) comunicar eficazmente estes resultados para os principais interessados.(50)

\subsubsection{Redução do consumo de sódio}

Os primeiros estudos que utilizaram a redução do consumo de sal no controle da pressão arterial datam do início do século 20.(51) Esses resultados foram confirmados durante vários anos por diversos pesquisadores, mas foi apenas após o estudo de Kempner (52) que a restrição de sal para o tratamento da hipertensão arterial se tornou largamente utilizada.(4)

Várias meta-análises e revisões dos ensaios para redução de consumo de sal e seu impacto na pressão arterial têm sido realizadas. Quando foram analisados os estudos com um ou mais meses de duração que testaram reduções moderadas de sal (4,3 a 4,6 g), foram observadas pequenas, porém de um ponto de vista populacional, significativas diminuições na pressão arterial frente às reduções no consumo de sal, tanto em indivíduos hipertensos como normotensos. Além disso, foi observado um efeito dose resposta entre a redução do sódio urinário e a diminuição da pressão arterial.(53) Esses dados foram posteriormente atualizados, analisando-se agora 20 ensaios clínicos em indivíduos com pressão arterial elevada (17 no estudo anterior) e 11 ensaios clínicos em normotensos 
(mesmo número que anteriormente) e, novamente, os resultados foram confirmados.(54)

A revisão dos estudos de intervenção com duração de 3 ou mais meses, que analisaram os efeitos do aconselhamento dietético na redução de fatores de risco cardiovascular em adultos saudáveis, demonstrou que a diminuição no consumo de sal em $2,5 \mathrm{~g}$ por dia produziu uma redução média de 2,1 $\mathrm{mmHg}$ na PAS e de 1,2 mmHg na PAD.(55)

\subsubsection{Dieta DASH}

Em 1997 foi publicado um ensaio clínico que avaliou os efeitos dos padrões dietéticos sobre a pressão arterial. Foram incluídos 459 adultos com pressão arterial sistólica inferior a $160 \mathrm{mmHg}$ e pressão arterial diastólica de 80 a $95 \mathrm{mmHg}$. Durante 8 semanas, os participantes foram aleatorizados para consumir uma dieta controle (pobre em frutas, verduras e laticínios e com teores de gordura típicos da dieta média nos EUA), uma dieta rica em frutas e legumes ou uma dieta rica em frutas, verduras e produtos lácteos com baixos teores de gordura total e de gordura saturada. A ingestão de sódio e o peso corporal foram mantidos em níveis constantes. Os participantes que consumiram a última de dieta (que mais tarde ficaria conhecida como dieta DASH - Dietary Approach to Stop Hypertension) apresentaram reduções maiores das pressões arteriais sistólica e diastólica de 5,5 e 3,0 mmHg, respectivamente, em comparação com a dieta controle, tendo sido os resultados mais expressivos entre os indivíduos com hipertensão arterial (reduções de 11,4 e 5,5 mmHg).(56)

Anos mais tarde, foram estudados os efeitos de diferentes níveis de sódio na dieta DASH, em comparação com dietas controles típicas de consumo nos EUA. Os participantes alocados no grupo da dieta DASH e controle com altos teores de sódio apresentaram excreção urinária médias de sódio de 24 horas de 144 e $141 \mathrm{mmol} / \mathrm{d}$, no grupo intermediário de sódio de 107 e 106 mmol/d e no grupo de baixos teores de 67 e 64 mmol/d, respectivamente. Concluiu-se que tanto a redução de sódio quanto a dieta 
DASH foram capazes de reduzir a pressão arterial, sendo que os maiores efeitos foram observados na combinação de ambos.(57)

\subsection{Controvérsias}

Na literatura, é possível se encontrar estudos que colocam dúvidas quanto à efetividade e segurança da redução do consumo de sal pela população.

Aqueles a favor da redução alegam que a recomendação é justificada porque ficou provada de forma convincente que a restrição de sódio diminui a pressão arterial e que isto certamente irá prevenir a ocorrência de acidentes vasculares cerebrais e de infartos do miocárdio. Os céticos argumentam que a modificação desta única variável não garante um benefício à saúde e, além disso, poderia afetar, de forma desfavorável, outros marcadores de doença cardiovascular.(58)

Fatores genéticos, comportamentais e ambientais determinam grande variação individual de consumo de sódio. Porém, uma revisão recente que analisou 62 pesquisas publicadas entre 1982 e 2008, compreendendo 19.151 participantes em 33 países, constatou uma gama mundial bastante estreita de consumo de sódio (média de $3,7 \mathrm{~g} / \mathrm{d}$ ). Além disso, não ficou demonstrado que a ingestão de sódio tem aumentado ao longo do tempo.(59) Segundo alguns autores, estes resultados podem fornecer explicação para a dificuldade em limitar o consumo de sódio, após décadas de esforços: por apresentar um parâmetro fisiológico definido, o consumo de sódio pode não ser influenciado por intervenções de saúde pública.(59)

De outro lado, Cook e colaboradores relatam que as conclusões a cerca dos efeitos deletérios da redução do consumo de sódio estão baseadas em estudos de baixa qualidade, com sérias falhas metodológicas e em erros de interpretação: contabilização de estudos nos quais os pacientes hipertensos estavam fora da terapia anti-hipertensiva e foram instruídos a evitar alimentos de elevado teor de sal antes das avaliações de excreção de sódio; inclusão de pacientes com grave insuficiência cardíaca e 
sob uso de diuréticos, nos quais a restrição de sódio pode mesmo ser prejudicial e falha na interpretação dos resultados do ensaio ranzomizado de redução de consumo de sódio TOPH (Trials of Hypertension Prevention Prevention), quando se alegou ter o estudo apresentado um efeito nulo sobre a mortalidade.(60)

Além disso, as associações nulas ou deletérias entre baixo consumo de sódio e hipertensão arterial ou doença cardiovascular têm sido atribuídos, no geral, à questionável utilização de métodos dietéticos para avaliar o consumo do nutriente.(61) A dificuldade destes métodos em estimar a fração de adição de sódio no preparo ou à mesa podem causar distorções nas associações entre sódio e os desfechos analisados.

Da mesma forma, medidas não acuradas de pressão arterial podem distorcer as associações com o consumo de sódio. Tipo (mercúrio, aneroide ou dispositivos híbridos), validação e calibração do aparelho de pressão arterial, local da medida (consultório versus em casa), treinamento do observador, posição do paciente e seleção do tamanho do manguito do aparelho são fatores importantes na acurácia da medida da pressão arterial. A utilização da monitorização por $24 \mathrm{~h}$ constitui-se em medida mais fidedigna da pressão arterial, pois permite a feitura de medidas repetidas, o cálculo da pressão arterial média e avaliação da queda noturna da pressão arterial.(62)

Deve-se ter em mente também nos estudos que analisam associações entre a redução do consumo de sódio e a pressão arterial ou risco cardiovascular, a não determinação da ingestão de potássio pode causar modificações nestas associações, pois este último induz redução dos níveis tensionais.(63)

Em dois estudos de revisão, concluiu-se que a redução de sal apresentou pequeno efeito sobre a pressão arterial em indivíduos com pressão arterial normal e não se justificava uma redução de sal pela população como um todo.(64, 65) No entanto, esses estudos incluíram pesquisas de curta duração (14 e 8 dias, respectivamente) e algumas comparando os efeitos agudos de consumo de sal com severa restrição do nutriente (de $20 \mathrm{~g}$ para menos de $1 \mathrm{~g}$ de sal por dia). Sabe-se que essas 
alterações agudas na ingestão de sal podem aumentar a atividade simpática, a atividade da renina plasmática, angiotensina II e aldosterona, (66) que poderiam contrabalançar os efeitos de redução da pressão arterial. Quando a redução no consumo de sal é modesta, ocorre pequeno aumento da atividade da renina (53) e não se detectam alterações na atividade nervosa simpática.(67) Portanto, não seria apropriado incluir ensaios de restrições agudas de sal em uma meta-análise, cujos resultados seriam utilizados como base para recomendações de saúde pública de reduções modestas e de longo prazo na ingestão de sal.(4)

Além dos efeitos no sistema nervoso e no sistema renina angiotensina aldosterona, têm sido descritos também efeitos adversos no perfil lipídico.(68) Porém, com reduções moderadas de sódio não foram observadas modificações no colesterol total, triglicérides e proteínas de baixa e alta densidades.(53) Outros estudos têm documentado modificações na tolerância à glicose e sensibilidade à insulina. Contudo, a maioria envolve, novamente, alterações intensas no consumo de sal realizadas em poucos dias.(69) Estudos de médio prazos com reduções moderadas na ingestão de sal não observaram efeito significativo no metabolismo da glicose.(70)

Finalmente, os efeitos da redução ou suplementação de sódio na pressão arterial dependem das condições iniciais da intervenção, em relação ao consumo de sódio. Quando se aumentou a ingestão de sódio, partindo-se de um nível de consumo baixo, observou-se, como esperado, retenção de sódio e fluido. Porém, quando a carga de sódio foi fornecida a partir de um nível médio de consumo, houve novamente retenção de sódio, mas não de fluidos, demonstrando-se, desta forma, diferenças nos balanços de sódio e água no organismo, na dependência de as cargas de sal se iniciarem de situações onde existe consumo baixo ou médio de sódio. Estimou-se que $78 \%$ do sódio retido foi armazenado em uma forma osmoticamente inativa, além de não terem sido observadas modificações significativas na pressão arterial.(71) 


\section{OBJETIVOS}

1- Estimar a disponibilidade de sódio no Brasil.

2- Avaliar os efeitos de dietas com baixos teores de sódio na Síndrome Metabólica e/ou resistência à insulina.

3- Avaliar o impacto de intervenção voltada para redução da adição de sal aos alimentos.

\subsection{Objetivos específicos}

1- Estimar a disponibilidade de sódio no Brasil, por macrorregião, situação do domicílio (urbana ou rural) e por classe de renda, bem como avaliar as principais fontes de sódio.

2- Revisar a literatura de forma sistemática acerca dos ensaios clínicos realizados em adultos entre os anos de 2004 e 2008.

3- Avaliar o impacto de intervenção realizada em trabalhadores de empresas da cidade de São Paulo. 


\section{MÉTODOS}

As respostas aos objetivos apresentados serão fornecidas por meio dos três artigos que compõem esta tese.

Por se tratarem de artigos independentes, com base de dados e análises estatísticas diferentes, os detalhamentos de cada um dos métodos, resultados, conclusões e referências estão incluídos nos textos dos respectivos artigos. 


\section{PRIMEIRO ARTIGO}

Publicado na Revista de Saúde Pública. 2009;43(2):219-225. ISSN 0034-8910. doi: 10.1590/S0034-89102009005000002. 
Estimativa de consumo de sódio pela população brasileira, 2002-2003

Estimated sodium intake by the Brazilian population, 20022003

Flávio Sarno '; Rafael Moreira Claro '; Renata Bertazzi Levy "; Daniel Henrique Bandoni I, 'I; Sandra Roberta Gouvêa Ferreira "'; Carlos Augusto Monteiro II, III

' Programa de Pós-Graduação de Nutrição em Saúde Pública. Faculdade de Saúde Pública (FSP). Universidade de São Paulo (USP). São Paulo, SP, Brasil

"Núcleo de Pesquisas Epidemiológicas em Nutrição e Saúde. FSP-USP. São Paulo, SP, Brasil

II'Departamento de Nutrição. FSP-USP. São Paulo, SP, Brasil 


\section{Resumo}

Objetivos: Estimar a magnitude e a distribuição regional e socioeconômica do consumo de sódio no Brasil e identificar as fontes alimentares que mais contribuem para esse consumo. Métodos: As estimativas foram baseadas nos dados da Pesquisa de Orçamentos Familiares, realizada no Brasil entre julho de 2002 e junho de 2003. Foram analisados 969.989 registros de aquisição de alimentos efetuados por uma amostra probabilística de 48.470 domicílios localizados em 3.984 setores censitários do País. Realizou-se conversão dos registros das aquisições de alimentos em nutrientes por meio de tabelas de composição de alimentos. Foram calculadas as disponibilidades médias de sódio por pessoa e por dia e as disponibilidades médias ajustadas para um consumo energético equivalente a $2.000 \mathrm{kcal}$. Calculou-se a contribuição de grupos de alimentos selecionados para o total de sódio disponível para consumo no domicílio. As estimativas são apresentadas segundo regiões, situação urbana ou rural do domicílio, e estratos de renda. Resultados: A quantidade diária de sódio disponível para consumo nos domicílios brasileiros foi de 4,5 g por pessoa (ou 4,7 g para uma ingestão diária de $2.000 \mathrm{kcal}$ ), excedendo, assim, em mais de duas vezes o limite recomendado de ingestão desse nutriente. Embora a maior parte do sódio disponível para consumo em todas as classes de renda provenha do sal de cozinha e de condimentos à base desse sal (76,2\%), a fração proveniente de alimentos processados com adição de sal aumenta linear e intensamente com o poder aquisitivo domiciliar, representando 9,7\% do total de sódio no quinto inferior da distribuição da renda per capita e $25,0 \%$ no quinto superior. Conclusões: Os resultados indicam que o consumo de sódio no Brasil excede largamente a recomendação máxima para esse nutriente em todas as macrorregiões brasileiras e em todas as classes de renda. 
Descritores: Sódio na Dieta. Consumo de Alimentos. Fatores Socioeconômicos. Brasil. 


\section{Abstract}

Objectives: To estimate the magnitude and distribution of sodium intake in Brazil and to identify major dietary sources contributing to this intake. Methods: Estimates were based on data from a Brazilian household budget survey carried between July 2002 and June 2003. A total of 969,989 food purchase records from a probabilistic sample of 48,470 households located in 3,984 census tracts across the country were analyzed. Purchase records were converted into nutrients using food composition charts. Mean sodium availability per person per day and mean adjusted availability considering a 2,000 kcal daily energy intake were calculated, as well as the contribution of selected food groups to total household sodium availability. Estimates are presented according to geographical region, urban or rural status of the household, and income stratum. Results: Mean daily sodium availability in Brazilian households was $4.5 \mathrm{~g}$ per person (or $4.7 \mathrm{~g}$ considering a daily calorie intake of $2,000 \mathrm{kcal}$ ), thus exceeding by more than two times the recommended levels of intake for this nutrient. Although most of the sodium available for intake across all income strata was derived from kitchen salt or salt-based condiments (76.2\%), the fraction derived from processed foods with added salt showed a strong linear increase as household purchasing power increased, representing $9.7 \%$ of total sodium intake in the lower quintile of the per capita income distribution and $25.0 \%$ in the upper quintile. Conclusions: Results indicate that sodium intake in Brazil widely exceeds the maximum recommended intake level for this nutrient in all of the country's macro regions and across all income strata.

Key words: Sodium, Dietary; Food Consumption; Socioeconomic Factors; Brazil. 


\section{Introdução}

São várias as evidências que relacionam o consumo excessivo de sal ao desenvolvimento de doenças crônicas.(1) Estima-se que, entre 25 e 55 anos de idade, uma diminuição de apenas 1,3 g na quantidade de sódio consumida diariamente se traduziria em redução de $5 \mathrm{mmHg}$ na pressão arterial sistólica ou de $20 \%$ na prevalência de hipertensão arterial. Além disso, haveria também substanciais reduções na mortalidade por acidentes vasculares cerebrais (14\%) e por doença coronariana $(9 \%)$, representando 150.000 vidas salvas anualmente em todo o mundo.(2) O consumo excessivo de sal também está associado ao câncer gástrico (3) podendo contribuir, ainda, para o desenvolvimento de osteoporose.(4)

Nos países desenvolvidos, que contam com estimativas confiáveis sobre o consumo de sódio, a ingestão desse mineral tende a ultrapassar o limite máximo de $2 \mathrm{~g}$ (ou $5 \mathrm{~g}$ de sal) por pessoa por dia recomendado pela Organização Mundial da Saúde (OMS),(5) sendo a maior parte deste sódio proveniente de alimentos industrializados.(6-8)

Nos países em desenvolvimento, as informações sobre o consumo de sódio ainda são escassas em face da complexidade envolvida na avaliação de sua ingestão pelos indivíduos.

Estimativa indireta, calculada a partir da quantidade de sal por habitante comercializada pelas indústrias brasileiras do setor, indicam que 0 consumo de sódio no Brasil ultrapassa o limite máximo recomendado para sua ingestão. ${ }^{\text {b,c }}$ À conclusão semelhante chegaram estudos realizados em três cidades brasileiras a partir do perfil de aquisição de alimentos pelas famílias (9) ou de estimativas diretas obtidas com a avaliação da excreção urinaria de sódio.(10)

\footnotetext{
a Ministério da Saúde. Secretaria de Atenção à Saúde. Coordenação-Geral da Política de Alimentação e Nutrição. Guia alimentar para a população brasileira: promovendo a alimentação saudável. Brasília; 2005.

b Serviço Nacional de Aprendizagem Industrial. Plano de apoio ao desenvolvimento da cadeia produtiva do sal. [Acesso em 18/04/08]. Disponível em: http://www.fiern.org.br/servicos/estudos/mossoro/cadeia produtiva sal.htm
} 
O presente estudo objetiva estimar o consumo de sódio pela população brasileira e identificar as fontes alimentares que mais contribuem para este consumo.

\section{Métodos}

Os dados analisados procedem da Pesquisa de Orçamentos Familiares (POF) realizada entre julho de 2002 e junho de 2003 pelo Instituto Brasileiro de Geografia e Estatística (IBGE).

De forma resumida, a POF é uma pesquisa que objetiva a obtenção de informações acerca dos rendimentos e despesas das famílias brasileiras. A edição 2002/03 estudou uma amostra probabilística representativa do conjunto dos domicílios brasileiros, bem como das cinco macrorregiões do País conforme situação urbana ou rural do domicílio. Para tanto, foi utilizado um plano amostral complexo, envolvendo a constituição prévia de estratos sociogeográficos (em número de 443) integrados por setores censitários pertencentes a um mesmo domínio territorial (região, Estado e situação urbana ou rural do setor) e homogêneo quanto ao nível de escolaridade do chefe do domicílio no setor (informação obtida do Censo Demográfico de 2000). Posteriormente, realizou-se sorteio de setores censitários (unidades primárias de amostragem) dentro de cada estrato e sorteio de domicílios (unidades secundárias de amostragem) dentro de cada setor. Por fim, para que a coleta de dados fosse uniforme nos quatro trimestres do ano, as entrevistas realizadas dentro de cada estrato foram distribuídas para estudo ao longo dos 12 meses de duração da pesquisa. Detalhes do plano amostral da POF estão descritos em outra publicação. ${ }^{d}$

A informação central analisada compreende os registros de todas as aquisições de alimentos e bebidas feitas ao longo de sete dias consecutivos pelos domicílios que integraram a amostra da POF 2002/03 (969.989

\footnotetext{
d Instituto Brasileiro de Geografia e Estatística. Coordenação de Índices de Preços. Pesquisa de orçamentos familiares 2002-2003: análise da disponibilidade domiciliar e estado nutricional no Brasil. Rio de Janeiro; 2004.
} 
registros efetuados por 48.470 domicílios localizados em 3.984 setores censitários). Considerando que o período de referência de sete dias para a coleta de informações não é suficiente para caracterizar o padrão de aquisição de alimentos em cada domicílio, adotamos como unidade de estudo os agrupamentos de domicílios correspondentes aos 443 estratos da amostra da POF, não o domicílio individual estudado. Esses estratos são constituídos por unidades domiciliares homogêneas do ponto de vista de domínio territorial e condição socioeconômica das famílias, estudadas de modo uniforme ao longo dos quatro trimestres do ano. O número médio de domicílios estudados em cada estrato da POF 2002/03 foi de 109,6, variando de 9 a 804. O peso amostral de cada unidade de estudo (estrato de domicílios) corresponde à somatória dos pesos amostrais dos domicílios que constituem o estrato.

Inicialmente, excluiu-se, quando necessário, a fração não comestível da quantidade bruta em gramas de cada alimento adquirido pelos domicílios, usando-se para tanto fatores de correção recomendados pelo IBGE. ${ }^{e}$ A quantidade comestível de cada alimento foi então convertida em energia (kcal) e sódio (gramas) utilizando a Tabela Brasileira de Composição dos Alimentos - versão $1^{f}$ ou, na ausência desta, a tabela oficial de composição de alimentos dos Estados Unidos, versão 15. No caso específico da aquisição de alimentos preservados em sal, como charque, carne seca e de sol e peixes salgados, considerou-se a quantidade equivalente do alimento após hidratação e a concentração de sódio referente ao alimento já dessalgado.

Após a conversão dos registros semanais das aquisições de alimentos em nutrientes, calculou-se, para cada unidade de estudo (estratos de domicílios), a disponibilidade diária por pessoa de energia e de sódio. Adicionalmente, visando a contornar $o$ fato de que se analisa a disponibilidade domiciliar de sódio e não o consumo efetivo desse nutriente,

d Instituto Brasileiro de Geografia e Estatística. Estudo Nacional da Despesa Familiar ENDEF 1974/75. Rio de Janeiro; 1978. 
visto que não são consideradas as refeições feitas fora do domicílio, nem a fração de alimentos adquiridos e não consumidos, calculou-se a disponibilidade de sódio ajustada para um valor energético total de 2.000 kcal, correspondente à recomendação brasileira para a ingestão diária per capita de energia. ${ }^{a}$

Médias da disponibilidade de sódio (e respectivos erros padrão) são apresentadas para o País como um todo, para as cinco macrorregiões geográficas, desagregadas em situação urbana ou rural e para quintos da distribuição da renda per capita observada nos 443 estratos. A participação percentual de grupos de alimentos na disponibilidade domiciliar total de sódio é descrita para o País como um todo e segundo quintos da distribuição da renda per capita.

Assim, os alimentos adquiridos pelas famílias foram divididos em quatro grupos: 1) sal e condimentos à base de sal; 2) alimentos processados com adição de sal; 3) alimentos in natura ou alimentos processados sem adição de sal; e 4) refeições prontas. Análises de regressão linear foram empregadas para testar a relação entre renda familiar (quintos da distribuição da renda per capita dos estratos de domicílios) e a contribuição de cada grupo de alimentos para o total de sódio.

Para a conversão das quantidades $(\mathrm{kg})$ brutas adquiridas de alimentos em nutrientes (kcal e sódio) utilizou-se o aplicativo AQUINUT. ${ }^{\mathrm{g}}$ Para todos os demais procedimentos e para as análises estatísticas empregou-se o aplicativo Stata versão 9.2, considerando os pesos amostrais das unidades de estudo.

\section{Resultados}

A tabela 1 apresenta estimativas para a disponibilidade domiciliar de sódio no Brasil e nas macrorregiões. Para o País como um todo, a quantidade de sódio disponível para consumo foi de 4,5 gramas por pessoa

f Núcleo de Pesquisas Epidemiológicas em Nutrição e Saúde. Conversor de aquisições de alimento em energia e nutrientes (AQUINUT): versão 1.0 [Internet] [Acesso em 12/10/07]; Disponível em: http://www.fsp.usp.br/nupens 
por dia $(\mathrm{g} / \mathrm{p} / \mathrm{d})$, portanto mais de duas vezes superior ao limite máximo de consumo de $2 \mathrm{~g} / \mathrm{p} / \mathrm{d}$. Em nenhuma região brasileira a disponibilidade domiciliar de sódio foi inferior a $4 \mathrm{~g} / \mathrm{p} / \mathrm{d}$. Em todas as regiões, a disponibilidade de sódio foi maior nos estratos de domicílios rurais. A menor disponibilidade de sódio, encontrada nos estratos de domicílios urbanos da região Centro-Oeste, superou em $70 \%$ o consumo máximo recomendado. $\mathrm{A}$ disponibilidade de sódio ajustada para um consumo de 2.000 kcal diárias não alterou substancialmente o cenário de consumo excessivo em todas as regiões do País, atenuando apenas o excesso adicional observado nas áreas rurais.

A tabela 2 apresenta estimativas para a disponibilidade domiciliar de sódio segundo quintos da distribuição da renda per capita observada nos estratos de domicílios. A disponibilidade domiciliar de sódio ajustada para um consumo de $2.000 \mathrm{kcal} / \mathrm{p} / \mathrm{d}$ excedeu em duas vezes e meia a ingestão máxima recomendada nos dois quintos de menor renda e em pouco mais de duas vezes nos três quintos de maior renda.

A tabela 3 descreve a contribuição de grupos de alimentos para a disponibilidade domiciliar total de sódio. Levando em conta o conjunto dos domicílios brasileiros, verifica-se que cerca de três quartos do sódio disponível para consumo provêm da aquisição de sal de cozinha $(71,5 \%)$ ou de condimentos à base desse sal (4,7\%). O restante do sódio disponível para consumo provinha da aquisição de alimentos processados com adição de sal (15,8\%), de alimentos in natura ou alimentos processados sem adição de sal $(6,6 \%)$ e de refeições prontas (1,4\%). Embora majoritária em todos os grupos de renda, a contribuição do sal de cozinha e dos condimentos à base de sal decresceu de forma linear com o aumento da renda ( $p<0,001$ ), variando de $83,8 \%$ no quinto de menor renda a $62,5 \%$ no quinto de maior renda. Por outro lado, a contribuição de alimentos processados com adição de sal apresentou relação direta com a renda per capita ( $p<0,001$ ), aumentando duas e meia vezes do quinto de menor $(9,7 \%$ do total de sódio) para o quinto de maior renda (25,0\% do total de sódio). A contribuição de refeições prontas para o total de sódio disponível para consumo nos 
domicílios, embora pequena, também aumentou intensamente com a renda per capita $(p<0,001)$, representando $0,4 \%$ do total de sódio no quinto de menor renda e $3,7 \%$ no quinto de maior renda. A contribuição do conjunto de alimentos in natura e dos alimentos processados sem adição de sal para o total de sódio foi relativamente pequena e estável nos três primeiros quintos da distribuição da renda, cerca de $6 \%$, aumentando para $7,3 \%$ e $8,8 \%$ nos dois quintos de maior renda.

\section{Discussão}

Os resultados encontrados no presente estudo indicam que a quantidade de sódio disponível para consumo nos domicílios brasileiros excede em mais de duas vezes a ingestão máxima recomendada.(5) Excesso na disponibilidade de sódio foi encontrado em todas as macrorregiões do País, no meio urbano e no meio rural e em todas as classes de renda.

Embora em todas as classes de renda a maior parte do sódio disponível para consumo provenha do sal de cozinha e de alimentos à base desse sal, a fração proveniente de alimentos processados com adição de sal aumenta sua importância com o poder aquisitivo domiciliar, representando $9,7 \%$ do total de sódio no quinto inferior da distribuição da renda per capita e $25,0 \%$ no quinto superior.

Destaca-se que os dados da POF referem-se à disponibilidade domiciliar de sódio e não ao consumo efetivo deste nutriente, visto que não foram consideradas as refeições feitas pelos indivíduos fora do domicílio, nem a fração de alimentos adquiridos, mas não consumidos. Visando a contornar essas limitações, apresentamos estimativas para as disponibilidades de sódio ajustadas para uma disponibilidade fixa de 2.000 $\mathrm{kcal} / \mathrm{p} / \mathrm{d}$. A eficácia deste ajuste pressupõe duas premissas básicas: 1) a de que as refeições feitas fora do domicílio tenham teor de sódio semelhante ao das refeições feitas no domicilio e 2) a de que a fração desperdiçada dos alimentos seja independente do seu teor de sódio. 
Embora não conheçamos estudos brasileiros que tenham comparado o teor de sódio de refeições feitas dentro e fora do domicílio, de modo geral, admite-se que as refeições feitas fora de casa tendam a apresentar maior teor de sódio.(11) Se este fenômeno for de fato observado no Brasil, o real consumo de sódio pela população poderia ser mesmo maior do que aquele estimado neste estudo. A ingestão de sódio poderia estar subestimada particularmente no meio urbano, onde o hábito de fazer refeições fora do domicílio tende a ser mais comum. Utilizando os dados da POF 2002/03, estimamos que os alimentos consumidos fora do domicílio representem $24 \%$ das despesas totais com alimentação para famílias urbanas e 12\% para famílias rurais.

Dois procedimentos culinários domésticos podem fazer com que 0 desperdício de sal de cozinha, a maior fonte de sódio da dieta brasileira, seja superior ao dos demais itens da dieta: a cocção de alimentos em água de salmoura e o salgamento de alimentos. No Brasil, os alimentos que mais comumente são cozidos em água de salmoura são macarrão, batata e cenoura. Considerando-se a quantidade média que as famílias brasileiras adquirem desses alimentos, ${ }^{\mathrm{h}}$ a concentração de sal habitual na água de salmoura ${ }^{i}(12)$ e estimativas sobre a fração de sal retida por esses alimentos após sua cocção,(13) estima-se que a cocção do macarrão, da batata e da cenoura determinaria um desperdício de sal equivalente a $9 \%$ do total de sódio adquirido pelas famílias brasileiras. Este desperdício não seria suficiente para modificar as conclusões do presente estudo com relação ao consumo excessivo de sódio no Brasil.

Não é fácil avaliar o possível impacto do salgamento doméstico de alimentos no desperdício de sal. De qualquer modo, a excepcionalidade desta prática no meio urbano indica efeito pequeno das estimativas feitas para os cerca de quatro quintos dos brasileiros que vivem nas cidades. $A$

g Instituto Brasileiro de Geografia e Estatística. Coordenação de Índices de Preços. Pesquisa de Orçamentos Familiares 2002-2003: análise da disponibilidade domiciliar e estado nutricional no Brasil. IBGE; 2004.

h Pinheiro ABV, Lacerda EMA, Benzecry EH, Gomes MCS, Costa VM. Tabela para avaliação de consumo alimentar em medidas caseiras. 3. ed. Rio de Janeiro; 1993. 
possível maior frequência do salgamento doméstico no meio rural poderia, por outro lado, justificar a maior disponibilidade de sódio evidenciada nos domicílios rurais.

Apesar das limitações características das POF, estimativas médias do consumo de vários grupos de alimentos obtidas a partir de inquéritos de compra de alimentos tendem a concordar com resultados obtidos por meio de inquéritos individuais de consumo.(14, 15) Ademais, no caso de alimentos utilizados como ingredientes de preparações, como óleo, açúcar e condimentos, admite-se que inquéritos de compra possam refletir melhor a ingestão real dos indivíduos, do que inquéritos de consumo. Isso ocorreria em face da dificuldade dos indivíduos em relatar a quantidade consumida de alimentos ingeridos como parte de preparações.(14)

Outra limitação relativa à estimativa do consumo de sódio, comum a todos os inquéritos dietéticos, decorre do uso de tabelas de composição de alimentos, que nem sempre avaliam com precisão o teor de sódio dos alimentos consumidos pelos indivíduos. No caso do presente estudo, para a maior parte dos alimentos, empregou-se tabela construída a partir de análise bromatológica direta de alimentos comercializados no Brasil (Tabela Brasileira de Composição de Alimentos), fato que determinou que 97\% do total de sódio disponível para consumo nos domicílios pesquisados pela POF 2002/03 sejam procedentes de alimentos cuja composição foi avaliada por essa tabela (dados não mostrados).

A comparação das estimativas feitas para o Brasil com estimativas de outros países é dificultada pelo uso de diferentes metodologias de avaliação do consumo de sódio. Inquéritos populacionais realizados em países desenvolvidos indicam, de modo geral, consumo excessivo de sódio com estimativas variando entre 3,0 e 4,2 g/p/d. $(7,8)$ Ainda que menos frequentes, estudos realizados em países em desenvolvimento também indicam excesso de consumo de sódio, com estimativas entre 3,4 a 5,6 g/p/d. $(16,17)$

A partir de dados fornecidos pelas indústrias salineiras brasileiras sobre a produção de sal para consumo humano e considerando a população 
brasileira no ano de 2000, estimou-se para aquele ano uma disponibilidade per capita de sódio de 6,0 gramas por dia, valor três vezes superior ao limite recomendado de consumo diário desse mineral. ${ }^{\mathrm{a}, \mathrm{b}}$ Análise a partir de dados provenientes da Pesquisa de Orçamentos Familiares da Fundação Instituto de Pesquisas Econômicas, realizada na cidade de São Paulo em 1999, estimou que a disponibilidade domiciliar diária de sódio era de 4,4 g para uma aquisição de 2.000 kcal.(9) Portanto, muito semelhante ao valor estimado pelo presente estudo para o conjunto dos domicílios brasileiros.

Dois estudos realizados no Brasil, em períodos próximos ao ano 2000, avaliaram o consumo de sódio a partir da excreção desse mineral na urina e encontraram estimativas de consumo de sódio bastante próximas à observada no presente estudo. O primeiro desses, realizado em amostra probabilística da população da cidade de Vitória (ES), entre 25 a 64 anos de idade, estimou o consumo de sódio em 5,0 g/p/d.(18) O segundo estudo, realizado entre crianças e adolescentes de 6 a 17 anos de idade da cidade de Porto Alegre (RS) estimou o consumo de sódio em 3,4 g/p/d.(10)

A relação inversa entre renda e disponibilidade de sódio encontrada no presente estudo tem sido descrita em trabalhos realizados em países desenvolvidos. $(19,20)$

Se o consumo excessivo de sódio no Brasil não parece diferir substancialmente do que vem sendo registrado nos países desenvolvidos, outra é a situação com relação à procedência do nutriente. Nesses países, estima-se que a maior parte do sódio consumido pelos indivíduos de - $60 \%$ a $90 \%$ - provenha de alimentos processados pela indústria e não do sal adicionado aos alimentos pelos indivíduos. $(6,7)$ Situação semelhante à situação encontrada no Brasil, onde a maior parte do sódio consumido aparenta ser proveniente do sal de cozinha e de condimentos à base de sal, ocorre em outros países em desenvolvimento.(21) De qualquer modo, a forte relação positiva entre a renda domiciliar e a fração de sódio proveniente de alimentos processados e a rápida e intensa expansão que vem caracterizando o consumo desses alimentos no Brasil (22), indicam 
tendência crescente de sua importância para o consumo de sódio nesse País.

Em conclusão, nossos resultados confirmam a suposição de que o consumo de sódio no Brasil excede largamente a recomendação máxima para esse nutriente em todas regiões brasileiras e classes de renda. Apontam, também, a pertinência para o País das recentes recomendações da OMS relativas à adoção de políticas públicas que, simultaneamente, informem a população sobre a importância de reduzir a quantidade de sal adicionada aos alimentos e regulem o teor de sódio dos alimentos processados. 
Tabela 1. Disponibilidade domiciliar de energia e de sódio, decorrente da aquisição de alimentos, segundo macrorregião e situação urbana ou rural do domicílio. Brasil, 2002/03.

\begin{tabular}{|c|c|c|c|c|c|c|}
\hline \multirow{2}{*}{$\begin{array}{c}\text { Região / } \\
\text { situação } \\
\text { do } \\
\text { domicílio }\end{array}$} & \multicolumn{2}{|c|}{ Energia (Kcal/p/dia) } & \multicolumn{2}{|c|}{ Sódio (g/p/dia) } & \multicolumn{2}{|c|}{$\begin{array}{c}\text { Sódio }(\mathrm{g} / \mathrm{p} / 2.000 \\
\text { Kcal) }\end{array}$} \\
\hline & Média & $\begin{array}{c}\text { (Erro } \\
\text { Padrão) }\end{array}$ & Média & $\begin{array}{c}\text { (Erro } \\
\text { Padrão) }\end{array}$ & Média & $\begin{array}{c}\text { (Erro } \\
\text { Padrão) }\end{array}$ \\
\hline \multicolumn{7}{|l|}{ Norte } \\
\hline Urbana & 1848,6 & $(75,0)$ & 4,3 & $(0,4)$ & 4,7 & $(0,4)$ \\
\hline Rural & 2951,6 & $(142,2)$ & 11,4 & $(3,9)$ & 7,4 & $(2,2)$ \\
\hline Total & 2111,9 & $(107,5)$ & 6,0 & $(1,1)$ & 5,4 & $(0,6)$ \\
\hline \multicolumn{7}{|l|}{ Nordeste } \\
\hline Urbana & 1720,6 & $(27,2)$ & 3,9 & $(0,1)$ & 4,5 & $(0,1)$ \\
\hline Rural & 2092,3 & $(52,3)$ & 6,5 & $(0,4)$ & 6,2 & $(0,4)$ \\
\hline Total & 1818,4 & $(30,9)$ & 4,6 & $(0,2)$ & 5,0 & $(0,2)$ \\
\hline \multicolumn{7}{|l|}{ Sudeste } \\
\hline Urbana & 1760,8 & $(61,8)$ & 3,8 & $(0,2)$ & 4,3 & $(0,1)$ \\
\hline Rural & 2623,4 & $(316,2)$ & 7,0 & $(1,0)$ & 5,8 & $(1,3)$ \\
\hline Total & 1830,0 & $(64,3)$ & 4,0 & $(0,2)$ & 4,4 & $(0,2)$ \\
\hline \multicolumn{7}{|l|}{ Sul } \\
\hline Urbana & 1858,5 & $(67,1)$ & 4,4 & $(0,2)$ & 4,8 & $(0,2)$ \\
\hline Rural & 3008,7 & $(244,5)$ & 8,0 & $(0,9)$ & 5,4 & $(0,4)$ \\
\hline Total & 2045,8 & $(94,5)$ & 5,0 & $(0,3)$ & 4,9 & $(0,1)$ \\
\hline \multicolumn{7}{|l|}{$\begin{array}{l}\text { Centro- } \\
\text { Oeste }\end{array}$} \\
\hline Urbana & 1654,3 & $(47,0)$ & 3,4 & $(0,2)$ & 4,1 & $(0,3)$ \\
\hline Rural & 2588,3 & $(136,5)$ & 8,7 & $(2,1)$ & 6,4 & $(1,3)$ \\
\hline Total & 1763,7 & $(61,6)$ & 4,0 & $(0,4)$ & 4,3 & $(0,3)$ \\
\hline \multicolumn{7}{|l|}{ Brasil } \\
\hline Urbana & 1764,6 & $(33,5)$ & 3,9 & $(0,1)$ & 4,4 & $(0,1)$ \\
\hline Rural & 2489,5 & $(110,0)$ & 7,5 & $(0,6)$ & 6,1 & $(0,4)$ \\
\hline Total & 1875,1 & $(34,7)$ & 4,5 & $(0,1)$ & 4,7 & $(0,1)$ \\
\hline
\end{tabular}


Tabela 2. Disponibilidade domiciliar de energia e de sódio, decorrente da aquisição de alimentos, segundo quintos crescentes da distribuição de renda domiciliar per capita. Brasil, 2002/03.

\begin{tabular}{|c|c|c|c|c|c|c|}
\hline \multirow{2}{*}{$\begin{array}{c}\text { Quintos de } \\
\text { Renda }\end{array}$} & \multicolumn{2}{|c|}{ Energia (Kcal/p/dia) } & \multicolumn{2}{|c|}{ Sódio (g/p/dia) } & \multicolumn{2}{|c|}{$\begin{array}{c}\text { Sódio (g/p/2.000 } \\
\text { Kcal) }\end{array}$} \\
\hline & Média & $(E P)$ & Média & $(E P)$ & Média & $(E P)$ \\
\hline $1^{\circ}$ & 1950,6 & $(59,3)$ & 4,9 & $(0,3)$ & 5,0 & $(0,2)$ \\
\hline $2^{\circ}$ & 1976,7 & $(87,7)$ & 5,1 & $(0,4)$ & 5,0 & $(0,2)$ \\
\hline $3^{\circ}$ & 1922,9 & $(93,2)$ & 4,6 & $(0,4)$ & 4,7 & $(0,3)$ \\
\hline $4^{\circ}$ & 1735,0 & $(92,2)$ & 3,8 & $(0,2)$ & 4,4 & $(0,1)$ \\
\hline $5^{\circ}$ & 1787,7 & $(46,1)$ & 3,8 & $(0,2)$ & 4,3 & $(0,2)$ \\
\hline Brasil & 1875,1 & $(34,7)$ & 4,5 & $(0,1)$ & 4,7 & $(0,1)$ \\
\hline
\end{tabular}


Tabela 3. Distribuição (\%) da disponibilidade domiciliar de sódio, decorrente da aquisição de alimentos, em quintos crescentes da distribuição da renda domiciliar per capita, segundo grupos de alimentos. Brasil, 2002/03.

\section{Quintos de renda}

\begin{tabular}{lcccccc} 
Grupos de alimentos & Brasil & $1^{\circ}$ & $2^{\circ}$ & $3^{\circ}$ & $4^{\circ}$ & $5^{\circ}$ \\
\hline $\begin{array}{l}\text { Sal e condimentos à base } \\
\text { de sal }\end{array}$ & 76,2 & 83,8 & 81,9 & 77,8 & 70,2 & 62,5
\end{tabular}

Alimentos processados

com adição de sal

$\begin{array}{llllll}15,8 & 9,7 & 11,8 & 15,2 & 21,0 & 25,0\end{array}$

Alimentos in natura ou processados sem adição de sal

$6,6 \quad 6,1 \quad 5,6 \quad 6,0 \quad 7,3 \quad 8,8$

\begin{tabular}{ccccccc} 
Refeições prontas & 1,4 & 0,4 & 0,7 & 1,0 & 1,5 & 3,7 \\
\hline Total & 100,0 & 100,0 & 100,0 & 100,0 & 100,0 & 100,0 \\
\hline
\end{tabular}




\section{Referências}

1. World Health Organization. Reducing salt intake in populations: report of a WHO forum and technical meeting, 5-7 October 2006, Paris, France. 2007 [Acesso em 17/10/09]; Disponível em: http://www.who.int/dietphysicalactivity/Salt_Report_VC_april07.pdf.

2. Dickinson BD, Havas S. Reducing the population burden of cardiovascular disease by reducing sodium intake: a report of the Council on Science and Public Health. Arch Intern Med. 2007;167(14):1460-8.

3. Tsugane S, Sasazuki S. Diet and the risk of gastric cancer: review of epidemiological evidence. Gastric Cancer. 2007;10(2):75-83.

4. Frassetto LA, Morris RC, Jr., Sellmeyer DE, Sebastian A. Adverse effects of sodium chloride on bone in the aging human population resulting from habitual consumption of typical American diets. J Nutr. 2008;138(2):419S$22 S$.

5. World Health Organization. Diet, Nutrition and the Prevention of Chronic Diseases. WHO Technical Report Series 916. Report of a Joint WHO/FAO Expert Consultation. Geneva. 2003 [Acesso em 23/02/10]; Disponível em: http://whqlibdoc.who.int/trs/WHO_trs_916.pdf.

6. Andersen L, Rasmussen LB, Larsen EH, Jakobsen J. Intake of household salt in a Danish population. Eur J Clin Nutr. 2009;63(5):598-604.

7. Beer-Borst S, Costanza MC, Pechere-Bertschi A, Morabia A. Twelve-year trends and correlates of dietary salt intakes for the general adult population of Geneva, Switzerland. Eur J Clin Nutr. 2009;63(2):155-64.

8. Laatikainen T, Pietinen P, Valsta L, Sundvall J, Reinivuo H, Tuomilehto J. Sodium in the Finnish diet: 20-year trends in urinary sodium excretion among the adult population. Eur J Clin Nutr. 2006;60(8):965-70.

9. Claro RM, Machado FMS, Bandoni DH. Evolução da disponibilidade domiciliar de alimentos no município de São Paulo no período de 1979 a 1999. Rev Nutr. 2007;20(5):483-90. 
10. Micheli ET, Rosa AA. Estimation of sodium intake by urinary excretion and dietary records in children and adolescents from Porto Alegre, Brazil: a comparision of two methods. Nutr Res. 2003;23(11):1477-87.

11. Guthrie JF, Lin BH, Frazao E. Role of food prepared away from home in the American diet, 1977-78 versus 1994-96: changes and consequences. J Nutr Educ Behav. 2002;34(3):140-50.

12. Fisberg R, Villar B. Manual de receitas e medidas caseiras para cálculo de inquéritos alimentares. $1^{\text {a }}$ ed. São Paulo: Signus; 2002.

13. Sanchez-Castillo CP, James WP. Defining cooking salt intakes for patient counselling and policy making. Arch Latinoam Nutr. 1995;45(4):259-64.

14. Becker W. Comparability of household and individual food consumption data - evidence from Sweden. Public Health Nutr. 2001;4(5B):1177-82.

15. Naska A, Vasdekis VG, Trichopoulou A. A preliminary assessment of the use of household budget survey data for the prediction of individual food consumption. Public Health Nutr. 2001;4(5B):1159-65.

16. Radhika G, Sathya RM, Sudha V, Ganesan A, Mohan V. Dietary salt intake and hypertension in an urban south Indian population - [CURES - 53]. J Assoc Physicians India. 2007;55:405-11.

17. Zhou BF, Stamler J, Dennis B, Moag-Stahlberg A, Okuda N, Robertson $\mathrm{C}$, et al. Nutrient intakes of middle-aged men and women in China, Japan, United Kingdom, and United States in the late 1990s: the INTERMAP study. J Hum Hypertens. 2003;17(9):623-30.

18. Molina M, Cunha R, Herkenhoff L, Mill J. Hipertensão arterial e consumo de sal em população urbana. Rev Saude Publica. 2003;37(6):743-50.

19. Purdy J, Armstrong G, Mcllveen H. The influence of socio-economic status on salt consumption in Northern Ireland. International Journal of Consumer Studies. 2002;26(1):71-80.

20. Turrell G, Hewitt B, Patterson C, Oldenburg B, Gould T. Socioeconomic differences in food purchasing behaviour and suggested implications for dietrelated health promotion. J Hum Nutr Diet. 2002;15(5):355-64.

21. Tian HG, Hu G, Dong QN, Yang XL, Nan $Y$, Pietinen $P$, et al. Dietary sodium and potassium, socioeconomic status and blood pressure in a 
Chinese population. Appetite. 1996;26(3):235-46.

22. Levy-Costa RB, Sichieri R, Pontes Ndos S, Monteiro CA. Household food availability in Brazil: distribution and trends (1974-2003). Rev Saude Publica. 2005;39(4):530-40. 
5. SEGUNDO ARTIGO

Publicado nos Arquivos Brasileiros de Endocrinologia e Metabologia. 2009;53(5):608-616. ISSN 0004-2730. doi: 10.1590/S0004-27302009000500013. 
Consumo de sódio e síndrome metabólica: uma revisão sistemática

Sodium intake and metabolic syndrome: a systematic review

\author{
Flávio Sarno ${ }^{1}$ \\ Patrícia Constante Jaime ${ }^{2}$ \\ Sandra Roberta Gouvea Ferreira ${ }^{3}$ \\ Carlos Augusto Monteiro ${ }^{3}$
}

1 Doutorando do Programa de Pós-graduação em Nutrição em Saúde Pública. Faculdade de Saúde Pública (FSP). Universidade de São Paulo (USP). São Paulo, SP, Brasil

2 Professora Doutora do Departamento de Nutrição. FSP/USP. São Paulo, SP, Brasil

${ }^{3}$ Professor(a) Titular do Departamento de Nutrição. FSP/USP. São Paulo, SP, Brasil 


\section{Resumo}

Introdução: Estudos recentes mostram que restrições na ingestão de sódio podem aumentar a resistência à insulina $(\mathrm{RI})$ e induzir alterações nas lipoproteínas séricas e em marcadores de inflamação semelhantes às encontradas na Síndrome Metabólica (SM). Métodos: Realizou-se uma revisão sistemática da literatura sobre os efeitos da restrição do consumo de sódio sobre a SM ou a RI. Nove artigos foram incluídos na revisão. Resultados: A restrição no consumo de sódio associou-se ao aumento da $\mathrm{RI}$ em dois artigos e à diminuição em três outros. Em sete dos nove artigos, a restrição na ingestão de sal determinou redução da pressão arterial e em dois artigos ocorreram efeitos adversos em marcadores da SM. Conclusões: A maioria dos estudos mostrou efeitos benéficos da restrição moderada de sódio da dieta, associada ou não a outras modificações nutricionais ou ao aumento da atividade física. Novos estudos são necessários para avaliar os efeitos de reduções moderadas no consumo de sódio sobre a SM e a RI.

Descritores: Dieta Hipossódica; Sódio na Dieta; Síndrome Metabólica; Resistência à Insulina; Hipertensão Arterial. 


\begin{abstract}
Introduction: Recent studies have shown that sodium intake restrictions may increase insulin resistance (IR) and induce changes on serum lipoproteins and on inflammation markers similar to those found in Metabolic Syndrome (MS). Methods: We performed a systematic review of literature regarding the effects of restricting sodium intake on MS or on IR. Nine articles were included in the review. Results: Restriction of sodium consumption was associated with increase insulin resistance in two articles and decrease in three others. In seven of nine articles, salt intake restriction determined blood pressure reduction and in two articles adverse effects on markers of MS were found. Conclusions: Most studies showed beneficial effects of moderate sodium intake restriction, associated or not to others nutritional modifications or increase physical activity. Further studies are needed to evaluate the effects of moderate sodium consumption reductions on MS and IR.
\end{abstract}

Keywords: Sodium-Restricted Diet; Dietary Sodium; Metabolic Syndrome; Insulin Resistance, Hypertension. 


\section{Introdução}

- Definição da síndrome metabólica e riscos

Em 1988, Reaven descreveu a "Síndrome X", hoje conhecida como Síndrome Metabólica (SM), como a ocorrência de resistência à insulina, hiperglicemia, elevação da lipoproteína de baixa densidade, diminuição da lipoproteína de alta densidade (HDL-c) e hipertensão arterial sistêmica (HAS).(1)

Apesar do debate sobre a existência como síndrome e da importância prognóstica de sua caracterização (2), organizações de saúde e sociedades científicas propuseram critérios diagnósticos para padronizar sua definição, tanto para fins clínicos como para pesquisas. Devido a diferenças étnicas no risco de desenvolvimento de certas doenças, alguns critérios e pontos de corte, especificamente para a circunferência da cintura, têm sido diferenciados de forma a adaptar a definição de SM às diversas populações.(3)

Em 1999, a World Health Organization (WHO) (4) e o European Group for the Study of Insulin Resistance (EGIR) (5) apresentaram as primeiras propostas, mas foi a do National Cholesterol Education Program (NCEP) (6) de 2001 a mais amplamente utilizada, em grande parte pela simplicidade dos parâmetros diagnósticos (glicemia de jejum $\geq 110 \mathrm{mg} / \mathrm{dl}$, pressão arterial $\geq 130 \times 85 \mathrm{mmHg}$, triglicérides - TG $\geq 150 \mathrm{mg} / \mathrm{dl}$, HDL-c $\leq 40$ mg/dl (50 para mulheres) e circunferência abdominal $\geq 102 \mathrm{~cm}$ (80 para mulheres)), sendo necessário pelo menos 3 desses fatores para se estabelecer tal diagnóstico. Posteriormente, o NCEP sugeriu pequenas modificações em seus critérios, buscando incorporar o conhecimento atual na área.(7)

Critérios mais abrangentes, incluindo determinações mais complexas, fizeram com que as definições da American Association of Clinical Endocrinologists e do American College of Endocrinology fossem menos empregadas na prática clínica e em pesquisas. $(8,9)$ Mais recentemente, a 
International Diabetes Federation (IDF) propôs um consenso para estabelecer os critérios diagnósticos da SM, que permitem individualização para grupos populacionais.(10) Esta proposta foi acatada pelo National Heart, Lung, and Blood Institute e American Heart Association (11), havendo, porém, diferenças nos pontos de corte de circunferência abdominal utilizados nas duas definições.

No Brasil, em 2005, foi publicada a primeira diretriz de diagnóstico e tratamento da SM (12), baseada nos critérios do NCEP.(6) As sociedades científicas brasileiras recomendam considerar, além dos valores de corte, o uso de medicação anti-hipertensiva ou hipolipemiante para o estabelecimento da presença de HAS e dislipidemia e o diagnóstico prévio de diabetes mellitus (DM), para o preenchimento dos critérios dos respectivos distúrbios. Em face da recomendação da American Diabetes Association (13), o ponto de corte proposto para o diagnóstico de glicemia de jejum alterada passou de $110 \mathrm{mg} / \mathrm{dl}$ para $100 \mathrm{mg} / \mathrm{dl}$. A recomendação brasileira estabelece que a circunferência abdominal seja medida a meia distância entre a crista ilíaca e o rebordo costal inferior e sugere que mulheres com circunferência abdominal entre 80 e $88 \mathrm{~cm}$ e homens entre 94 e $102 \mathrm{~cm}$ realizem monitorização mais frequente dos fatores de risco para doença cardiovascular (DCV).

Embora as definições disponíveis abordem alguns aspectos diferentes dentro do espectro de anormalidades da SM, a literatura é concordante em seus componentes essenciais: obesidade, hipertrigliceridemia, níveis baixos de HDL-c, HAS e intolerância à glicose. Além disso, tais definições compartilham do mesmo objetivo, o de auxiliar na identificação de indivíduos de risco para DCV e DM, que se beneficiariam da intervenção precoce sobre estas anormalidades.(3)

- Aspectos fisiopatológicos da síndrome metabólica

A resistência à insulina - definida como redução na captação de glicose em resposta à ação insulínica - é apontada como a alteração central 
da SM. Os fatores de risco e os mecanismos associados com a síndrome são múltiplos e não estão totalmente esclarecidos, envolvendo uma complexa inter-relação entre fatores genéticos e adquiridos.(14-19) É provável que fatores agressores de diversas naturezas atinjam o organismo, desencadeando respostas compensatórias por meio do sistema neurohormonal, sendo a condição de resistência à insulina um dos principais marcadores desses processos.(20)

Fatores ambientais relacionados ao estilo de vida têm sido fortemente implicados na fisiopatologia da SM. Estes últimos incluem hábitos dietéticos (21) e inatividade física (22), ambos contribuindo para obesidade e especialmente para o acúmulo de tecido adiposo na região abdominal, tecido este diretamente envolvido na gênese da resistência à insulina. A grande liberação de ácidos graxos na circulação portal e sistêmica, decorrente da alta atividade lipolítica da gordura visceral, associada à produção de citocinas pró inflamatórias e pró aterogênicas, reduzem a captação de glicose no fígado, musculatura esquelética e outros tecidos, gerando uma condição de alto risco cardio metabólico.(23)

As anormalidades que compõem a SM se caracterizam por um alto grau de interação, uma contribuindo para o estabelecimento de outra e viceversa. Porém, recentemente, dois estudos analisaram a sequência de eventos na fisiopatologia da SM. O primeiro, utilizando dados de três coortes, revelou que a circunferência da cintura basal pode predizer a deterioração de 4 a 5 outros componentes da SM, indicando que a obesidade visceral desempenha papel central no desenvolvimento da síndrome e parece preceder o aparecimento dos seus outros componentes.(24) O segundo estudo, utilizando os dados do National Health and Nutrition Examination Survey (NHANES 1999 a 2002), sugeriu também a ocorrência de um efeito sequencial na instalação da SM: a partir da obesidade (identificada por meio do índice de massa corporal - IMC ou pela circunferência da cintura), seguem-se a inflamação sub-clínica (definida pela proteína $\mathrm{C}$ reativa - $\mathrm{PCR}$ ), a resistência à insulina e a dislipidemia.(25) 
- Resistência à insulina, hipertensão arterial sistêmica e resposta ao sódio

A captação tecidual de glicose mediada pela insulina varia amplamente entre os indivíduos e quanto mais insulinorresistente, maior a quantidade necessária de insulina a ser secretada no sentido de prevenir o desenvolvimento de DM tipo 2. A presença de resistência à insulina e a hiperinsulinemia compensatória predispõem o indivíduo a vários distúrbios metabólicos e hemodinâmicos.(26).

Modelos animais fornecem evidências da participação da resistência à insulina e do sódio na fisiopatogênese da HAS. Em ratos Dahl, modelo de pressão arterial sensível ao sal, demonstra-se que a resistência à insulina precede a elevação da pressão arterial e que a sobrecarga de sódio antecipa o surgimento da HAS.(27)

Diferentes respostas pressóricas às variações na ingestão de sódio são encontradas em modelos animais de HAS e em seres humanos e as razões para tal heterogeneidade não estão completamente elucidadas. Também não está claro como a sensibilidade ao sal interfere no controle da pressão arterial de indivíduos com ou sem resistência à insulina. Apesar disso, reconhece-se que modificações na ingestão de sódio podem provocar efeitos no metabolismo da glicose.

Piora na sensibilidade à insulina foram obtidas em modelos animais expostos a dietas hipossódicas. Ratos submetidos por 12 semanas a uma dieta com baixos teores de sódio $(0,06 \%)$ apresentaram menor captação de glicose, quando comparados com grupo controle, que consumiu dieta com níveis normais de sódio $(0,50 \%)$. Os resultados do estudo evidenciaram o envolvimento do aumento da atividade do sistema nervoso simpático e da diminuição da vasodilatação mediada pelo óxido nítrico no aumento da resistência à insulina induzida pela restrição de sal.(28)

Já os achados em seres humanos não são consistentes: a restrição do consumo de sódio reduziu resistência à insulina (29), não alterou (30) ou foi maior em subgrupos específicos de HAS.(31) 
A insulina promove a reabsorção renal de sódio e em condições de hiperinsulinemia espera-se exacerbação desta ação. Em estados de resistência à insulina este efeito retentor está mantido nos rins, mostrando que a sensibilidade à insulina nas células tubulares proximais está preservada. De fato, comparando-se indivíduos com e sem SM, observou-se que os portadores da síndrome apresentavam reabsorção proximal de sódio significativamente maior.(32)

Em suma, a resposta da pressão arterial frente ao consumo de sódio é influenciada pela condição - possivelmente geneticamente determinada de sensibilidade ao sal. A quantidade de sódio consumida pode alterar o metabolismo da glicose, enquanto que as concentrações de insulina ou a sensibilidade tecidual a esse hormônio podem também interferir no controle renal do sódio corporal.(33)

\section{- Síndrome metabólica e consumo de sódio}

A excreção urinária do mineral - indicativa do seu consumo na dieta mostra-se aumentada nos indivíduos com, quando comparados com aqueles sem SM (4,0 g/d versus 3,4 g/d, p < 0,01).(34). No estudo de Hoffmann e Cubeddu,(35) a média de excreção de sódio urinário em homens e mulheres sem características da SM foi de $3,2 \mathrm{~g} / \mathrm{d}$ e 2,7 $\mathrm{g} / \mathrm{d}$, respectivamente, enquanto naqueles com 4 ou 5 componentes da síndrome foi de, respectivamente, $4,0 \mathrm{~g} / \mathrm{d}$ e $3,1 \mathrm{~g} / \mathrm{d}$ ( $\mathrm{p}<0,001$ ), o que indicaria uma ingestão diária extra de 1,5 a $2 \mathrm{~g}$ de sal entre os indivíduos com a síndrome.

As mais recentes diretrizes para o tratamento da HAS na SM recomendam a redução no consumo de sódio.(10,11) A diretriz brasileira recomenda a redução da ingestão de sal de todas as formas, tanto para prevenção primária, como para tratamento não medicamentoso da síndrome (consumo de sal limitado a $6 \mathrm{~g}$ por dia).(12)

Porém, além das controvérsias a respeito do papel do consumo reduzido de sódio sobre o metabolismo da glicose, esta conduta poderia induzir alterações desfavoráveis nas lipoproteínas do plasma e em 
marcadores de inflamação, similares às encontradas na $\mathrm{SM},(36)$ efeitos estes indesejáveis para se minimizar o risco cardiovascular.

Resultados desfavoráveis à dieta hipossódica foram obtidos também em estudo de meta-análise, quando se compararam dietas com baixos e altos teores de sódio: a primeira aumentou significantemente os níveis de renina, aldosterona, adrenalina, noradrenalina, colesterol total, lipoproteína de baixa densidade (LDL-c) e TG. Apesar das limitações decorrentes de ensaios de curto prazo e ao questionamento dos estudos que avaliaram eficácia ou efetividade, concluiu-se que a redução no consumo de sódio foi útil para reduzir a pressão arterial em indivíduos hipertensos no curto prazo e que a magnitude do efeito sobre a pressão arterial em indivíduos normotensos da raça branca não justifica uma recomendação generalizada para diminuir o consumo deste nutriente.(37)

Embora os estudos que avaliaram os efeitos de dietas restritas em sal em humanos tenham sido, no geral, realizados no estado de jejum e os resultados obtidos em intervenções de curta duração, não se pode garantir que alterações metabólicas secundárias a essa restrição poderiam, eventualmente, superar 0 benefício esperado na aterogênese pela diminuição da pressão arterial.

O objetivo deste estudo foi realizar uma revisão da literatura no que se refere à associação entre SM ou resistência à insulina e consumo de sódio.

\section{Métodos}

Foram pesquisados artigos que analisaram os efeitos de restrições no consumo de sódio, associados ou não a outras alterações nutricionais ou a outras intervenções, na SM ou na resistência a insulina.

- Critérios de inclusão e exclusão de estudos 
Foram incluídos estudos originais, do tipo ensaio clínico (aleatorizados ou não, controlados ou não) e que tenham apresentado resultados referentes ao impacto de restrições no consumo de sódio na SM ou na resistência à insulina. Os demais critérios de inclusão foram: data da publicação do estudo entre janeiro de 2004 e dezembro de 2008, terem sido realizados em adultos e publicados nos idiomas inglês e português. Foram excluídos os estudos observacionais e aqueles realizados em animais, recém nascidos, crianças e adolescentes. Também não foram incluídos estudos que avaliaram o efeito de dietas com redução de sódio em associação ao uso de medicamentos.

- Estratégia de busca

A pesquisa dos artigos foi realizada na base de dados PubMed, utilizando-se três conjuntos de intersecção de termos de busca bibliográfica: síndrome metabólica como desfecho (metabolic syndrome, cardiovascular syndrome, cardiometabolic syndrome, Syndrome $X$, dysmetabolic syndrome, insulin resistance syndrome, insulin resistance, insulin sensitivity ou reaven Syndrome); dieta como exposição (intake, consumption, diet, dietary ou excretion) e sódio como nutriente de interesse (salt, sodium ou $\mathrm{Na}$ ). Foram pesquisadas também as referências bibliográficas dos artigos incluídos.

Realizou-se uma primeira avaliação, tendo por base os títulos e o resumo dos artigos e foram rejeitados aqueles que não preencheram os critérios de inclusão ou apresentaram algum dos critérios de exclusão. Quando um estudo não pôde ser incluído ou rejeitado com certeza, o texto completo foi analisado em uma segunda avaliação.

- Síntese e comparação dos estudos

Foi realizada síntese narrativa dos estudos selecionados, que foram apresentados segundo as características das populações e das 
intervenções. Número de participantes, idade média, IMC médio e prevalências de HAS e SM compuseram a caracterização das populações.

Para as intervenções, foram apresentados detalhes dos ensaios propriamente ditos, como tempo, tipo de intervenção (apenas dietética ou associada a recomendações de aumento da atividade física), níveis da restrição de sódio testados e forma de avaliação da adesão do participante em relação ao sódio consumido (coleta de sódio urinário de 24 horas ou aplicação de questionários - diários ou recordatórios alimentares de 24 horas).

Além disso, relacionaram-se os dados referentes à forma de avaliação do metabolismo da glicose (homeostatic model assessment - HOMA, clamp euglicêmico hiperinsulinêmico, teste oral de tolerância à glicose, índice de sensibilidade à insulina ou glicemia) e da pressão arterial (médias de medidas de repouso ou de 24 horas), além da ocorrência de modificações de peso durante a restrição de sódio (aumento, diminuição ou sem modificações).

Sintetizou-se também a forma utilizada para comparar os resultados obtidos (diferenças intragrupo $=$ apuradas no mesmo grupo de indivíduos após os períodos controle e intervenção ou efeito líquido $=$ diferenças apuradas em grupos diferentes de indivíduos entre o início e o final dos períodos controle e intervenção) e resultados e conclusões principais.

Os desfechos analisados foram resistência à insulina, lípides plasmáticos, peso, cintura abdominal, pressão arterial, renina, aldosterona, atividade do sistema nervoso simpático e marcadores de inflamação. Foram consideradas significativas as diferenças apuradas cujos valores de $p$ foram menores que 0,05 .

Devido à heterogeneidade das características das populações e das intervenções testadas, não foi possível realizar a síntese por meta-análise.

\section{Resultados}


A estratégia de pesquisa descrita resultou no encontro de 192 artigos, sendo 38 revisões. Ao final, nove artigos de oito estudos originais foram incluídos na revisão (dois artigos analisaram a mesma base de dados estudo PREMIER).(38, 39)

- Populações

O número de indivíduos estudados variou de 20 a 796, a idade média foi superior a 50 anos em cinco artigos, entre 40 e 50 anos em três e 30 anos em um artigo. O IMC médio dos participantes esteve acima do recomendado ( $\geq 25 \mathrm{Kg} / \mathrm{m}^{2}$ ) na maioria dos artigos. Todos os indivíduos apresentavam pré-hipertensão ou HAS em três artigos, em outros três a prevalência da doença variou de $12,3 \%$ a $65,2 \%$, em dois os participantes apresentavam pressão arterial normal e em um dos artigos a prevalência da doença não foi informada. Os critérios do NCEP 2001 foram utilizados para o diagnóstico de SM em quatro artigos, os da IDF 2005 em um deles, em três artigos a prevalência da síndrome não foi informada e em um deles os participantes eram indivíduos saudáveis. Quando relatada, a prevalência de SM variou de $26,8 \%$ a $100 \%$ dos participantes (tabela 1 ).

- Intervenções

A duração da intervenção variou de seis a sete dias em quatro artigos, três semanas em um deles e de 3 a 6 meses em quatro artigos. Recomendações de aumento de atividade física, além de modificações no conteúdo de sódio da dieta, foram analisadas em dois artigos, sendo que quatro deles utilizaram o padrão dietético DASH - Dietary Approaches to Stop Hypertension. Em todos os artigos, a restrição no consumo de sódio se situou abaixo de 2,4 g/d (cinco deles na faixa entre 0,4 e 1,4g/d) e a adesão ao consumo de sódio foi avaliada por meio da coleta de urina de $24 \mathrm{~h}$ e/ou pela aplicação de questionários (diários ou recordatórios alimentares de 24 h). 
A maioria dos artigos utilizou o HOMA ou o clamp euglicêmico hiperinsulinêmico para analisar o metabolismo da glicose. Observou-se perda de peso dos participantes em quatro artigos e a pressão arterial foi avaliada pelas médias de duas ou três medidas de repouso na maioria dos artigos (tabela 2).

- Resultados - efeitos da restrição de sódio sobre os desfechos analisados

A restrição de sódio associou-se ao aumento da resistência à insulina em dois artigos $(36,40)$ e à diminuição em três outros $(38,39,41)$. Encontrou-se associação entre sensibilidade ao sal e resistência à insulina ou SM em três artigos (42-44). Foi observada redução da pressão arterial em sete artigos $(36,38,39,41-43,45)$, efeito benéfico nos lípides plasmáticos em três deles $(38,41,45)$ e diminuição da PCR e da atividade simpática em um artigo.(41) Efeitos adversos, como aumento de TG, quilomícrons, marcadores de inflamação (PCR, interleucina 6 e fator de necrose tumoral alfa) foram mostrados em um artigo (36) e elevação de renina e aldosterona em dois artigos $(36,40)$ (tabela 3$)$.

\section{Discussão}

A maioria dos estudos analisados mostrou efeitos benéficos, tanto em parâmetros metabólicos quanto na pressão arterial, da restrição moderada de sódio da dieta, associada ou não a outras modificações nutricionais ou ao aumento da atividade física.

Os artigos que constataram efeitos adversos frente a uma ingestão diminuída de sódio, utilizaram reduções além da usualmente recomendada de 2,4 g/d para prevenção e tratamento da HAS na SM.(12). Quando a redução do sódio na dieta foi moderada, observou-se diminuição das concentrações séricas de PCR, efeito desejável em termos de risco cardiovascular.(41) Deve-se salientar, entretanto, que a constatação de 
efeitos adversos ou benéficos esteve limitada somente aos desfechos analisados e apenas dois artigos estudaram os efeitos da redução de sódio sobre marcadores de inflamação $(36,40,41)$, dois sobre renina e aldosterona $(36,40)$ e um sobre a atividade simpática.(41)

O efeito da restrição no consumo de sódio sobre a resistência à insulina parece depender do nível da restrição planejada e possivelmente da duração da intervenção. No estudo de Gomi e colaboradores, a restrição de sódio para 2,3 g/d por uma semana não resultou em mudanças significativas da sensibilidade à insulina e trouxe diminuições significativas da pressão arterial, ao passo que reduções maiores do consumo de sódio (para 0,7 g/d) por sete dias afetaram adversamente o metabolismo da glicose, sem ganhos maiores na pressão arterial, sugerindo que o consumo moderado de sódio pode diminuir a pressão arterial sem modificar a sensibilidade à insulina em indivíduos com HAS.(46)

Apesar de, em parte dos artigos apresentados, apenas os efeitos de curto prazo terem sido analisados, estudo de meta-análise mostrou que a redução moderada de consumo de sal por um período de quatro ou mais semanas apresentou efeito significativo na diminuição da pressão arterial em indivíduos com pressão arterial normal ou elevada.(47)

Diferentemente da suplementação ou restrição de nutrientes específicos, a utilização de dietas completas nos estudos de intervenção não permite a determinação de quais de seus componentes individuais foram os responsáveis pelas modificações metabólicas observadas ou se essas modificações deveram-se ao conjunto dos vários componentes. Quatro estudos testaram a dieta DASH, que apresenta maior conteúdo de cálcio, potássio, magnésio, nozes, grãos integrais e menor conteúdo de carne vermelha, gordura total, gordura saturada, colesterol e doces quando comparada com a uma dieta padrão voltada para redução de peso.(48) 0 consumo de grandes quantidades de laticínios, típico do padrão dietético DASH, associa-se inversamente com a SM e com a resistência à insulina e a restrição de sódio e os altos níveis de potássio, também presentes neste padrão de dieta, apresentam efeitos favoráveis sobre a pressão arterial. 0 
benefício da dieta DASH no metabolismo da glicose pode ser resultado do alto consumo de fibras ou de grãos integrais, alimentos com baixo índice glicêmico.(49)

Mesmo com a utilização de análise e controle estatístico de variáveis importantes para os desfechos, como peso ou nível de atividade física, como forma de se obterem os efeitos líquidos das intervenções, não se pode afastar a possibilidade de que os resultados observados nos estudos nos quais ocorreram modificações nessas variáveis possam ter sido, em parte, influenciados pelos benefícios obtidos tanto pela perda de peso como pelo aumento do preparo físico dos participantes. $(22,50)$

A sensibilidade à insulina foi medida, na maioria dos estudos, por meio do HOMA, fórmula matemática que estima a captação de glicose em jejum; porém a correlação deste índice com o clamp euglicêmico, padrão ouro para avaliação da sensibilidade à insulina, é bastante satisfatória.(51)

O número limitado de artigos revisados e diferenças relativas às populações e ao conteúdo das intervenções dificultaram a generalização dos resultados obtidos e recomendam a realização de mais estudos sobre os efeitos de reduções moderadas no consumo de sódio sobre a SM e resistência á insulina.

\section{Agradecimentos}

Os autores informam não haver conflitos de interesses. Por se tratar de uma revisão, o estudo não foi submetido ao comitê de ética em pesquisa. 
Tabela 1. Artigos incluídos na revisão de acordo com autor, ano de publicação e segundo características das populações submetidas às intervenções.

\begin{tabular}{|c|c|c|c|c|c|c|c|c|c|}
\hline $\begin{array}{l}\begin{array}{r}\text { Autor, ano } \\
\text { (Referência) }\end{array} \\
\text { Variáveis }\end{array}$ & $\begin{array}{c}\text { Nakandakare } \\
\text { et al, } 2008 . \\
(36)\end{array}$ & $\begin{array}{c}\text { Hoffman e } \\
\text { Cubeddu, } \\
2007 . \\
(42) \\
\end{array}$ & $\begin{array}{l}\text { Lien et al, } \\
2007 . \\
(38)\end{array}$ & $\begin{array}{l}\text { Townsend } \\
\text { et al, } \\
2007 . \\
(40) \\
\end{array}$ & $\begin{array}{c}\text { Uzu et al, } \\
2006 . \\
(43)\end{array}$ & $\begin{array}{l}\text { Straznicky } \\
\text { et al, } \\
2005 . \\
(41) \\
\end{array}$ & $\begin{array}{l}\text { Azadbakht } \\
\text { et al, } 2005 . \\
(45)\end{array}$ & $\begin{array}{c}\text { Ard et al, } \\
2004 . \\
(39)\end{array}$ & $\begin{array}{l}\text { Vedovato } \\
\text { et al, } \\
2004 . \\
(44)\end{array}$ \\
\hline $\begin{array}{l}\text { Participantes } \\
\text { (Homens / } \\
\text { Mulheres) }\end{array}$ & $\begin{array}{c}41 \\
(15 / 26)\end{array}$ & $\begin{array}{c}301 \\
(87 / 214)\end{array}$ & $\begin{array}{c}796 \\
(304 / 492)\end{array}$ & $\begin{array}{c}20 \\
(12 / 8)\end{array}$ & $\begin{array}{c}56 \\
(35 / 21)\end{array}$ & $\begin{array}{c}23 \\
(15 / 8)\end{array}$ & $\begin{array}{c}116 \\
(34 / 82)\end{array}$ & $\begin{array}{c}52 \\
(16 / 36)\end{array}$ & $\begin{array}{c}41^{*} \\
(31 / 10)\end{array}$ \\
\hline $\begin{array}{l}\text { Média de idade } \\
\text { (anos) }\end{array}$ & 53,5 & 41,5 & $\begin{array}{l}49,9 \text { sem } \\
\text { SM } \\
49,7 \text { com } \\
\text { SM }\end{array}$ & 30 & $\begin{array}{l}51,5 \text { sem } \\
\text { SM } \\
50,2 \mathrm{com} \\
\text { SM }\end{array}$ & 58,0 & 41,2 & 51,7 & $57-60$ \\
\hline $\begin{array}{l}\text { Média do IMC } \\
\left(\mathrm{kg} / \mathrm{m}^{2}\right)\end{array}$ & 26,1 & $\begin{array}{l}27,9 \text { sem SM } \\
32,2 \text { com SM }\end{array}$ & NR & 23,1 & $\begin{array}{l}23,1 \mathrm{sem} \\
\text { SM } \\
26,6 \mathrm{com} \\
\text { SM }\end{array}$ & 33,3 & 29,7 & 32,6 & $28-29$ \\
\hline $\begin{array}{l}\text { Prevalência de } \\
\text { HAS }\end{array}$ & $100 \%$ & $12,3 \%$ & $100 \%$ & $0 \%$ & $100 \%$ & $65,2 \%$ & NR & $36,5 \%$ & $0 \%$ \\
\hline Prevalência de SM & NR & $\begin{array}{l}\text { NCEP-01 } \\
34 \%\end{array}$ & $\begin{array}{l}\text { NCEP-01 } \\
50,1 \%\end{array}$ & $0 \%$ & $\begin{array}{l}\text { IDF-05 } \\
26,8 \%\end{array}$ & $\begin{array}{l}\text { NCEP-01 } \\
100 \%\end{array}$ & $\begin{array}{l}\text { NCEP-01 } \\
100 \%\end{array}$ & NR & NR \\
\hline
\end{tabular}

NR = Não relatado; IMC = Índice de Massa Corporal; HAS = Pré ou Hipertensão Arterial Sistêmica; SM = Síndrome Metabólica - critério diagnóstico; NCEP-01 - National Cholesterol Education Program 2001; IDF-05 - International Diabetes Federation 2005; * participantes diabéticos. 
Tabela 2. Artigos incluídos na revisão de acordo com autor, ano de publicação e segundo características das intervenções.

\begin{tabular}{|c|c|c|c|c|c|c|c|c|c|}
\hline $\begin{array}{r}\text { Autor, ano } \\
\text { (Referência) } \\
\text { Variáveis }\end{array}$ & $\begin{array}{l}\text { Nakandakare } \\
\text { et al, } 2008 . \\
(36)\end{array}$ & $\begin{array}{l}\text { Hoffman e } \\
\text { Cubeddu, } \\
2007 . \\
(42) \\
\end{array}$ & $\begin{array}{c}\text { Lien et al, } \\
2007 . \\
(38)\end{array}$ & $\begin{array}{l}\text { Townsend } \\
\text { et al, } \\
\text { 2007. (40) }\end{array}$ & $\begin{array}{l}\text { Uzu et al, } \\
2006 . \\
(43)\end{array}$ & $\begin{array}{c}\text { Straznicky } \\
\text { et al, } 2005 . \\
(41)\end{array}$ & $\begin{array}{c}\text { Azadbakht } \\
\text { et al, } 2005 \text {. } \\
\text { (45) }\end{array}$ & $\begin{array}{c}\text { Ard et al, } \\
2004 . \\
(39)\end{array}$ & $\begin{array}{l}\text { Vedovato et } \\
\text { al, 2004. } \\
\text { (44) }\end{array}$ \\
\hline Duração & 3 semanas & 1 semana & 6 meses & 6 dias & 1 semana & 3 meses & 6 meses & 6 meses & 1 semana \\
\hline Intervenção & Dieta & Dieta & $\begin{array}{l}\text { Dieta + } \\
\text { Atividade } \\
\text { Física }\end{array}$ & Dieta & Dieta & Dieta & Dieta & $\begin{array}{l}\text { Dieta + } \\
\text { Atividade } \\
\text { Física }\end{array}$ & Dieta \\
\hline $\begin{array}{l}\text { Restrição de sódio } \\
\text { (g/d) }\end{array}$ & 1,40 & 1,00 & 2,30 & 0,46 & $0,40-1,20$ & 2,30 & 2,40 & 2,40 & 0,60 \\
\hline $\begin{array}{l}\text { Avaliação do } \\
\text { sódio da dieta }\end{array}$ & $\mathrm{NaU}$ & $\mathrm{NaU}$ & $\mathrm{NaU}$ & $\mathrm{NaU}$ & $\mathrm{NaU}$ & $\mathrm{NaU}$ & Q & Q & $\mathrm{NaU}$ \\
\hline $\begin{array}{l}\text { Metabolismo da } \\
\text { glicose }\end{array}$ & HOMA & TOTG & HOMA & Clamp & HOMA & HOMA & Glicemia & ISS & Clamp* \\
\hline $\begin{array}{l}\text { Modificação do } \\
\text { peso }\end{array}$ & Não & NR & Redução & Não & NR & Redução & Redução & Redução & NR \\
\hline Pressão arterial & $\begin{array}{c}\text { Média de } 24 \\
h\end{array}$ & $\begin{array}{l}\text { Média em } \\
\text { repouso }\end{array}$ & $\begin{array}{c}\text { Média em } \\
\text { repouso }\end{array}$ & $\begin{array}{c}\text { Média em } \\
\text { repouso }\end{array}$ & $\begin{array}{l}\text { Média de } \\
24 \mathrm{~h}\end{array}$ & $\begin{array}{l}\text { Média em } \\
\text { repouso }\end{array}$ & $\begin{array}{c}\text { Média em } \\
\text { repouso }\end{array}$ & $\begin{array}{c}\text { Média em } \\
\text { repouso }\end{array}$ & $\begin{array}{c}\text { Média de } 24 \\
\mathrm{~h}\end{array}$ \\
\hline
\end{tabular}

NR = não relatado; $\mathrm{NaU}=$ Sódio urinário de 24 horas; $\mathrm{Q}=$ Questionário (diário ou recordatório alimentar 24 h); HOMA = Homeostatic model assessment; TOTG = Teste oral de tolerância à glicose; ISS = Índice de sensibilidade à insulina; *o clamp euglicêmico hiperinsulinêmico foi realizado em 18 participantes. 
Tabela 3. Artigos incluídos na revisão de acordo com autor, ano de publicação e segundo características das intervenções, diferenças avaliadas e resultados e conclusões principais.

\begin{tabular}{|c|c|c|c|c|}
\hline $\begin{array}{l}\text { Intervenção } \\
\text { Autor, ano, } \\
\text { (referência) }\end{array}$ & $\begin{array}{c}\text { Características das dietas e } \\
\text { das intervenções }\end{array}$ & $\begin{array}{l}\text { Diferenças } \\
\text { avaliadas }\end{array}$ & Resultados principais & Conclusões principais \\
\hline $\begin{array}{l}\text { Nakandakare } \\
\text { et al, } 2008 . \\
\text { (36) }\end{array}$ & $\begin{array}{l}\text { A- sódio }=3,7 \mathrm{~g} / \mathrm{d} \text { e } \mathrm{B} \text { - } \\
\text { sódio }=1,4 \mathrm{~g} / \mathrm{d} \text {. }\end{array}$ & Intragrupo & $\begin{array}{l}\uparrow \text { TG, quilomicrom colesterol, PCR, TNF-alfa, } \\
\text { IL-6, atividade da renina, aldosterona, insulina } \\
\text { e HOMA. } \\
\downarrow \text { PAS, PAD, PAM. }\end{array}$ & $\begin{array}{l}\text { A restrição no consumo de sódio } \\
\text { induziu alterações nas lipoproteínas } \\
\text { séricas e marcadores de } \\
\text { inflamação que são características } \\
\text { da SM. }\end{array}$ \\
\hline $\begin{array}{l}\text { Hoffman e } \\
\text { Cubeddu, } \\
2007 . \\
(42)\end{array}$ & $\begin{array}{l}\text { A- sódio = 3,2 g/d, B- sódio } \\
=7,2 \mathrm{~g} / \mathrm{d} \text { e } C-=1,0 \mathrm{~g} / \mathrm{d} \text {. }\end{array}$ & $\begin{array}{l}\text { Efeito } \\
\text { líquido }\end{array}$ & $\begin{array}{l}\text { Maior } \downarrow \text { PAS e PAD na SM. } \\
\downarrow \text { PAS e PAD proporcional ao número de } \\
\text { características de SM. } \\
\downarrow \text { prevalência de HAS na SM }(23,8 \% \text { para } \\
8,2 \%) \text {. }\end{array}$ & $\begin{array}{l}\text { Aumento da prevalência da } \\
\text { sensibilidade ao sal no grupo com } \\
\text { SM, estando esta diretamente } \\
\text { relacionada ao número de } \\
\text { características da síndrome em } \\
\text { cada indivíduo. }\end{array}$ \\
\hline $\begin{array}{l}\text { Lien et al, } \\
2007 . \\
(38)\end{array}$ & $\begin{array}{l}\text { A- aconselhamento } \\
\text { individual, B- intervenção } \\
\text { comportamental intensa e } \\
\text { C- = B + dieta DASH. Em B } \\
\text { e C - sódio } \leq 2,3 \mathrm{~g} / \mathrm{d} \text {. }\end{array}$ & $\begin{array}{l}\text { Efeito } \\
\text { líquido }\end{array}$ & $\begin{array}{l}\downarrow \text { PAS }(\mathrm{mmHg}) \text { sem e com SM: A: }-6,2 \text { e }-6,8(p \\
=0,60) ; B:-12,0 \text { e }-8,4(p=0,00) ; C:-11,2 \text { e }- \\
9,9(p=0,23) . \\
\downarrow \text { HOMA, colesterol total em B e C (com SM). }\end{array}$ & $\begin{array}{l}\text { A SM atenuou a diminuição da PAS } \\
\text { em B, atenuação esta superada } \\
\text { com a dieta DASH em C. }\end{array}$ \\
\hline $\begin{array}{l}\text { Townsend et } \\
\text { al, } 2007 \text {. } \\
(40)\end{array}$ & $\begin{array}{l}\text { A- sódio }=4,6 \mathrm{~g} / \mathrm{d} \text { e } \mathrm{B} \text { - } \\
\text { sódio }=0,46 \mathrm{~g} / \mathrm{d} \text {. }\end{array}$ & Intragrupo & $\begin{array}{l}\downarrow \text { captação de glicose mediada pela insulina } \\
\left(7,41 \times 6,1 \mathrm{mg} / \mathrm{kg}^{*} \min , p=0.03\right) . \rightarrow \text { PA. } \\
\uparrow \text { de renina e aldosterona. }\end{array}$ & $\begin{array}{l}\text { A restrição de sal reduziu a } \\
\text { sensibilidade à insulina. }\end{array}$ \\
\hline
\end{tabular}




\begin{tabular}{|c|c|c|c|c|}
\hline $\begin{array}{l}\text { Uzu et al, } \\
2006 . \\
(43)\end{array}$ & $\begin{array}{l}\text { A- sódio }=4 \text { a } 4,8 \mathrm{~g} / \mathrm{d} \text { e } \mathrm{B} \text { - } \\
\text { sódio }=0,4 \text { a } 1,2 \mathrm{~g} / \mathrm{d} \text {. }\end{array}$ & $\begin{array}{l}\text { Efeito } \\
\text { líquido }\end{array}$ & $\begin{array}{l}\uparrow \text { prevalência de HAS sódio sensível no grupo } \\
\text { com SM }(70,6 \% \text { versus } 36,0 \%, p=0,02) \text {. } \\
\text { O efeito de B na queda da PAM noturna foi } \\
\text { maior nos pacientes com SM. }\end{array}$ & $\begin{array}{l}\text { Foi mostrada uma relação } \\
\text { significativa entre SM, sensibilidade } \\
\text { da PA ao sódio e diminuição da PA } \\
\text { noturna. }\end{array}$ \\
\hline $\begin{array}{l}\text { Straznicky et } \\
\text { al, } 2005 . \\
(41)\end{array}$ & $\begin{array}{l}\text { Dieta DASH modificada } \\
\text { (sódio = } 2,3 \mathrm{~g} / \mathrm{d} \text { ) e redução } \\
\text { de energia para diminuição } \\
\text { de peso. }\end{array}$ & Intragrupo & $\begin{array}{l}\downarrow \text { PAS, peso, IMC, CA, colesterol total, TG, } \\
\text { glicemia, insulina, PCR, atividade simpática e } \\
\text { HOMA. } \\
\uparrow \mathrm{HDL} .\end{array}$ & $\begin{array}{l}\text { A diminuição de peso por meio de } \\
\text { uma dieta hipocalórica com } \\
\text { restrição moderada de sódio trouxe } \\
\text { melhorias nos componentes da SM. }\end{array}$ \\
\hline $\begin{array}{l}\text { Azadbakht et } \\
\text { al, } 2005 . \\
(45)\end{array}$ & $\begin{array}{c}\text { A- Dieta controle, B- }=\text { A e } \downarrow \\
500 \text { Kcal/d para redução de } \\
\text { peso e C- dieta DASH }(\downarrow \\
500 \mathrm{Kcal} / \mathrm{d} \text { e sódio }< \\
2,4 \mathrm{~g} / \mathrm{d}) .\end{array}$ & $\begin{array}{l}\text { Efeito } \\
\text { líquido }\end{array}$ & $\begin{array}{c}\text { C versus } \mathrm{B}: \text { > aumento de HDL e > redução de } \\
\text { PAS, PAD, TG, glicemia, peso e prevalência } \\
\text { SM. }\end{array}$ & $\begin{array}{l}\text { A dieta DASH diminuiu a maioria } \\
\text { dos fatores de risco metabólicos. }\end{array}$ \\
\hline $\begin{array}{l}\text { Ard et al, } \\
2004 . \\
(39)\end{array}$ & $\begin{array}{l}\text { A- aconselhamento } \\
\text { individual, B-Intervenção } \\
\text { comportamental intensa e } \\
\text { C- = B + dieta DASH. Em B } \\
\text { e C - sódio } \leq 2,4 \mathrm{~g} / \mathrm{d} \text {. }\end{array}$ & $\begin{array}{l}\text { Efeito } \\
\text { líquido }\end{array}$ & $\begin{array}{l}B-A: \downarrow \text { peso, IMC, insulina, glicemia. } \\
C-A: \uparrow \text { ISS }(1,96 \text { para } 2,95-p=0,047) \text { e } \downarrow \\
\text { PAS, peso, CA, IMC. } \\
\text { C - B: } \rightarrow \text { ISS ( } p=0,62),>\text { razão de mudança } \\
\text { insulina-glicose. }\end{array}$ & $\begin{array}{l}\text { A Dieta DASH aumentou a ação da } \\
\text { insulina além do efeito de } B \text {. }\end{array}$ \\
\hline $\begin{array}{l}\text { Vedovato et } \\
\text { al, } 2004 \text {. } \\
(44)\end{array}$ & $\begin{array}{l}\text { A- sódio = 0,6g/d e B- sódio } \\
6 \mathrm{~g} / \mathrm{d} \text {. }\end{array}$ & $\begin{array}{l}\text { Análise de } \\
\text { correlação }\end{array}$ & $\begin{array}{l}\text { As mudanças na PAM induzidas pelo sal } \\
\text { estiveram inversamente relacionadas com a } \\
\text { sensibilidade à insulina }(r=-0,51, p=0,01) \text {. }\end{array}$ & $\begin{array}{l}\text { A resistência à insulina pode } \\
\text { contribuir para a } \\
\text { sensibilidade ao sal. }\end{array}$ \\
\hline
\end{tabular}

$1 \mathrm{~g} \mathrm{sal} \approx 0,4 \mathrm{~g}$ de sódio $\approx 17,4$ mmol de sódio; $\uparrow=$ aumento, $\downarrow=$ redução, $\rightarrow=$ sem modificação, PA = pressão arterial; PAS = pressão arterial sistólica; $\mathrm{PAD}=$ pressão arterial diastólica; $\mathrm{PAM}=$ pressão arterial média; TG = triglicérides; $\mathrm{LDL}=$ lipoproteína de baixa densidade; HDL = lipoproteína de alta densidade; $\mathrm{PCR}=$ proteína $\mathrm{C}$ reativa; TNF-alfa = fator de necrose tumoral alfa; IL-6 = interleucina 6 ; HOMA = homeostasis model assessment; SM = síndrome metabólica; ISS = índice de sensibilidade à insulina; IMC = índice de massa corporal; CA = circunferência abdominal.

$\mathrm{A}, \mathrm{B}$ e $\mathrm{C}$ referem-se às características das dietas utilizadas nas intervenções e os resultados principais, quando não especificado, referem-se àquelas com restrição de sódio. 


\section{Referências}

1. Reaven GM. Banting lecture 1988. Role of insulin resistance in human disease. Diabetes. 1988;37(12):1595-607.

2. Kahn R, Buse J, Ferrannini E, Stern M, American Diabetes A, European Association for the Study of D. The metabolic syndrome: time for a critical appraisal: joint statement from the American Diabetes Association and the European Association for the Study of Diabetes. Diabetes Care. 2005;28(9):2289-304.

3. Levesque J, Lamarche B. The Metabolic Syndrome: Definitions, Prevalence and Management. J Nutrigenet Nutrigenomics. 2008;1:100-8.

4. World Health Organization. Definition, Diagnosis and Classification of Diabetes Mellitus and its Complications. Part 1: Diagnosis and classification of diabetes mellitus. Department of Noncommunicable Disease Surveillance, Geneva, 1999. [Acesso em 18/08/10]; Disponível em: http://whqlibdoc.who.int/hq/1999/WHO_NCD_NCS_99.2.pdf.

5. Balkau B, Charles MA. Comment on the provisional report from the WHO consultation. European Group for the Study of Insulin Resistance (EGIR). Diabet Med. 1999;16(5):442-3.

6. III ATP. Executive Summary of The Third Report of The National Cholesterol Education Program (NCEP) Expert Panel on Detection, Evaluation, And Treatment of High Blood Cholesterol In Adults. JAMA. 2001;285(19):2486-97.

7. Grundy SM, Brewer HB, Jr., Cleeman JI, Smith SC, Jr., Lenfant C, American Heart A, et al. Definition of metabolic syndrome: Report of the National Heart, Lung, and Blood Institute/American Heart Association conference on scientific issues related to definition. Circulation. 2004;109(3):433-8.

8. Bloomgarden ZT. American Association of Clinical Endocrinologists (AACE) consensus conference on the insulin resistance syndrome: 25-26 August 2002, Washington, DC. Diabetes Care. 2003;26(4):1297-303. 
9. Einhorn D, Reaven GM, Cobin RH, Ford E, Ganda OP, Handelsman Y, et al. American College of Endocrinology position statement on the insulin resistance syndrome. Endocr Pract. 2003;9(3):237-52.

10. Alberti KG, Zimmet P, Shaw J. Metabolic syndrome - a new world-wide definition. A Consensus Statement from the International Diabetes Federation. Diabet Med. 2006;23(5):469-80.

11. Grundy SM, Cleeman JI, Daniels SR, Donato KA, Eckel RH, Franklin BA, et al. Diagnosis and management of the metabolic syndrome: an American Heart Association/National Heart, Lung, and Blood Institute Scientific Statement. Circulation. 2005;112(17):2735-52.

12. Sociedade Brasileira de Hipertensão, Sociedade Brasileira de Cardiologia, Sociedade Brasileira de Endocrinologia e Metabologia, Sociedade Brasileira de Diabetes, Sociedade Brasileira de Estudos da Obesidade. I Brazilian guidelines on diagnosis and treatment of metabolic syndrome. Arq Bras Cardiol. 2005;84 Suppl 1:1-28.

13. American Diabetes A. Diagnosis and classification of diabetes mellitus. Diabetes Care. 2004;27 Suppl 1:S5-S10.

14. Gallagher EJ, LeRoith D, Karnieli E. The metabolic syndrome - from insulin resistance to obesity and diabetes. Endocrinol Metab Clin North Am. 2008;37(3):559-79.

15. Kressel G, Trunz B, Bub A, Hulsmann O, Wolters M, Lichtinghagen R, et al. Systemic and vascular markers of inflammation in relation to metabolic syndrome and insulin resistance in adults with elevated atherosclerosis risk. Atherosclerosis. 2009;202(1):263-71.

16. Goossens $\mathrm{GH}$. The role of adipose tissue dysfunction in the pathogenesis of obesity-related insulin resistance. Physiol Behav. 2008;94(2):206-18.

17. Lara-Castro C, Garvey WT. Intracellular lipid accumulation in liver and muscle and the insulin resistance syndrome. Endocrinol Metab Clin North Am. 2008;37(4):841-56.

18. Grattagliano I, Palmieri VO, Portincasa P, Moschetta A, Palasciano G. Oxidative stress-induced risk factors associated with the metabolic syndrome: a unifying hypothesis. J Nutr Biochem. 2008;19(8):491-504. 
19. Briana D, Malamitsi-Puchner A. Intrauterine growth restriction and adult disease: the role of adipocytokines. Eur J Endocrinol. 2009;160(3):337-47.

20. Sjostrand M, Eriksson JW. Neuroendocrine mechanisms in insulin resistance. Mol Cell Endocrinol. 2009;297(1-2):104-11.

21. Esposito K, Ceriello A, Giugliano D. Diet and the metabolic syndrome. Metab Syndr Relat Disord. 2007;5(4):291-6.

22. Lakka TA, Laaksonen DE. Physical activity in prevention and treatment of the metabolic syndrome. Appl Physiol Nutr Metab. 2007;32(1):76-88.

23. Despres JP, Lemieux I, Bergeron J, Pibarot P, Mathieu P, Larose E, et al. Abdominal obesity and the metabolic syndrome: contribution to global cardiometabolic risk. Arterioscler Thromb Vasc Biol. 2008;28(6):1039-49.

24. Cameron AJ, Boyko EJ, Sicree RA, Zimmet PZ, Soderberg S, Alberti KG, et al. Central Obesity as a Precursor to the Metabolic Syndrome in the AusDiab Study and Mauritius. Obesity (Silver Spring). 2008;16(12):2707-16.

25. Lin LY, Kuo HK, Li HY, Hwang JJ, Lin JW. Confirming a Biological Pathway in the Metabolic Syndrome-Insight from the NHANES 1999-2002. Obesity (Silver Spring). 2008;16(12):2676-81.

26. Reaven GM. Insulin resistance, the insulin resistance syndrome, and cardiovascular disease. Panminerva Med. 2005;47(4):201-10.

27. Shehata MF. Genetic and dietary salt contributors to insulin resistance in Dahl salt-sensitive (S) rats. Cardiovasc Diabetol. 2008;7:7.

28. Ruivo GF, Leandro SM, do Nascimento CA, Catanozi S, Rocha JC, Furukawa LN, et al. Insulin resistance due to chronic salt restriction is corrected by alpha and beta blockade and by L-arginine. Physiol Behav. 2006;88(4-5):364-70.

29. Donovan DS, Solomon CG, Seely EW, Williams GH, Simonson DC. Effect of sodium intake on insulin sensitivity. Am J Physiol. 1993;264(5 Pt 1):E730-4.

30. Foo M, Denver AE, Coppack SW, Yudkin JS. Effect of salt-loading on blood pressure, insulin sensitivity and limb blood flow in normal subjects. Clin Sci (Lond). 1998;95(2):157-64. 
31. Raji A, Williams GH, Jeunemaitre X, Hopkins PN, Hunt SC, Hollenberg NK, et al. Insulin resistance in hypertensives: effect of salt sensitivity, renin status and sodium intake. J Hypertens. 2001;19(1):99-105.

32. Strazzullo P, Barbato A, Galletti F, Barba G, Siani A, lacone R, et al. Abnormalities of renal sodium handling in the metabolic syndrome. Results of the Olivetti Heart Study. J Hypertens. 2006;24(8):1633-9.

33. Sarafidis PA, Bakris GL. The antinatriuretic effect of insulin: an unappreciated mechanism for hypertension associated with insulin resistance? Am J Nephrol. 2007;27(1):44-54.

34. Ohta Y, Tsuchihashi T, Arakawa K, Onaka U, Ueno M. Prevalence and lifestyle characteristics of hypertensive patients with metabolic syndrome followed at an outpatient clinic in fukuoka, Japan. Hypertens Res. 2007;30(11):1077-82.

35. Hoffmann IS, Cubeddu LX. Salt and the metabolic syndrome. Nutr Metab Cardiovasc Dis. 2008;19(2):123-8.

36. Nakandakare ER, Charf AM, Santos FC, Nunes VS, Ortega K, Lottenberg AM, et al. Dietary salt restriction increases plasma lipoprotein and inflammatory marker concentrations in hypertensive patients. Atherosclerosis. 2008;200(2):410-6.

37. Jurgens G, Graudal NA. Effects of low sodium diet versus high sodium diet on blood pressure, renin, aldosterone, catecholamines, cholesterols, and triglyceride. Cochrane Database Syst Rev. 2004(1):CD004022.

38. Lien LF, Brown AJ, Ard JD, Loria C, Erlinger TP, Feldstein AC, et al. Effects of PREMIER lifestyle modifications on participants with and without the metabolic syndrome. Hypertension. 2007;50(4):609-16.

39. Ard JD, Grambow SC, Liu D, Slentz CA, Kraus WE, Svetkey LP, et al. The effect of the PREMIER interventions on insulin sensitivity. Diabetes Care. 2004;27(2):340-7.

40. Townsend RR, Kapoor S, McFadden CB. Salt intake and insulin sensitivity in healthy human volunteers. Clin Sci (Lond). 2007;113(3):141-8.

41. Straznicky NE, Lambert EA, Lambert GW, Masuo K, Esler MD, Nestel PJ. Effects of dietary weight loss on sympathetic activity and cardiac risk 
factors associated with the metabolic syndrome. J Clin Endocrinol Metab. 2005;90(11):5998-6005.

42. Hoffmann IS, Cubeddu LX. Increased blood pressure reactivity to dietary salt in patients with the metabolic syndrome. J Hum Hypertens. 2007;21(6):438-44.

43. Uzu T, Kimura G, Yamauchi A, Kanasaki M, Isshiki K, Araki S, et al. Enhanced sodium sensitivity and disturbed circadian rhythm of blood pressure in essential hypertension. J Hypertens. 2006;24(8):1627-32.

44. Vedovato M, Lepore G, Coracina A, Dodesini AR, Jori E, Tiengo A, et al. Effect of sodium intake on blood pressure and albuminuria in Type 2 diabetic patients: the role of insulin resistance. Diabetologia. 2004;47(2):300-3.

45. Azadbakht L, Mirmiran P, Esmaillzadeh A, Azizi T, Azizi F. Beneficial effects of a Dietary Approaches to Stop Hypertension eating plan on features of the metabolic syndrome. Diabetes Care. 2005;28(12):2823-31.

46. Gomi T, Shibuya Y, Sakurai J, Hirawa N, Hasegawa K, Ikeda T. Strict dietary sodium reduction worsens insulin sensitivity by increasing sympathetic nervous activity in patients with primary hypertension. Am J Hypertens. 1998;11(9):1048-55.

47. He FJ, MacGregor GA. Effect of longer-term modest salt reduction on blood pressure. Cochrane Database Syst Rev. 2004(3):CD004937.

48. Vogt TM, Appel LJ, Obarzanek E, Moore TJ, Vollmer WM, Svetkey LP, et al. Dietary Approaches to Stop Hypertension: rationale, design, and methods. DASH Collaborative Research Group. J Am Diet Assoc. 1999;99(8 Suppl):S12-8.

49. Van Horn L, McCoin M, Kris-Etherton PM, Burke F, Carson JA, Champagne CM, et al. The evidence for dietary prevention and treatment of cardiovascular disease. J Am Diet Assoc. 2008;108(2):287-331.

50. Klein S. Outcome success in obesity. Obes Res. 2001;9(Suppl 4):354S$8 S$.

51. Wallace TM, Levy JC, Matthews DR. Use and abuse of HOMA modeling. Diabetes Care. 2004;27(6):1487-95. 
6. TERCEIRO ARTIGO 
Impacto de uma intervenção no ambiente de trabalho para redução da adição de sal aos alimentos

Impact of a workplace intervention to reduce the added salt to food

Flavio Sarno ${ }^{1}$, Daniel Henrique Bandoni ${ }^{1}$, Patrícia Constante Jaime ${ }^{2}$, Carlos Augusto Monteiro ${ }^{3}$

${ }^{1}$ Programa de Pós-Graduação de Nutrição em Saúde Pública. Faculdade de Saúde Pública (FSP). Universidade de São Paulo (USP). São Paulo, SP, Brasil

${ }^{2}$ Professora Doutora do Departamento de Nutrição. FSP-USP. São Paulo, SP, Brasil

${ }^{3}$ Professor Titular do Departamento de Nutrição. FSP-USP. São Paulo, SP, Brasil 


\section{RESUMO}

Introdução: No Brasil, estima-se que o consumo de sódio corresponda a aproximadamente duas vezes o consumo máximo recomendado e que cerca de três quartos desse consumo provenha da adição de sal e de condimentos à base de sal aos alimentos. O ambiente de trabalho é um dos locais propícios para a promoção de modificações nos comportamentos alimentares precursores de doenças. Objetivos: Avaliar o impacto de uma intervenção que promoveu a redução da adição de sal aos alimentos, consumidos por funcionários de empresas da cidade de São Paulo. Métodos: Estudo de intervenção randomizado controlado envolvendo 28 empresas, sendo 14 no grupo intervenção e 14 no grupo controle. Participaram da pesquisa 2.417 funcionários, 1.179 no grupo intervenção e 1.238 no grupo controle, com idades entre 18 e 65 anos. A intervenção teve duração de seis meses e foi baseada no modelo ecológico de promoção de saúde. Os gestores das unidades de alimentação e nutrição receberam um manual com informações sobre alimentação saudável, foram realizadas oficinas culinárias, forneceram-se materiais educativos e os funcionários que participaram da coleta de dados receberam um fôlder com informações sobre alimentação saudável. Todas as ações e materiais fornecidos visavam estimular a redução da adição de sal aos alimentos. A variável desfecho foi a adição de sal aos alimentos ou no prato quente e o impacto da intervenção foi avaliado por meio de testes de diferenças de proporções e modelos de regressão de poisson multinível. Resultados: Na avaliação inicial, cerca de dois terços dos funcionários de ambos os grupos referiram adicionar sal aos alimentos e em torno de um quinto o fazia no prato quente. Após a intervenção, foi observada redução na frequência de adição de sal nos funcionários alocados no grupo intervenção $(-3,1 \%)$ e aumento naqueles do grupo controle (1,4\%), não atingindo, entretanto, a significância estatística. No grupo intervenção, observou-se maior redução da frequência de adição de sal no prato quente $(-12,6 \%)$, quando comparada com o grupo controle ($5,1 \%)$. $\mathrm{Na}$ análise multivariada, homens $(\mathrm{IRR}=0,51)$ e aqueles 
categorizados como normotensos (IRR $=0,61)$ alocados no grupo intervenção no momento final apresentaram menor taxa de adição de sal no prato quente. Conclusões: A intervenção realizada no ambiente de trabalho reduziu a taxa de relato de adição de sal no prato quente dos participantes homens e daqueles categorizados como normotensos.

Descritores: Sódio na Dieta; Cloreto de Sódio na Dieta; Redução da adição de sal; ambiente de trabalho. 


\section{ABSTRACT}

Introduction: In Brazil, it is estimated that the sodium intake corresponds to approximately twice the maximum recommended intake and that about three quarters of this consumption comes from adding salt and salt-based seasonings to foods. The work environment is ideal for the promotion of changes in eating behaviors precursors of diseases. Objectives: To evaluate the impact of an intervention that promoted the reduction of added salt to foods consumed by employees of the city of Sao Paulo. Methods: A randomized controlled intervention trial involving 28 companies, 14 in the intervention group and 14 in the control group. The findings included 2417 employees, 1179 in the intervention group and 1,238 in the control group, aged between 18 and 65 years. The intervention lasted for six months and was based on the ecological model of health promotion. The managers of food and nutrition unit received a manual with information on healthy eating, cooking workshops were held, educational materials were provided and employees, who participated in data collection, had received a folder with information about healthy eating. All the actions and materials provided were intended to encourage the reduction of added salt to food. The outcome variable was adding salt to food or to the hot meal and the impact of the intervention was evaluated by differences proportions tests and multilevel Poisson regression models. Results: At baseline, approximately two thirds of the employees of both groups referred adding salt to food and around a fifth did so in hot meal. After the intervention, a decrease in the frequency of adding salt of employees allocated in the intervention group $(-3.1 \%)$ was observed and increase those of the control group (1.4\%), not reaching, however, statistical significance. In the intervention group, there was a greater reduction in the frequency of adding salt on the hot meal $(-12.6 \%)$, when compared with the control group $(-5.1 \%)$. In multivariate analysis, men $(I R R=0.51)$ and those categorized as normotensive $(I R R=0.61)$ allocated in the intervention group at the final moment had lower rate of addition of salt in the hot meal. Conclusions: The intervention carried out at the workplace 
reduced the reporting rate of salt addition in hot meal of male participants and those categorize as normotensive.

Key words: Sodium, Dietary; Sodium Chloride, Dietary; Reduction of adding salt; Workplace. 


\section{Introdução}

O consumo excessivo de sódio é considerado fator de risco para a ocorrência das doenças crônicas não transmissíveis (DCNT), tanto que a Organização Mundial da Saúde recomendou que governos (atuando por meio de políticas públicas) e o setor privado da sociedade (representado pela indústria de alimentos) trabalhassem em conjunto na limitação no consumo de sódio pela população.(1)

O consumo de sal deveria ser menor que 5 gramas por dia (correspondente a 2 gramas de sódio) (2), porém, no Brasil, a disponibilidade média diária de sódio, apenas à correspondente ao domicílio, foi estimada em 4,7 gramas por pessoa para um consumo de $2.000 \mathrm{Kcal}$, ou seja, mais de duas vezes o consumo máximo recomendado. Do total, cerca de três quartos da disponibilidade de sódio provinham da adição do nutriente aos alimentos por meio de sal e de condimentos à base de sal.(3)

Dentro do panorama de intervenções voltadas para promoção de alimentação saudável e fatores relacionados ao estilo de vida, o ambiente de trabalho vem atraindo cada vez mais interesse como um dos locais propícios para modificações de comportamentos precursores de doenças, não apenas aqueles específicos da função ocupacional, mas também os relacionados à dieta, atividade física e tabagismo.(4)

O objetivo deste estudo foi avaliar o impacto de uma intervenção que promoveu a redução da adição de sal aos alimentos consumidos por trabalhadores de empresas da cidade de São Paulo.

\section{Métodos}

Delineamento e população do estudo

Este estudo está inserido na pesquisa "Impacto de intervenção para promoção do consumo de frutas e hortaliças em empresas cadastradas no Programa de Alimentação do Trabalhador". 
Os dados das empresas foram obtidos do banco do Ministério do Trabalho e Emprego, tendo sido pareadas pelo número de funcionários, modalidade de gestão do PAT (autogestão, terceirizada, outros) e setor de atividade econômica (industrial, comércio ou serviços). Para serem incluídas na pesquisa, foram sorteadas aquelas que possuíam mais de 150 funcionários e que preparavam e distribuíam refeições para o funcionário no próprio local de trabalho. Inicialmente, 30 empresas aceitaram participar da pesquisa e foram sorteadas 15 para cada grupo intervenção e controle. Entretanto uma das empresas do grupo controle desistiu de participar do estudo após a primeira coleta de dados.

Coleta de dados

A coleta de dados foi realizada no refeitório de cada empresa entre outubro de 2006 e abril de 2007 e outra coleta ocorreu 6 meses após. Todos os funcionários foram convidados a participar da pesquisa por meio da divulgação prévia do estudo pela empresa. A amostra de trabalhadores nestas duas coletas foi independente.

Foram estudadas 28 empresas, sendo 14 no grupo intervenção e 14 no grupo controle. Participaram da pesquisa 2.417 funcionários, 1.179 no grupo intervenção (603 antes e 576 depois da intervenção) e 1.238 no grupo controle (644 antes e 594 após a intervenção), com idades entre 18 e 65 anos. A média de funcionários participantes por empresa foi de 85,7 (mínimo 55 e máximo 116).

O questionário utilizado constou de perguntas para caracterização sócio-demográfica dos funcionários, que foram categorizados segundo: sexo (masculino ou feminino), idade (18 a 29, 30 a 39, 40 ou mais anos), escolaridade (0 a 11 ou 12 ou mais anos de estudo), referência ao uso de medicamentos para controle da hipertensão arterial (sim ou não) e dados auto referidos de peso e altura. O questionário foi aplicado por alunas do curso de nutrição, devidamente treinadas para a tarefa. A aferição da pressão arterial foi realizada por um dos autores da pesquisa (FS) utilizando 
técnicas padronizadas (5) e empregando o aparelho eletrônico BP 3BTO-A, previamente aferido e certificado.(6)

O índice de massa corporal (calculado por meio do quociente peso em quilos e altura em metros ao quadrado) foi categorizado em $<25$ ou $\geq 25$ $\mathrm{Kg} / \mathrm{m}^{2}$.(7) Considerou-se hipertenso o indivíduo com pressão arterial sistólica $\geq 140 \mathrm{mmHg}$ ou pressão arterial diastólica $\geq 90 \mathrm{mmHg}$ ou quando houve referência à utilização de medicamento(s) para controle da pressão arterial.(8)

O hábito de adicionar sal aos alimentos foi obtido por meio da pergunta "O Sr.(a) costuma acrescentar sal aos alimentos?" (adaptada da NHANES - National Health and Nutrition Examination Survey). A resposta foi categorizada em não, nunca; sim, às vezes e sim, sempre ou quase sempre.(9) Para os participantes que responderam positivamente em relação à adição de sal, foi também questionado se o hábito ocorria apenas nas saladas, apenas no prato quente ou em ambos.

Intervenção

A intervenção foi baseada no modelo ecológico de promoção de saúde. De forma resumida, o modelo estabelece que os comportamentos sejam resultados das influências mútuas entre características individuais (valores, experiências, crenças e história pessoal) e ambientais (ambientes físico, social, cultural e organizacional).(10) A atuação em ambos os termos desta equação pode contribuir na geração de comportamentos promotores de saúde.

A intervenção teve duração de 6 meses e seus focos foram os gestores das unidades de alimentação e nutrição (UAN), o ambiente (refeitório) e os funcionários das empresas.

A intervenção se iniciou com o fornecimento aos gestores das UAN um manual com informações sobre a importância do papel da unidade na promoção da alimentação saudável no local de trabalho (anexo 1). Salientou-se o possível impacto no aumento da produtividade, redução das 
DCNT e diminuição dos gastos da empresa com serviços de saúde com a melhoria da alimentação dos funcionários. As informações contidas no manual tiveram como base o que é atualmente recomendado para uma alimentação saudável para população brasileira (o consumo de sal diário deve ser no máximo de 5 gramas por dia - 1 colher rasa de chá por pessoa) (11) e nos novos parâmetros nutricionais do PAT (valores diários de referência para sódio $\leq 2.400 \mathrm{mg}) \cdot(12)$

Em seguida, foram realizadas oficinas culinárias com os funcionários que preparavam a alimentação das empresas com vistas a incentivar a utilização de menor quantidade de sal. Foram fornecidos materiais educativos com informações sobre alimentação saudável dispostas em formato de álbum seriado para serem utilizados nas mesas do refeitório (anexo 2).

Incentivou-se a colocação dos saleiros em uma posição central do refeitório (no lugar de um saleiro em cada mesa) e sugeriu-se a confecção de cartazes ou fundos de bandeja com informações sobre o conteúdo nutricional de alimentos. Tais informações poderiam ser veiculadas nos holerites dos funcionários ou pela intranet, jornais, revistas ou painéis de avisos da empresa (anexo 3), sendo que todos esses materiais visavam, entre outras recomendações nutricionais, a encorajar a redução na adição de sal aos alimentos.

Finalmente, os funcionários que participaram da coleta de dados receberam um fôlder com informações sobre alimentação saudável, novamente enfatizando a importância da redução no consumo de sal. Este material também apresentava os valores ideais de pressão arterial e um local para anotação da pressão arterial medida. O funcionário do grupo controle recebeu uma filipeta, onde foram anotados os valores obtidos na medida da pressão arterial (anexo 4).

Na eventualidade da ocorrência de medidas de pressão arterial acima do recomendado ( $\geq 140 \times 90 \mathrm{mmHg}$ ), o funcionário era orientado a procurar por avaliação médica para a confirmação da hipertensão arterial. 
Análise estatística

Inicialmente foi realizada análise descritiva das variáveis do estudo de acordo com a alocação das empresas (grupos intervenção e controle) e momento da intervenção (antes e depois). As diferenças nas distribuições das variáveis antes e após a intervenção foram analisadas por meio do teste qui quadrado.

O impacto da intervenção no hábito de adicionar sal aos alimentos foi avaliado por meio de testes de diferenças de proporções e modelos de regressão de Poisson multinível, com o nível 1 representado pelo trabalhador e o nível 2 pela empresa. $(13,14)$

As variáveis desfechos foram os relatos de adição (às vezes e sempre) ou não de sal aos alimentos ou no prato quente (no prato quente e no prato quente e nas saladas). A variável explanatória foi definida como a interação entre o momento da intervenção (antes ou depois) e a categoria de alocação das empresas (intervenção ou controle). Sexo, idade, escolaridade, IMC e hipertensão arterial foram consideradas como variáveis de confusão.

Os valores de incidence rate ratio (IRR) das variáveis desfechos obtidos nos modelos de regressão de Poisson avaliaram o efeito da intervenção. Foram utilizadas tanto a estratégia forward (as variáveis de confusão foram introduzidas uma a uma nos modelos), quanto backward (todas as variáveis de confusão compuseram os modelos iniciais) para o ajuste dos modelos. Foram mantidas nos modelos finais as variáveis que causaram variações de pelo menos $10 \%$ no valor das IRR das variáveis desfechos. Ao final, os resultados foram estratificados segundo as variáveis do estudo. Foi utilizado o programa Stata para análise dos dados, considerando-se o intervalo de confiança de $95 \%$ e significativos valores de $\mathrm{p}<0,05$.

As empresas e todos os funcionários que aceitaram participar do estudo assinaram um termo de consentimento livre e esclarecido. O estudo foi submetido à avaliação do Comitê de Ética em Pesquisa da Faculdade de Saúde Pública da USP, tendo recebido sua aprovação (anexo 5). É 
importante destacar que as empresas e funcionários do grupo controle ao final do estudo receberam o mesmo material educativo desenvolvido para as empresas do grupo intervenção.

\section{Resultados}

À exceção da variável sexo, não houve diferenças estatísticas significantes nas variáveis, idade, escolaridade, IMC e hipertensão arterial antes e após a intervenção, tanto no grupo intervenção como no grupo controle (tabela 1).

$\mathrm{Na}$ avaliação inicial de ambos os grupos, cerca de dois terços $(66,7 \%)$ de todos os funcionários referiram ter o hábito de adicionar sal aos alimentos (18,9\% referiram adicionar sal aos alimentos às vezes e $47,9 \%$ sempre ou quase sempre), enquanto que em torno de um quinto $(19,6 \%)$ o faziam no prato quente ou no prato quente e nas saladas.

No momento inicial, participantes homens, com idade acima de 40 anos, pertencentes à categoria de maior escolaridade, com IMC maior que $25 \mathrm{Kg} / \mathrm{m}^{2}$ e os que foram categorizados como hipertensos apresentaram menores frequências de adição de sal aos alimentos. Ao final dos seis meses, houve redução na frequência do hábito de adicionar sal aos alimentos relatada pelos participantes alocados no grupo intervenção ($3,1 \%)$ e aumento naqueles do grupo controle $(1,4 \%)$, sendo que estas variações não atingiram a significância estatística. De forma geral, os participantes alocados no grupo controle mostraram aumento das frequências de adição de sal aos alimentos (exceto aqueles com idade acima de 40 anos e com hipertensão arterial), enquanto que os participantes pertencentes ao grupo intervenção demonstraram reduções dessas frequências (exceto aqueles com idade entre 18 e 29 anos). Os participantes que inicialmente apresentavam as menores frequências de adição de sal aos alimentos foram os que também mostraram maiores reduções da frequência do hábito após 6 meses de intervenção (tabela 2).

De forma semelhante ao observado com a adição de sal, no momento 
inicial, participantes homens, com idade acima de 40 anos, pertencentes à categoria de menor escolaridade, com IMC maior que $25 \mathrm{Kg} / \mathrm{m}^{2}$ e os que foram categorizados como hipertensos apresentaram menores frequências de adição de sal ao prato quente. Foram observadas reduções dessas frequências após 6 meses, tendo sido maiores nos participantes alocados no grupo intervenção $(-12,6 \%)$, quando comparadas com o grupo controle ($5,1 \%$ ). Homens, da faixa etária entre 30 e 39 anos e categorizados como hipertensos apresentaram as maiores reduções da frequência de adicionar sal no prato quente (tabelas 3).

$\mathrm{Na}$ análise multivariada dos modelos de regressão, nenhuma das variáveis consideradas inicialmente como de confusão foram capazes de modificar o valor da IRR da variável desfecho acima de $10 \%$ e, portanto, não foram incluidas nos modelos finais. Foram observadas reduções nas taxas do hábito de adicionar sal aos alimentos ( $I R R=0,93, p=0,49$ ) e no prato quente $(\mathrm{IRR}=0,66, \mathrm{p}=0,06)$ nos parcipantes alocados no grupo intervenção. Nas análises estratificadas, à exceção dos indivíduos categorizados como hipertensos, houve novamente reduções dos relatos de adição de sal e no prato quente. Em especial, homens (IRR =0,51, $p=0,02)$ e aqueles considerados normotensos ( $I R R=0,61, p=0,05$ ) alocados no grupo intervenção no momento final apresentaram taxas menores do hábito de adicionar sal ao prato quente (tabela 4).

\section{Discussão}

Este estudo demonstrou que a intervenção realizada no ambiente de trabalho reduziu a taxa de relato de adição de sal no prato quente dos participantes do sexo masculino e daqueles categorizados como normotensos.

O uso de sal discrecional pode estar relacionado com preferências de ordem pessoal, quando é realizado após se provar o alimento ou ligado a comportamento meramente repetitivo (hábito), quando a adição é feita mesmo sem ter conhecimento prévio do conteúdo de sal do alimento. Além 
disso, influências sócioculturais, localização (15) e o número e área dos furos do saleiro (16) estão relacionadas com a frequência de utilização e quantidade de sal adicionada à mesa. Este comportamento pode ser estimado por meio de inquéritos, que já vêm sendo utilizados há vários anos na análise do consumo alimentar do nutriente.(17) A concordância entre o relato de adicionar sal aos alimentos e o comportamento real observado mostrou ser esse tipo de questionamento válido, com taxas de discordâncias entre o relato e o comportamento real observado de apenas $3 \%$ a $6 \%$.(18)

Outro fator importante é a relação entre o hábito de adicionar sal aos alimentos e o consumo total do nutriente. Kim e colaboradores analisaram os hábitos do uso de sal e de consumo de alimentos com alto teor do nutriente em adultos normotensos. Dentre as 15 perguntas aplicadas, observaram uma correlação significativa entre o hábito de adicionar sal aos alimentos prontos e a excreção urinária de sódio de 24 h.(19) Resultado semelhante foi observado na pesquisa canadense de saúde e nutrição de 2004, onde o consumo de sódio esteve diretamente associado às categorias de adição de sal, sendo de $3,4 \mathrm{~g}$ nos indivíduos que relataram adicionar sal frequentemente aos alimentos, de $3,1 \mathrm{~g}$ na categoria de raramente fazê-lo e de $2,9 \mathrm{~g}$ naqueles que referiram não ter o hábito de adicionar sal aos alimentos prontos.(20)

O local de trabalho é um ambiente considerado propício para a implementação de programas de promoção de saúde, em particular àqueles voltados para alimentação saudável. Revisão sistemática avaliou as intervenções voltadas para dieta realizadas no ambiente de trabalho, publicadas entre 1995 e 2009 e que apresentavam duração de pelo menos 8 semanas. Metade das 16 pesquisas incluídas na revisão esteve focada na estratégia de educação nutricional do trabalhador (em grupo ou individualmente) e o restante nas políticas e no ambiente das empresas (rotulagem nutricional, políticas de vendas e disponibilidade de alimentos na cantina ou no refeitório e reformulação do cardápio), isoladamente ou em combinação com o conteúdo educacional. Apesar das limitações metodológicas e de usualmente apresentarem resultados modestos, 
concluiu-se que as intervenções apresentaram efeitos positivos no comportamento alimentar.(21)

Estudo realizado na Dinamarca analisou o conteúdo de sal de 180 refeições consumidas por funcionários de 15 diferentes ambientes de trabalho. A quantidade de sal foi estimada por meio de porções duplicadas e da aferição do conteúdo de cloreto presente nestas refeições. Nas cantinas dos ambientes de trabalho, por refeição e por $10 \mathrm{MJ}$ (cerca de $2.400 \mathrm{Kcal}$ ), os valores observados foram de $3,8 \mathrm{~g}$ e $14,7 \mathrm{~g}$ em homens e 2,8 g e 14,4 g em mulheres, respectivamente. Apesar das análises não terem computado a quantidade de sal e condimentos adicionados à mesa, os teores de sal observados foram considerados elevados, comparáveis inclusive com os valores obtidos, utilizando a mesma metodologia, na análise de refeições rápidas (fast foods) de 13,8 g por 10 MJ em média.(22)

Vários estudos analisaram o impacto da redução do consumo de sódio, tanto como única modificação da dieta, quanto como compondo dietas específicas.(23) Mas foram poucas as pesquisas voltadas para a redução da adição de sal aos alimentos. Kojuri e Rahimi avaliaram o efeito da combinação da dieta DASH (Dietary Approach to Stop Hypertension) com o aconselhamento de não adicionar sal aos alimentos em hipertensos. Após 6 semanas, quando comparado com o grupo controle, o grupo intervenção apresentou redução significativa do sódio urinário e da pressão arterial de 24 h.(24) No geral, as intervenções com foco na redução da adição de sal, estiveram baseadas em modificações das características do sal discrecional (adicionado à mesa ou no preparo dos alimentos), resultando em sais substitutos com proporções menores de sódio e variáveis de potássio, magnésio e cálcio, em comparação com o sal convencional.(25-27)

Nas intervenções, deve-se ter a precaução quando do aconselhamento dietético, que pode estar focado em alguns nutrientes ou alimentos, mas deve também apresentar uma visão geral da alimentação saudável, pois existe o risco de haver melhoria em certas características da dieta e piora em outras. Este fato pode ser observado no estudo realizado no ambiente de trabalho, onde uma dieta vegana com baixos teores de gordura 
por 22 semanas proporcionou aumento da ingestão de nutrientes protetores (fibra, folato e vitamina $\mathrm{C}$ ) e diminuição do consumo de gordura total e saturada e colesterol em funcionários com excesso de peso e/ou diabetes. Houve, porém, aumento da ingestão de sódio.(28) Em nosso estudo, tivemos a precaução de associar mensagens voltadas para a promoção do consumo de hortaliças com o estímulo à redução da adição de sal aos alimentos, de forma a evitar o risco de o consumo aumentado de saladas causar também aumento da ingestão de sódio.

A amostra deste estudo esteve baseada no possível impacto da intervenção no consumo de frutas e hortaliças. Calculamos, então, o poder de teste para cada uma das variáveis desfechos, relacionadas ao consumo de sal. Estimamos um poder de teste de 21,2\% para a variável adição de sal e de $73,3 \%$ para a variável adição de sal ao prato quente, valor este próximo de $80 \%$ usualmente utilizado nos estudos de intervenção.

Na comparação entre os grupos intervenção e controle, observamos diferenças significativas das distribuições das variáveis idade e escolaridade, nos dois momentos da intervenção. Porém, na análise multivariada, nenhuma das variáveis se mostrou capaz de modificar as IRR das variáveis desfechos.

O delineamento deste estudo não é o usualmente encontrado nos ensaios que analisam os mesmos indivíduos antes e após a intervenção. Nas empresas, existem dificuldades em se realizar a randomização dos funcionários no início da pesquisa, bem como acessar os mesmos indivíduos no segundo momento da coleta de dados. A possível análise apenas daqueles funcionários que participaram nos dois momentos da pesquisa exigiria uma logística maior do que a disponível. De outro lado, o delineamento utilizado traz a vantagem de, ao se acessar indivíduos diferentes no segundo momento da intervenção, minimiza-se o viés de mudança de resposta, fenômeno que pode ocorrer na avaliação de intervenções por meio de variáveis auto-referidas.(29)

Na pesquisa canadense de saúde e nutrição de 2004 , cerca de $30 \%$ dos indivíduos entre 19 e 70 anos relataram não ter o hábito de adicionar sal 
aos alimentos, porcentagem bastante semelhante aos cerca de 33\% observado neste estudo. De forma semelhante também, foram observadas relações inversas entre as categorias de adição de sal e o diagnóstico autoreferido de hipertensão arterial.(20)

A limitação do estudo e de qualquer outro que utilize questionários na avaliação da dieta está baseada no viés de lembrança. Porém, grande parte dos inquéritos alimentares está baseada no auto relato, sendo a principal ferramenta utilizada para avaliação de padrões de comportamentos alimentares e de intervenções dietéticas. Para ser válido, o auto relato de consumo de qualquer alimento deve apresentar alta correlação com o real comportamento dos indivíduos e também com a(s) medida(s) do(s) nutriente(s) contido(s) no alimento em análise. Em relação ao sal, as pesquisas têm apontado para a alta correlação entre o relato da adição do nutriente aos alimentos e o real comportamento, bem como a relação direta entre esta adição e o consumo total de sódio.(18-20) A não avaliação da adesão das empresas às intervenções, em especial aquelas voltadas para modificações do ambiente e confecção de materiais educativos, pode ter causado diminuição dos resultados observados, quando da comparação com o grupo controle.

Em resumo, este estudo demonstrou que os participantes alocados no grupo intervenção do sexo masculino e aqueles considerados normotensos apresentaram menores taxas de adição de sal ao prato quente no momento final da intervenção. 
Tabela 1. Características dos participantes antes e após a intervenção e segundo grupo de alocação. São Paulo, 2006-2007.

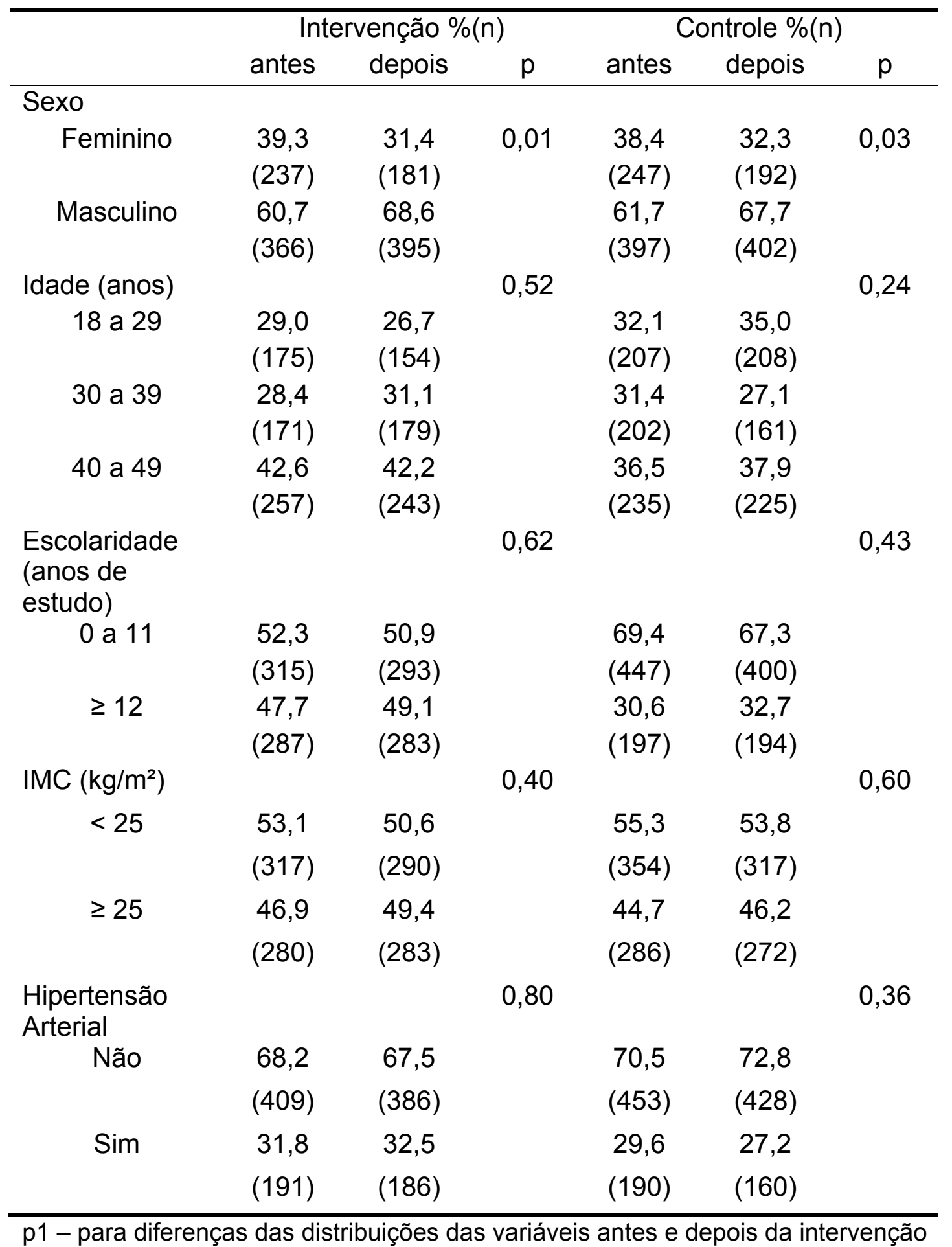


Tabela 2. Frequências (\%) e intervalos de confiança de 95\% (IC 95\%) do hábito de adicionar sal aos alimentos antes e após a intervenção, de acordo com as características dos participantes e segundo grupo de alocação. São Paulo, 20062007.

\begin{tabular}{|c|c|c|c|c|c|c|}
\hline & \multicolumn{3}{|c|}{ Intervenção \% (IC 95\%) } & \multicolumn{3}{|c|}{ Controle \% (IC 95\%) } \\
\hline & antes & depois & diferença & antes & depois & diferença \\
\hline \multicolumn{7}{|l|}{ Geral } \\
\hline & 66,2 & 63,3 & $-3,1$ & 67,1 & 68,5 & 1,4 \\
\hline & $(62,670,1)$ & $(59,367,1)$ & $(-8,62,3)$ & $(63,570,7)$ & $(64,872,3)$ & $(-3,86,7)$ \\
\hline \multicolumn{7}{|l|}{ Sexo } \\
\hline \multirow[t]{2}{*}{ Feminino } & 67,1 & 65,7 & $-1,3$ & 69,6 & 70,8 & 1,2 \\
\hline & $(61,173,1)$ & $(58,872,7)$ & $(-10,57,8)$ & $(63,975,4)$ & $(64,477,3)$ & $(-7,49,8)$ \\
\hline \multirow[t]{2}{*}{ Masculino } & 65,8 & 62,0 & $-3,8$ & 65,5 & 67,4 & 1,9 \\
\hline & $(61,070,7)$ & $(57,266,8)$ & $(-10,63,0)$ & $(60,870,2)$ & $(62,872,0)$ & $(-4,68,5)$ \\
\hline \multicolumn{7}{|l|}{ Idade (anos) } \\
\hline \multirow[t]{2}{*}{18 a 29} & 68,6 & 70,8 & 2,2 & 71,0 & 75,5 & 4,5 \\
\hline & $(61,775,5)$ & $(63,678,0)$ & $(-7,7$ 12,2) & $(64,877,2)$ & $(69,681,3)$ & $(-4,013,0)$ \\
\hline \multirow[t]{2}{*}{30 a 39} & 67,8 & 64,8 & $-3,0$ & 65,8 & 72,0 & 6,2 \\
\hline & $(60,874,9)$ & $(57,871,8)$ & $(-12,96,9)$ & $(59,372,4)$ & $(65,179,0)$ & $(-3,315,7)$ \\
\hline \multirow[t]{2}{*}{$\geq 40$} & 63,8 & 57,2 & $-6,6$ & 64,7 & 59,6 & $-5,1$ \\
\hline & $(57,969,7)$ & $(51,063,4)$ & $(-15,21,9)$ & $(58,770,8)$ & $(53,166,0)$ & $(-14,03,7)$ \\
\hline
\end{tabular}




\begin{tabular}{|c|c|c|c|c|c|c|}
\hline $\begin{array}{c}\text { Escolaridade } \\
\text { (anos de estudo) } \\
0 \text { a } 11\end{array}$ & $\begin{array}{c}67,9 \\
(62,873,1)\end{array}$ & $\begin{array}{c}65,9 \\
(60,471,3)\end{array}$ & $\begin{array}{c}-2,1 \\
(-9,65,4)\end{array}$ & $\begin{array}{c}67,8 \\
(63,572,1)\end{array}$ & $\begin{array}{c}69,5 \\
(65,074,0)\end{array}$ & $\begin{array}{c}1,7 \\
(-4,58,0)\end{array}$ \\
\hline$\geq 12$ & $\begin{array}{c}64,8 \\
(59,370,3)\end{array}$ & $\begin{array}{c}60,4 \\
(54,766,1)\end{array}$ & $\begin{array}{c}-4,4 \\
(-12,33,6)\end{array}$ & $\begin{array}{c}65,5 \\
(58,872,1)\end{array}$ & $\begin{array}{c}66,5 \\
(59,973,1)\end{array}$ & $\begin{array}{c}1,0 \\
(-8,410,4)\end{array}$ \\
\hline \multicolumn{7}{|l|}{$\mathrm{IMC}\left(\mathrm{kg} / \mathrm{m}^{2}\right)$} \\
\hline$<25$ & $\begin{array}{c}69,7 \\
(64,774,8)\end{array}$ & $\begin{array}{c}66,2 \\
(60,8-71,7)\end{array}$ & $\begin{array}{c}-3,5 \\
(-10,93,9)\end{array}$ & $\begin{array}{c}68,1 \\
(63,2-72,9)\end{array}$ & $\begin{array}{c}71,0 \\
(66,076,0)\end{array}$ & $\begin{array}{c}2,9 \\
(-4,19,9)\end{array}$ \\
\hline$\geq 25$ & $\begin{array}{c}64,4 \\
(58,170,7)\end{array}$ & $\begin{array}{c}61,0 \\
(54,467,6)\end{array}$ & $\begin{array}{c}-3,5 \\
(-12,65,7)\end{array}$ & $\begin{array}{c}66,1 \\
(60,671,6)\end{array}$ & $\begin{array}{c}65,8 \\
(60,271,4)\end{array}$ & $\begin{array}{c}-0,3 \\
(-8,17,6)\end{array}$ \\
\hline \multicolumn{7}{|l|}{$\mathrm{HA}(\%)$} \\
\hline Não & $\begin{array}{c}69,9 \\
(65,574,4)\end{array}$ & $\begin{array}{c}68,1 \\
(63,572,8)\end{array}$ & $\begin{array}{c}-1,8 \\
(-8,24,6)\end{array}$ & $\begin{array}{c}69,3 \\
(65,173,6)\end{array}$ & $\begin{array}{c}74,3 \\
(70,278,4)\end{array}$ & $\begin{array}{c}5,0 \\
(-0,910,9)\end{array}$ \\
\hline Sim & $\begin{array}{c}58,1 \\
(51,165,1)\end{array}$ & $\begin{array}{c}52,7 \\
(45,559,9)\end{array}$ & $\begin{array}{c}-5,4 \\
(-15,44,6)\end{array}$ & $\begin{array}{c}62,1 \\
(55,269,0)\end{array}$ & $\begin{array}{c}52,5 \\
(44,860,2)\end{array}$ & $\begin{array}{c}-9,6 \\
(-20,00,8)\end{array}$ \\
\hline
\end{tabular}


Tabela 3. Frequências (\%) e intervalos de confiança de 95\% (IC 95\%) do hábito de adicionar sal no prato quente antes e após a intervenção, de acordo com as características dos participantes e segundo grupo de alocação. São Paulo, 20062007.

\begin{tabular}{|c|c|c|c|c|c|c|}
\hline & \multicolumn{3}{|c|}{ Intervenção \% (IC 95\%) } & \multicolumn{3}{|c|}{ Controle \% (IC 95\%) } \\
\hline & antes & depois & diferença & antes & depois & diferença \\
\hline \multirow[t]{2}{*}{ Geral } & 22,2 & 9,6 & $-12,6$ & 17,1 & 12,0 & $-5,1$ \\
\hline & $(18,925,6)$ & $(7,212,0)$ & $(-16,7-8,5)$ & $(14,220,0)$ & $(9,414,7)$ & $(-9,0-1,2)$ \\
\hline \multicolumn{7}{|l|}{ Sexo } \\
\hline \multirow[t]{2}{*}{ Feminino } & 25,4 & 15,1 & $-10,3$ & 19,5 & 14,1 & $-5,4$ \\
\hline & $(19,831,0)$ & $(9,820,3)$ & $(-18,0-2,7)$ & $(14,624,5)$ & $(9,119,0)$ & $(-12,41,5)$ \\
\hline \multirow[t]{2}{*}{ Masculino } & 20,2 & 7,1 & $-13,0$ & 15,7 & 11,1 & $-4,6$ \\
\hline & $(16,024,3)$ & $(4,69,7)$ & $(-17,9-8,2)$ & $(12,119,2)$ & $(8,014,1)$ & $(-9,30,1)$ \\
\hline \multicolumn{7}{|l|}{ Idade (anos) } \\
\hline \multirow[t]{2}{*}{18 a 29} & 26,2 & 13,7 & $-12,4$ & 21,8 & 13,6 & $-8,3$ \\
\hline & $(19,632,7)$ & $(8,319,2)$ & $(-21,0-3,9)$ & $(16,227,5)$ & $(8,918,3)$ & $(-15,6-0,9)$ \\
\hline \multirow[t]{2}{*}{30 a 39} & 26,5 & 11,9 & $-14,6$ & 16,8 & 13,8 & $-3,1$ \\
\hline & $(19,833,2)$ & $(7,116,6)$ & $(-22,9-6,4)$ & $(11,722,0)$ & $(8,4$ 19,1) & $(-10,54,3)$ \\
\hline \multirow[t]{2}{*}{$\geq 40$} & 16,8 & 5,4 & $-11,4$ & 13,2 & 9,4 & $-3,9$ \\
\hline & $(12,221,4)$ & $(2,58,2)$ & $(-16,8-6,0)$ & $(8,917,6)$ & $(5,613,2)$ & $(-9,71,9)$ \\
\hline
\end{tabular}




\begin{tabular}{|c|c|c|c|c|c|c|}
\hline $\begin{array}{c}\text { Escolaridade } \\
\text { (anos de estudo) } \\
0 \text { a } 11\end{array}$ & $\begin{array}{c}23,0 \\
(18,327,7)\end{array}$ & $\begin{array}{c}10,3 \\
(6,813,8)\end{array}$ & $\begin{array}{c}-12,7 \\
(-18,5-3,0)\end{array}$ & $\begin{array}{c}15,9 \\
(12,519,3)\end{array}$ & $\begin{array}{c}13,4 \\
(10,016,7)\end{array}$ & $\begin{array}{c}-2,6 \\
(-7,32,2)\end{array}$ \\
\hline$\geq 12$ & $\begin{array}{c}21,5 \\
(16,726,3)\end{array}$ & $\begin{array}{c}8,9 \\
(5,612,2)\end{array}$ & $\begin{array}{c}-12,6 \\
(-18,4-6,8)\end{array}$ & $\begin{array}{c}19,9 \\
(14,325,5)\end{array}$ & $\begin{array}{c}9,3 \\
(5,213,4)\end{array}$ & $\begin{array}{c}-10,6 \\
(-17,5-3,6)\end{array}$ \\
\hline \multicolumn{7}{|l|}{ IMC $\left(\mathrm{kg} / \mathrm{m}^{2}\right)$} \\
\hline$<25$ & $\begin{array}{c}24,9 \\
(20,129,7)\end{array}$ & $\begin{array}{c}12,2 \\
(8,415,9)\end{array}$ & $\begin{array}{c}-12,8 \\
(-18,9-6,7)\end{array}$ & $\begin{array}{c}18,1 \\
(14,122,1)\end{array}$ & $\begin{array}{c}14,9 \\
(11,018,9)\end{array}$ & $\begin{array}{c}-3,2 \\
(-8,82,4)\end{array}$ \\
\hline$\geq 25$ & $\begin{array}{c}18,8 \\
(14,223,5)\end{array}$ & $\begin{array}{c}6,4 \\
(3,59,3)\end{array}$ & $\begin{array}{c}-12,4 \\
(-17,9-7,0)\end{array}$ & $\begin{array}{c}16,1 \\
(11,920,4)\end{array}$ & $\begin{array}{c}8,5 \\
(5,211,8)\end{array}$ & $\begin{array}{c}-7,6 \\
(-13,0-2,2)\end{array}$ \\
\hline \multicolumn{7}{|l|}{$\mathrm{HA}(\%)$} \\
\hline Não & $\begin{array}{c}23,4 \\
(19,227,5)\end{array}$ & $\begin{array}{c}10,9 \\
(7,814,1)\end{array}$ & $\begin{array}{c}-12,4 \\
(-17,6-7,3)\end{array}$ & $\begin{array}{c}17,7 \\
(14,221,2)\end{array}$ & $\begin{array}{c}14,9 \\
(11,518,2)\end{array}$ & $\begin{array}{c}-2,8 \\
(-7,72,0)\end{array}$ \\
\hline Sim & $\begin{array}{c}20,1 \\
(14,425,8)\end{array}$ & $\begin{array}{c}6,5 \\
(3,010,1)\end{array}$ & $\begin{array}{c}-13,6 \\
(-20,3-6,8)\end{array}$ & $\begin{array}{c}15,9 \\
(10,721,1)\end{array}$ & $\begin{array}{c}5,0 \\
(1,68,4)\end{array}$ & $\begin{array}{c}-10,9 \\
(-17,1-4,7)\end{array}$ \\
\hline
\end{tabular}


Tabela 4. Razão da taxa de incidência (IRR) dos participantes pertencentes ao grupo intervenção no momento final, segundo as variáveis do estudo. São Paulo, 2006-2007.

\begin{tabular}{|c|c|c|c|c|}
\hline & \multicolumn{2}{|c|}{ Adição de sal } & \multicolumn{2}{|c|}{$\begin{array}{c}\text { Adição de sal no prato } \\
\text { quente }\end{array}$} \\
\hline & IRR & (IC 95\%) & IRR & (IC 95\%) \\
\hline Geral & 0,93 & $(0,771,13)$ & 0,66 & $(0,431,02)$ \\
\hline \multicolumn{5}{|l|}{ Sexo } \\
\hline Feminino & 0,96 & $(0,69$ 1,34) & 0,87 & $(0,451,69)$ \\
\hline Masculino & 0,92 & $(0,721,17)$ & 0,51 & $(0,280,91)$ \\
\hline \multicolumn{5}{|l|}{ Idade (anos) } \\
\hline 18 a 29 & 0,97 & $(0,691,37)$ & 0,91 & $(0,451,84)$ \\
\hline 30 a 39 & 0,87 & $(0,611,25)$ & 0,59 & $(0,281,25)$ \\
\hline$\geq 40$ & 0,97 & $(0,701,35)$ & 0,49 & $(0,211,13)$ \\
\hline \multicolumn{5}{|c|}{$\begin{array}{l}\text { Escolaridade (anos } \\
\text { de estudo) }\end{array}$} \\
\hline 0 a 8 & 0,83 & $(0,49$ 1,39) & 0,61 & $(0,201,83)$ \\
\hline 9 a 11 & 0,98 & $(0,731,31)$ & 0,61 & $(0,321,19)$ \\
\hline$\geq 12$ & 0,92 & $(0,671,26)$ & 0,90 & $(0,431,88)$ \\
\hline \multicolumn{5}{|l|}{$\mathrm{IMC}\left(\mathrm{Kg} / \mathrm{m}^{2}\right)$} \\
\hline$<25$ & 0,91 & $(0,701,19)$ & 0,61 & $(0,351,06)$ \\
\hline$\geq 25$ & 0,97 & $(0,721,30)$ & 0,66 & $(0,311,38)$ \\
\hline \multicolumn{5}{|c|}{ Hipertensão arterial } \\
\hline Não & 0,91 & $(0,721,14)$ & 0,61 & $(0,371,00)$ \\
\hline Sim & 1,07 & $(0,731,58)$ & 1,07 & $(0,392,97)$ \\
\hline
\end{tabular}


ANEXOS 
1. Manual

\section{Promoção do aumento no consumo de frutas, legumes e verduras e redução no consumo de sal nas empresas}

Elaborado pelo Departamento de Nutrição da Faculdade de Saúde

Pública da Universidade de São Paulo

Junhol 2006 
As Doenças Crônicas Não Transmissíveis (DNCT), incluindo doenças cardiovasculares, diabetes, obesidade, câncer e doenças respiratórias, são responsáveis por $59 \%$ das 56,5 milhões de mortes anuais no mundo e $45,9 \%$ da carga total de doenças.

Os principais fatores de risco para essas doenças são hipertensão arterial, colesterol elevado, obesidade, sedentarismo, consumo insuficiente de frutas,

legumes e verduras (FLV) e consumo excessivo de sal. Associado ao consumo de tabaco e álcool, esses são fatores de risco preveníveis e estão fortemente associados ao estilo de vida.

Uma das principais iniciativas da Organização Mundial de Saúde (OMS) é a denominada "Estratégia Global para Alimentação, Atividade Física e Saúde", que foi aprovada por 192 países, incluindo o Brasil, na Assembléia Mundial da Saúde em maio de 2004. Uma das prioridades da Estratégia Global é 0 incentivo ao aumento do consumo de FLV e a redução no consumo de sal.

Frente a toda preocupação com a saúde no cenário mundial e considerando seu objetivo central de promover boas condições nutricionais dos trabalhadores com repercussões positivas para sua qualidade de vida, $\underline{0}$ Programa de Alimentação do Trabalhador (PAT) reformulou seus parâmetros nutricionais. Dentre esses, destacam-se:

- a oferta de pelo menos uma porção de frutas e uma porção de legumes ou verduras nas refeições principais (almoço, jantar e ceia);

- a oferta de uma porção de frutas nas refeições menores (desjejum e lanches);

- a redução no consumo de sal para menos de 6 gramas por dia. 
Considerando esta clara interface da nutrição e da saúde, o Departamento de Nutrição da Faculdade de Saúde Pública da Universidade de São Paulo desenvolveu sugestões para a promoção do consumo de frutas, legumes e vegetais, bem como a redução no consumo de sal, tendo como objetivos auxiliar a empresa no cumprimento dos novos parâmetros nutricionais do

PAT e colaborar na criação de um ambiente favorável para que os colaboradores desenvolvam hábitos saudáveis de alimentação.

\section{Por que consumir frutas, legumes e verduras?}

Porque além de tornarem a alimentação mais saudável, contêm vitaminas, minerais, fibras e fitoquímicos (pigmentos que dão cor as frutas, legumes e hortaliças e que atuam como protetores no organismo humano) além de

ofertarem poucas calorias. Devido a essas propriedades, o consumo mínimo de 5 porções de FLV ajuda a prevenir as DCNT's e a deficiência de vitaminas e minerais.

As frutas, legumes e verduras são componentes importantes de uma dieta saudável e o seu consumo diário em quantidades adequadas pode ajudar a prevenir doenças como as cardiovasculares e certos tipos de câncer. De

acordo com a Organização Mundial de Saúde (OMS/2002), o baixo consumo de frutas e vegetais é responsável por $31 \%$ das doenças isquêmicas do coração e $11 \%$ dos derrames no mundo. Estima-se que aproximadamente 2,7 milhões de vidas por ano poderiam ser salvas com 0 consumo adequado de frutas, legumes e verduras. Outro motivo é que ao aumentar o consumo de FLV, evita-se alimentos gordurosos e industrializados que apresentam alto teor de sódio e densidade energética elevada, favorecendo o controle do peso corpóreo e fatores de risco para as DCNT's.

\section{Por que consumir menor quantidade de sal?}

Porque em média, conforme o consumo de sal da dieta aumenta, também aumenta a pressão arterial. E quanto maior a pressão arterial, maior o risco da ocorrência de infarto agudo do miocárdio, insuficiência cardíaca, acidente vascular cerebral e insuficiência renal (Chobanian et al 2003).

Os dados da Pesquisa de Orçamento Familiar de 2002/3 indicam que 0 consumo de sal no Brasil encontra-se acima dos 10 gramas por dia por pessoa (IBGE 2004), ou seja, bem acima dos 6 gramas recomendado pelos novos parâmetros nutricionais do PAT (1 colher de chá de sal corresponde a aproximadamente 5 gramas de sal). 
Além de reduzir a pressão arterial a redução na ingestão de sal pode prevenir o surgimento da hipertensão arterial (TOHP 1997). Dessa forma, seria possível evitar $40 \%$ das mortes por acidente vascular encefálico e

$25 \%$ daquelas por doença arterial coronariana ( $\mathrm{NIH} 1997)$.

\section{Promoção da Saúde nas Empresas}

A perspectiva de implantar programas de promoção da saúde nas empresas dirige um esforço de racionalização de custos do sistema para ações capazes de intervir ativamente na redução de riscos, fomentando melhorias na qualidade de vida e saúde dos colaboradores. Iniciar ações de responsabilidade social dentro da empresa talvez seja 0 grande desafio das corporações. Uma empresa que tem políticas voltadas para o público externo deve envolver seus colaboradores para mostrar que o exemplo vem de dentro e para mostrar que a ação não tem conotação de marketing. As ações de responsabilidade social devem estar integradas à filosofia da empresa.

\section{Ações para sua Empresa}

Hábitos saudáveis de alimentação se refletem em:

a - uma maior disposição para o trabalho

$b$ - na redução de faltas e atrasos por motivos de saúde

$c$ - prevenção de doenças

\section{Envolvendo os colaboradores}

Rotinas implementadas nas empresas só surtem efeito quando todos estão envolvidos. Por isso, incentive seus colaboradores a consumir mais FLV e menos sal.

\section{Quer saber como?}

Implementando os 10 passos para uma alimentação mais saudável: 


\section{0 passos para uma alimentação mais saudável}

1 - Promova diariamente o consumo de pelo menos 5 porções de FLV. Ofereça uma alimentação colorida, variando as frutas, legumes e vegetais. Quanto mais colorida, mais saudável é a alimentação. Distribua FLV nas refeições ao longo do dia;

2 - Prepare os alimentos adicionando uma menor quantidade de sal;

3 - Incentive o menor consumo de sal dos colaboradores, centralizando 0 saleiro no balcão de serviços;

4 - Crie um momento em que os colaboradores parem para comer uma fruta, tomar um suco, degustar uma sopinha ou uma salada;

5 - Elabore cartilhas direcionadas às famílias para que os colaboradores levem o programa para dentro de casa;

Nota de saúde: A mudança de hábito é possível, porém é preciso persistência e determinação. Por isso, um programa que cria ferramentas para lembrar permanentemente a todos sobre a importância de uma alimentação saudável é muito importante. Na sua empresa não pode ser diferente. 
6 - Aproveite as datas expressivas do ano - dia mundial da saúde, dia da alimentação, dia de combate ao fumo, etc - para promover eventos e discussões sobre alimentação, organizando palestras com nutricionistas, oficinas de gastronomia ou encontros de degustação;

7 - Facilite o acesso a FLV aos colaboradores no refeitório, nos intervalos de reuniões, nas cantinas, etc. Que tal incluir sucos e frutas cortadinhas na hora da reunião, além da água e do cafezinho?

8 - Sempre que possível, inclua notas de saúde na rotina de seus colaboradores. É mais simples do que se imagina: utilize no contracheque dos colaboradores ou no rodapé de circulares um espaço para uma fase sobre alimentação saudável;

9 - Desenvolva campanhas dirigidas aos colaboradores, clientes e fornecedores, aproveitando os meios de comunicação e eventos já existentes;

10 - Crie um espaço no jornal interno, na intranet ou no jornal mural para falar sobre alimentação saudável.

\section{Aí está!}

Com a ajuda dessas sugestões, já é possível iniciar um programa de alimentação saudável em sua empresa.

\section{Vamos começar?}




\section{Mini Álbum Seriado}
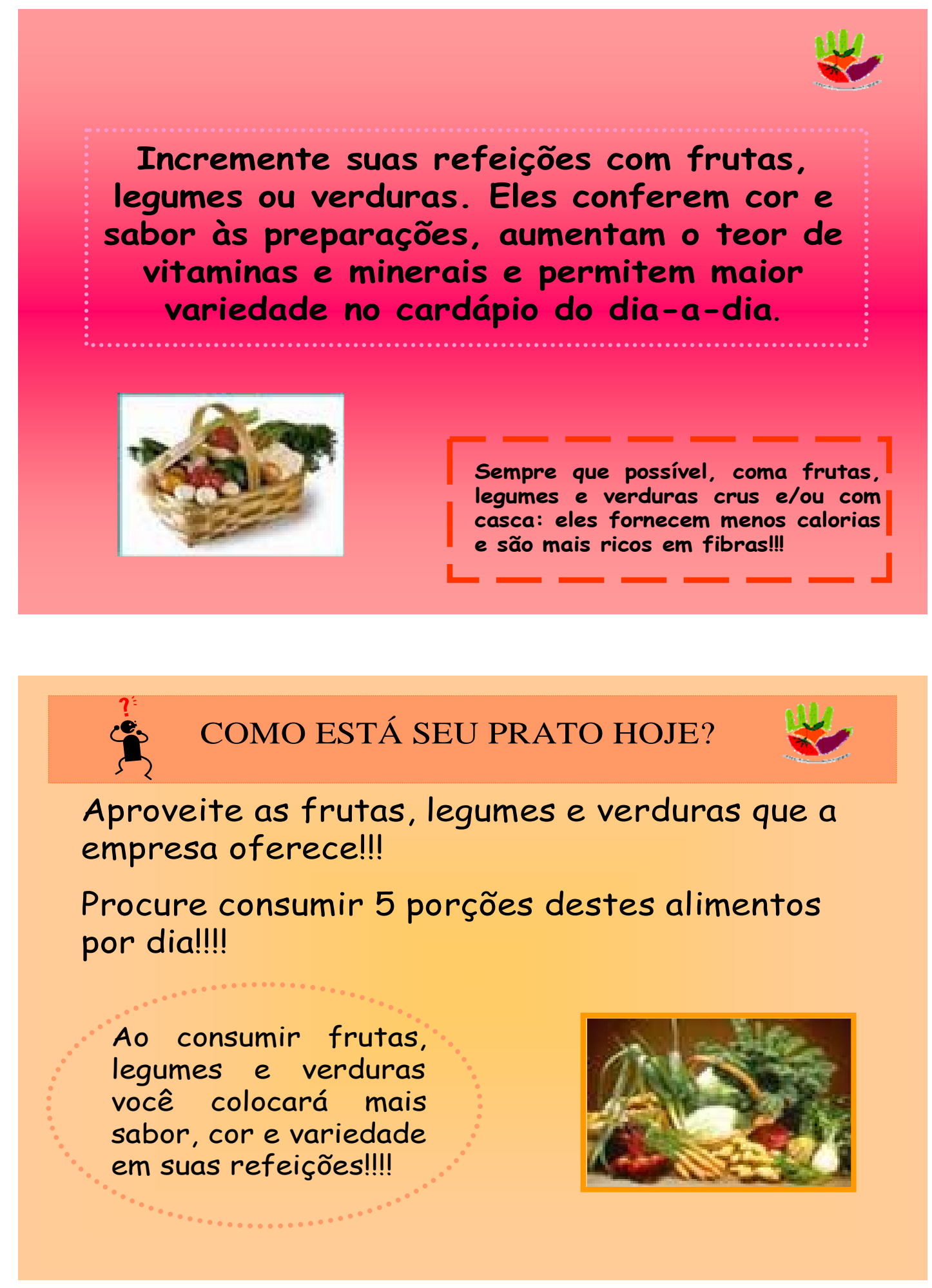

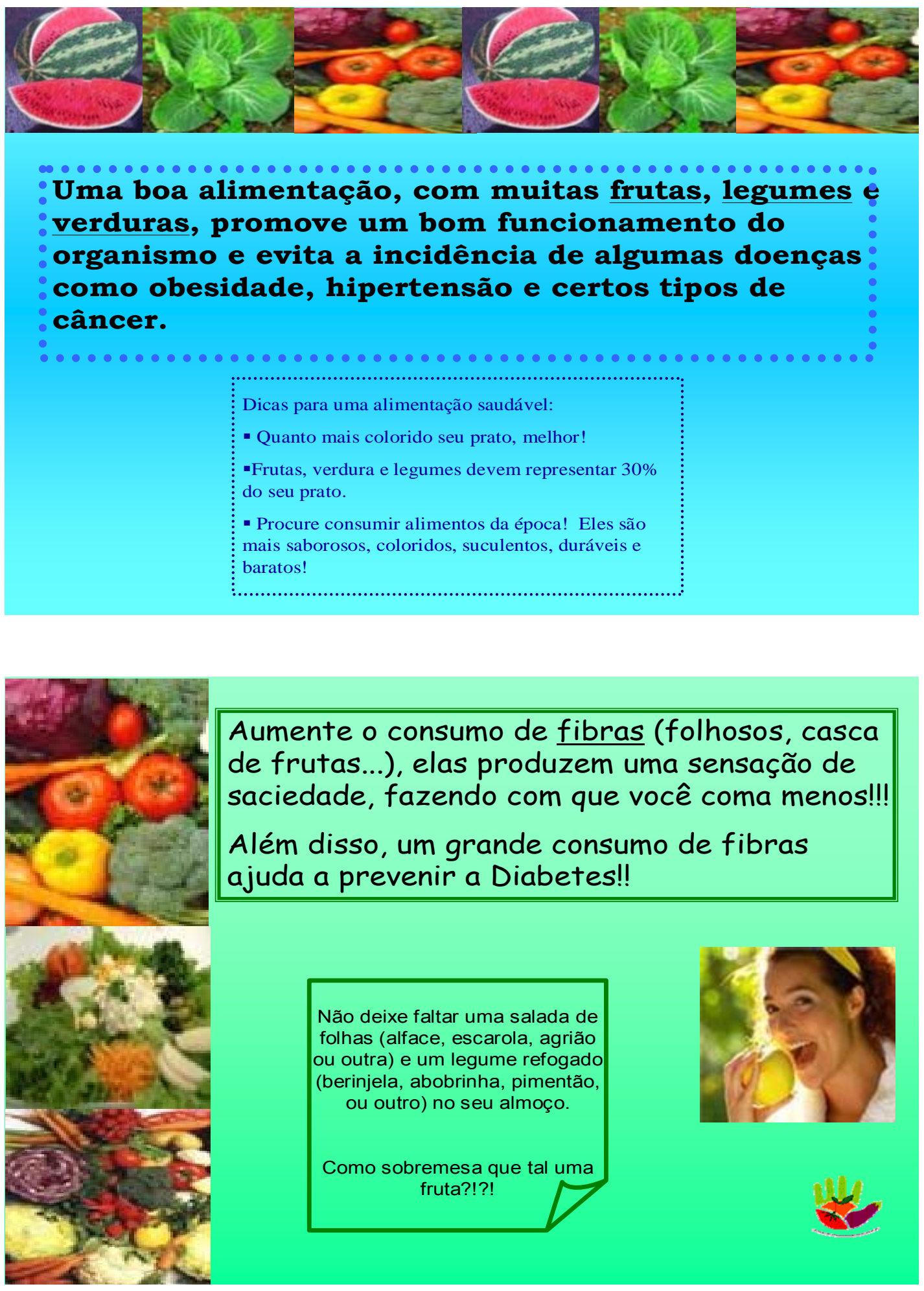


\section{Brinque com a cor dos alimentos...}
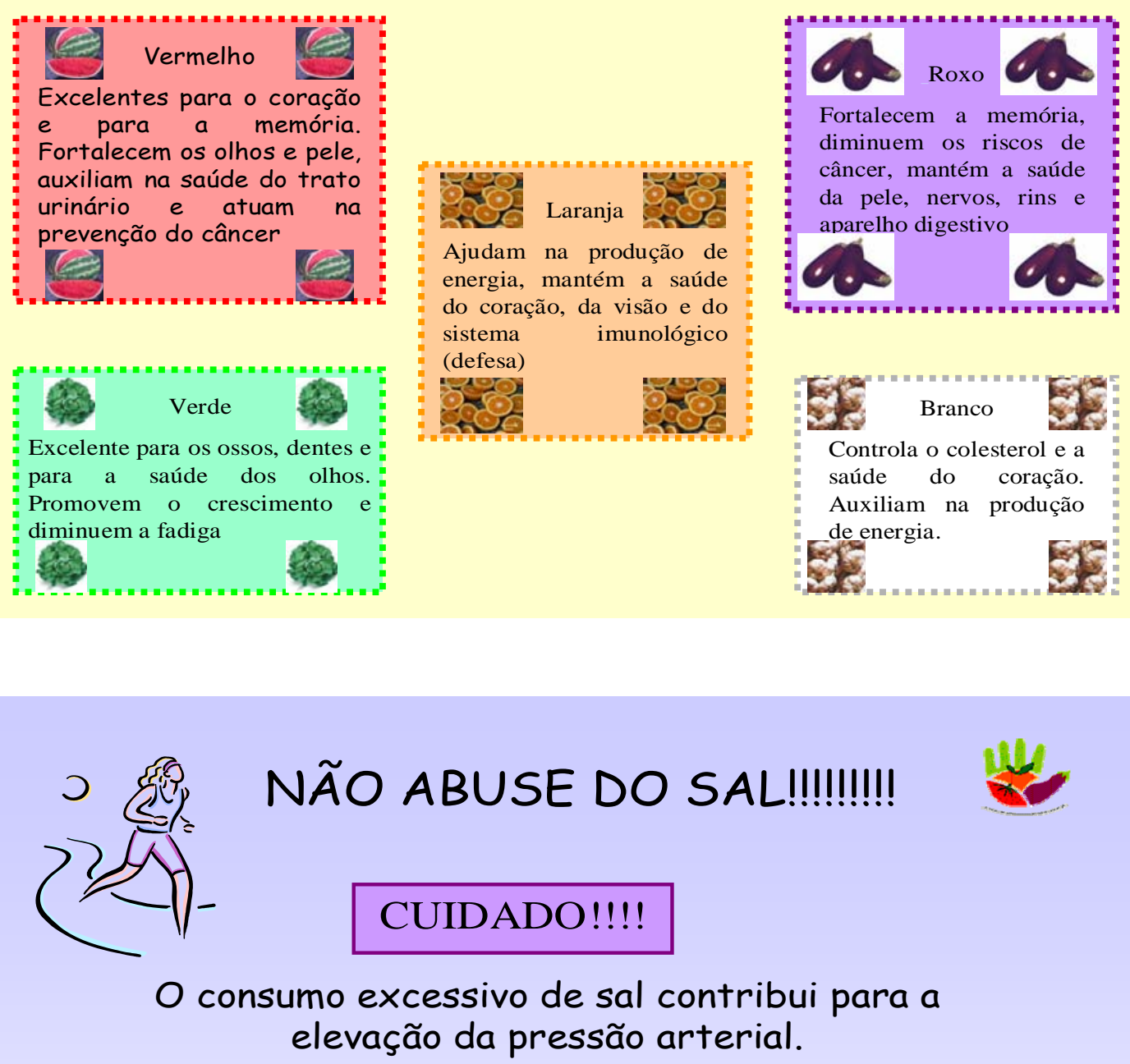

$O$ ideal é não consumir mais de 1 colher de chá $(5 g)$ por dia.

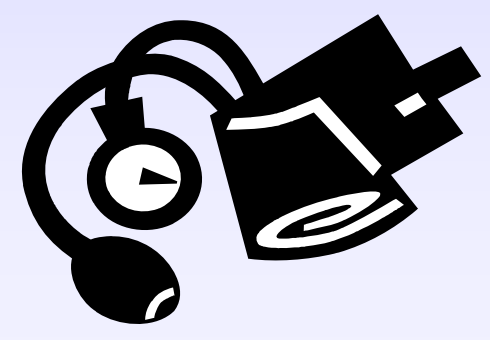

Experimente temperar sua salada com orégano, salsa, salsinha!!!

Fica uma delícia!!!! 
3. Cartazes ou fundos de bandeja, banner e frases para serem veiculadas por meio da mídia da empresa

\section{Como aumentar meu consumo de frutas, verduras e legumes?}
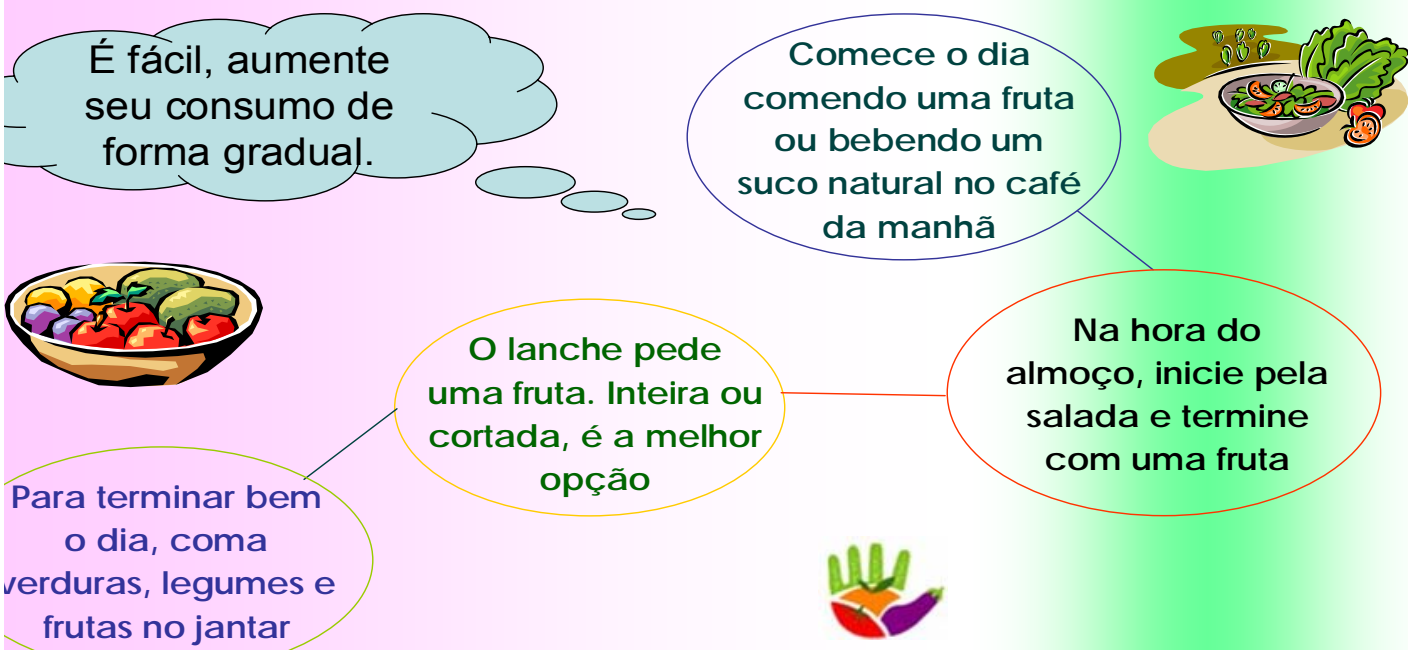

O lanche pede uma fruta. Inteira ou cortada, é a melhor opção
Na hora do almoço, inicie pela salada e termine com uma finta

\section{Porque comer frutas, verduras e legumes todos os dias?}

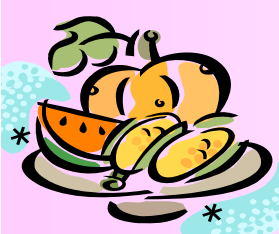

A Organização Mundial da Saúde recomenda sejam consumidas pelo menos 5 porções de frutas, legumes e verduras todos os dias, pois estes alimentos trazem diversos benefíc ios à saúde.

São fontes de fibras, vitaminas, minerais, antioxidantes e água

Previnem as doenças cardiovasc ulares e certos tipos de câncer

Ajudam a manter um peso coporal saudável Contêm pouc as calorias, gorduras e sódio

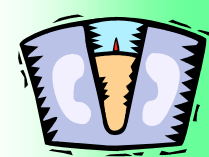

Mas cuidado com - coração, evite adicionar sal nos alimentos. 


\section{QUER UMA VIDA MAIS SAUDÁVEL?}

Inclua na sua alimentação diária, pelo menos 5 porções de FRUTAS, VERDURAS ou LEGUMES

Limite o seu consumo de SAL para 1 colher de chá por dia

Uma boa alimentação

promove o bom

funcionamento do nosso

organismo, evitando o

aparecimento de algumas

doenças como as do

coração, pressão alta, cânceres e diabetes.

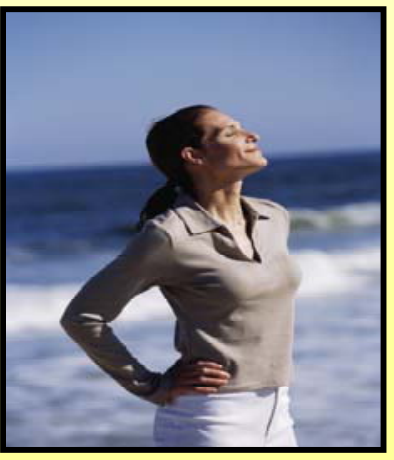

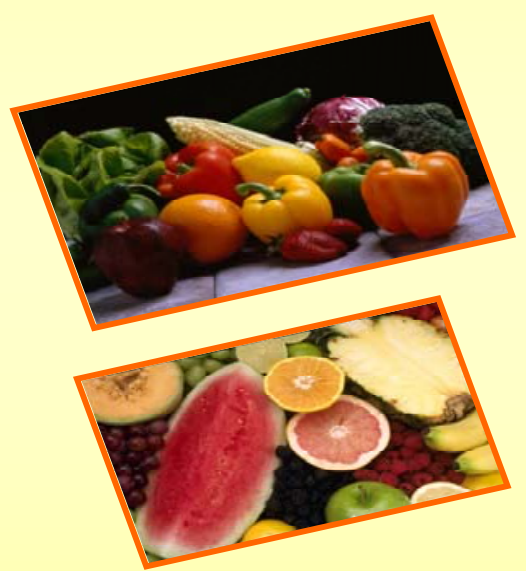

COM UMA ALIMENTAÇÃO SAUDÁVEL SUA VIDA SERÁ MUITO MAIS GOSTOSA!

1- O seu bem-estar em primeiro lugar, consuma frutas, verduras e legumes.

2- Cuidado com a pressão arterial, reduza o consumo de sal.

3- Saúde antes de tudo, coma mais frutas, verduras e legumes.

4- Seja mais saudável, consuma frutas, verduras e legumes regularmente.

5- Viva mais e melhor, coma mais salada 
4. Folder e Filipeta

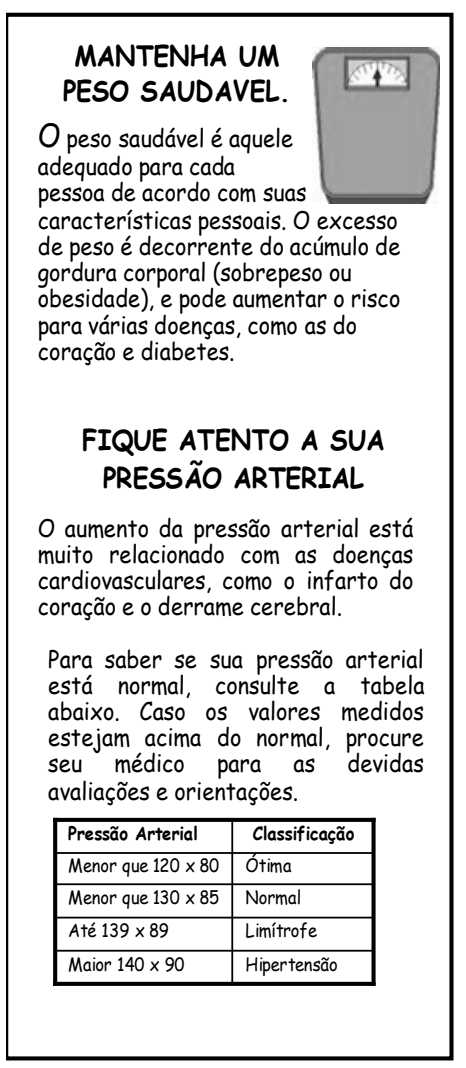

EQUIPE DE PESQUISADORES
Coordenadora da pesquisa
Patrícia Constante Jaime
Coordenador do Campo
Daniel H. Bandoni
Pesquisadores
Flávio Sarno
Iramaia Figueiredo
Mariana Almeida
Adriana Peloggio
Lia Buschinelli
Marilia Zagato
Contato:
3061-7705 R: 222
dbandoni@usp.br

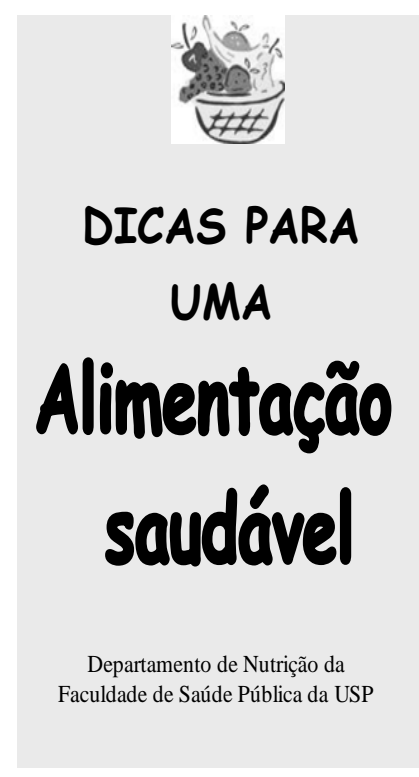

Nome:

PA: $\mathrm{X}$

\section{ESCOLHA ALIMENTOS RICOS EM FIBRAS}

As fibras ajudam na digestão e na redução do colesterol. Além das frutas, legumes e verduras, consuma regularmente feijão, soja lentilha, fava, grão-debico, e inclua na sua alimentação os cereais integrais, como aveia, farelo de arroz, pães integrais, arroz integral, entre outros.

REDUZA O CONSUMO DE SAL $O$ sal em excesso pode prejudicar sua saúde. O sal também está presente em muitos alimentos industrializados, como produtos enlatados, temperos prontos caldos concentrados, shoyu, catch-up. mostarda), conservas, salgadinhos, defumados, embutidos (presunto, mortadela, salame e similares). Para ter mais qualidade de vida, devemo evitar o consumo desses alimentos e reduzir a adição de sal no preparo e tempero da comida. Para realçar os sabores, descubra o valor das ervas e especiarias, como a salsa, cebolinha verde, coentro, cebola, alho, pimentão.

\section{EVITE OS ALIMENTOS QUE CONTÉM MUITO AÇÚCAR}

$O$ açúcar, bem como os refrigerantes, balas, doces e similares, contém somente calorias e nenhum outro nutriente. $O$ seu consumo excessivo pode levar a doenças como cárie dental obesidade diabetes e doenças do coraçã̃o. Por isso, a ingestão

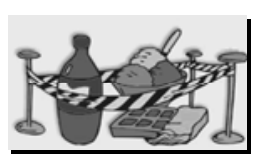
esse grupo de alimento deve ser moderada para todas as pessoas em todas as fases da vida.

\section{DIMINUA O CONSUMO} DE GORDURA

A redução no consumo de gordura é outra medida para a prevenção de doenças como obesidade, hipertensão, entre outras. Aqui vão algumas dicas: prefira leite desnatado e queijos brancos, escolha carnes magras, prepare alimentos com pouco óleo e

gorduras; evite frituras

e alimentos industrializados e retire o excesso de gordura visível antes do preparo dos alimentos. 

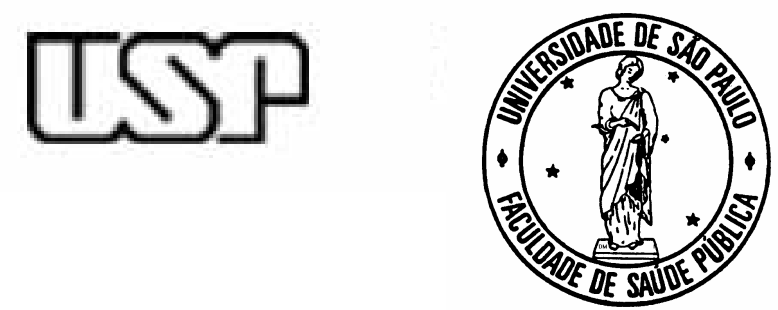

Departamento de Nutrição da FSP - USP. Contato:

Tel. 3061.7705 r 222

omail dhandoni Alucn hr

NOME:

DATA: 1

PRESSÃO ARTERIAL: $X$

PRESSÃO ARTERIAL ÓTIMA: ATÉ $120 \times 80$ mmHg PRESSÃO ARTERIAL NORMAL: ATÉ $130 \times 85 \mathrm{mmHg}$ LIMÍTROFE: ATÉ $139 \times 89 \mathrm{mmHg}$ HIPERTENSÃO ARTERIAL: MAIOR $140 \times 90 \mathrm{mmHg}$

SE SUA PRESSÃO ARTERIAL APRESENTOU VALORES MAIORES QUE OS MOSTRADOS, PROCURE SEU MÉDICO PARA AS DEVIDAS AVALIACÕES E ORIENTAÇÕES 


\section{Comitê de ética em pesquisa}

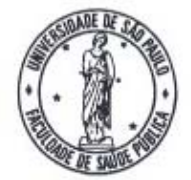

Universidade de São Paulo

Faculdade de Saúde Pública

\section{COMITÊ DE ÉTICA - COEP}

Av. Dr. Arnaldo, 715 - Assessoria Acadêmica - CEP 01246-904 - São Paulo - Brasil Telefones: (55-11) 3066-7779 - e-mail: coep@fsp.usp.br

\section{Of.COEP/75/06}

09 de março de 2006

Pelo presente, informo que o Comitê de Ética em Pesquisa da Faculdade de Saúde Pública da Universidade de São Paulo-COEP analisou e aprovou, em sua 2. \%/06 Sessão Ordinária, realizada em 08.03.06, de acordo com os requisitos da Resolucão CNS/196/96 e suas complementares, o Protocolo de Pesquisa n. ${ }^{\circ} 1426$, intitulado: "IMPACTO DE INTERVENÇÃO PARA PROMOÇĀO DO CONSUMO DE FRUTAS E HORTALIÇAS EM EMPRESAS CADASTRADAS NO PROGRAMA DE ALIMENTAÇĀO DO TRABALHADOR", apresentado pela pesquisadora Patrícia Constante Jaime.

Atenciosamente,

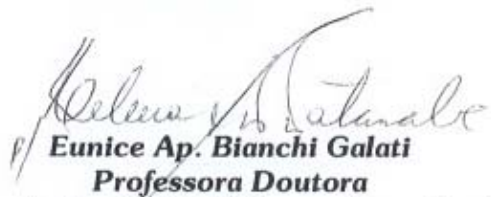

Coordenadora do Comitê de Ética em Pesquisa da FSP/USP 


\section{Referências}

1. World Health Organization. Global strategy on diet, physical activity and health. 2004 [Acesso em 17/10/09]; Disponível em: http://www.who.int/dietphysicalactivity/strategy/eb11344/strategy_english_we b.pdf.

2. World Health Organization. Reducing salt intake in populations : report of a WHO forum and technical meeting, 5-7 October 2006, Paris, France. 2007 [17/10/09];

Disponível

em:

http://www.who.int/dietphysicalactivity/Salt_Report_VC_april07.pdf.

3. Sarno F, Claro RM, Levy RB, Bandoni DH, Ferreira SR, Monteiro CA. [Estimated sodium intake by the Brazilian population, 2002-2003]. Rev Saude Publica. 2009;43(2):219-25.

4. Chu C, Breucker G, Harris N, Stitzel A, Gan X, Gu X, et al. Healthpromoting workplaces-international settings development. Health Promotion International. 2000;15(2):155-67.

5. Pickering TG, Hall JE, Appel LJ, Falkner BE, Graves J, Hill MN, et al. Recommendations for blood pressure measurement in humans and experimental animals: part 1: blood pressure measurement in humans: a statement for professionals from the Subcommittee of Professional and Public Education of the American Heart Association Council on High Blood Pressure Research. Circulation. 2005;111(5):697-716.

6. Cuckson AC, Reinders A, Shabeeh $H$, Shennan AH. Validation of the Microlife BP 3BTO-A oscillometric blood pressure monitoring device according to a modified British Hypertension Society protocol. Blood Press Monit. 2002;7(6):319-24.

7. World Health Organization. Global Database on Body Mass Index. BMI classification. [Acesso em 17/10/09]; Disponível em: http://apps.who.int/bmi/index.jsp?introPage=intro_3.html.

8. Chobanian AV, Bakris GL, Black HR, Cushman WC, Green LA, Izzo JL, Jr., et al. The Seventh Report of the Joint National Committee on Prevention, 
Detection, Evaluation, and Treatment of High Blood Pressure: the JNC 7 report. JAMA. 2003;289(19):2560-72.

9. National Health and Nutrition Examination Survey. Diet Behavior Questionnaire File Frequencies. [Acesso em 18/01/10]; Disponível em: http://www.cdc.gov/nchs/nhanes/frequency/dbq.htm\#DBQ100.

10. Fragelli T, Gunther I. A promoção de saúde na perspectiva social ecológica. Rev Bras Prom Saude. 2008;21(2):151-8.

11. Ministério da Saúde. Secretaria de Atenção Básica. Departamento de Atenção Básica. Coordenação-Geral da Política de Alimentação e Nutrição. Guia Alimentar para população brasileira. Promovendo a alimentação saudável. 2006 [Acesso em 21/10/09]; Disponível em: http://nutricao.saude.gov.br/documentos/guia_alimentar_conteudo.pdf.

12. Portaria Interministerial $n^{\circ} 66$ de 25 de agosto de 2006. Altera os parâmetros nutricionais do Programa de Alimentaçãodo Trabalhador - PAT. 2006 [Acesso em 21/10/09]; Disponível em: http://www.mte.gov.br/legislacao/Portarias/2006/p_20060825_66.pdf.

13. Hox J. Multilevel Analysis. Techniques and Applications. Marcoulides GA, editor: Lawrence Erlbaum Associates, Inc. Mahwah, New Jersey. London.; 2002.

14. Albright J. Estimating Multilevel Models using SPSS, Stata, and SAS. 2007 [Acesso em 25/10/09]; Disponível em: http://www.indiana.edu/ statmath/stat/all/hlm/hlm.pdf.

15. Greenfield H, Maples J, Wills R. Salting of food--a function of hole size and locatation of shakers. Nature. 1983;27(301):331-2.

16. Greenfield $H$, Smith $A$, Wills $R$. Influence of multi-holed shakers on salting on food. Hum Nutr Appl Nutr. 1984;38(3):199-201.

17. Dwyer J, Picciano MF, Raiten DJ. Collection of food and dietary supplement intake data: What We Eat in America-NHANES. J Nutr. 2003;133(2):590S-600S.

18. Mittelmark MB, Sternberg B. Assessment of salt use at the table: comparison of observed and reported behavior. Am $\mathrm{J}$ Public Health. 1985;75(10):1215-6. 
19. Kim HJ, Paik HY, Lee SY, Shim JE, Kim YS. Salt usage behaviors are related to urinary sodium excretion in normotensive Korean adults. Asia Pac J Clin Nutr. 2007;16(1):122-8.

20. Garriguet D. Sodium consumption at all ages. Statistics Canada, Catalogue 82-003. 2007;18(2):47-52.

21. Ni Mhurchu C, Aston LM, Jebb SA. Effects of worksite health promotion interventions on employee diets: a systematic review. BMC Public Health. 2010;10(1):62.

22. Rasmussen LB, Lassen AD, Hansen K, Knuthsen P, Saxholt E, Fagt S. Salt content in canteen and fast food meals in Denmark. Food Nutr Res. 2010;54.

23. He FJ, MacGregor GA. A comprehensive review on salt and health and current experience of worldwide salt reduction programmes. J Hum Hypertens. 2009;23(6):363-84.

24. Kojuri J, Rahimi R. Effect of "no added salt diet" on blood pressure control and 24 hour urinary sodium excretion in mild to moderate hypertension. BMC Cardiovasc Disord. 2007;7:34.

25. Mu J, Liu Z, Liu F, Xu X, Liang Y, Zhu D. Family-based randomized trial to detect effects on blood pressure of a salt substitute containing potassium and calcium in hypertensive adolescents. Am J Hypertens. 2009;22(9):943-7. 26. Katz A, Rosenthal T, Maoz C, Peleg E, Zeidenstein R, Levi Y. Effect of a mineral salt diet on 24-h blood pressure monitoring in elderly hypertensive patients. J Hum Hypertens. 1999;13(11):777-80.

27. Karppanen H, Tanskanen A, Tuomilehto J, Puska P, Vuori J, Jantti V, et al. Safety and effects of potassium- and magnesium-containing low sodium salt mixtures. J Cardiovasc Pharmacol. 1984;6 Suppl 1:S236-43.

28. Levin SM, Ferdowsian HR, Hoover VJ, Green AA, Barnard ND. A worksite programme significantly alters nutrient intakes. Public Health Nutr. 2010:1-7.

29. Oort FJ, Visser MRM, Sprangers MAG Formal definitions of measurement bias and explanation bias clarify measurement and conceptual perspectives on response shift. J Clin Epidemiol. 2009;62(11):1126-37. 


\section{RESULTADOS E CONCLUSÕES FINAIS}

Esta tese demonstrou que a disponibilidade de sódio no Brasil encontra-se acima do recomendado pela Organização Mundial da Saúde(13), ou seja, o consumo máximo de $5 \mathrm{~g}$ de sal por dia (equivalente a $87 \mathrm{mmmol}$ ou $2 \mathrm{~g}$ de sódio por dia).(17) Demonstrou também que a maioria dos estudos que avaliou a restrição moderada de sódio em indivíduos com Síndrome Metabólica apresentou efeitos benéficos, tanto em parâmetros metabólicos quanto na pressão arterial.(72) Por fim, a intervenção realizada no ambiente de trabalho possibilitou que os participantes do sexo masculino e aqueles categorizados como normotensos alocados no grupo intervenção, no momento final do estudo apresentassem taxas menores de referência à adição de sal ao prato quente.

As evidências apontam uma conexão causal entre o consumo cronicamente alto de sal e o desenvolvimento de hipertensão arterial, especialmente quando os rins apresentam uma capacidade reduzida de excretar sódio. A relação entre pressão arterial e consumo de sal, embora pequena e heterogênea, é contínua em vez de binária. Nas sociedades industrializadas, a prevalência de hipertensão arterial aumenta continuamente com a idade, sugerindo que se o consumo usual de sal se mantiver nos mesmos níveis atuais, a maioria dos indivíduos se tornará hipertenso, se viver tempo suficiente para tanto.(73)

Os dados também sugerem também que o consumo excessivo de sal aumenta a morbidade e mortalidade cardiovasculares, ambas pela influência do nutriente tanto na pressão arterial, como por efeitos independentes desta nos vasos e no coração.(74)

Reduções modestas no consumo de sal pela população podem causar pequenos deslocamentos na distribuição da curva de pressão arterial, tanto em hipertensos como em indivíduos com pressão arterial normal (54). Apesar de pequena, esta redistribuição poderia reduzir a prevalência de hipertensão arterial e a mortalidade por doença cardiovascular.(46) 
A redução da exposição ao sal deveria ser praticada também por crianças e adolescentes (75) e, sobretudo, por mulheres durante a gestação e no período pós natal precoce, de forma a se prevenir a elevação da pressão arterial na vida adulta.(76)

Existem evidências substanciais de que programas para reduzir o consumo de sal pela população são altamente custos efetivos. A redução de apenas $400 \mathrm{mg}$ de sódio nos indivíduos com hipertensão poderia causar uma diminuição de 1,5 milhão no número de hipertensos, com uma economia de aproximadamente 2,3 bilhões de dólares ao ano.(77) Estima-se que uma redução de $15 \%$ no consumo de sal se traduziria em 8,5 milhões de vidas salvas em 10 anos nos países em desenvolvimento, a um custo médio de 9 centavos de dólar por pessoa por ano (12 centavos de dólar no Brasil).(78)

A revisão da literatura entre 1980 e 2008, analisando as estratégias de redução de consumo de sódio, mostrou que as ações consideradas efetivas foram: parcerias e/ou regulação da indústria alimentos; reformulação dos alimentos processados para redução do teor de sódio; educação orientada para o consumidor; rotulagem, indicando de forma simples os alimentos com baixos teores de sódio e maior acesso e disponibilidade a estes alimentos.(79)

Em suma, os países deveriam periodicamente realizar 0 monitoramento do consumo de sódio, bem como de suas principais fontes, como base de programas e políticas públicas de redução de consumo de sal. Tais intervenções deveriam estar focadas na orientação da população para reduzir a adição de sal aos alimentos, tanto no seu preparo quanto à mesa e na regulação da adição de sal aos alimentos processados.(17) 


\section{REFERÊNCIAS}

1. Franco V, Oparil S. Salt sensitivity, a determinant of blood pressure, cardiovascular disease and survival. J Am Coll Nutr. 2006;25(3 Suppl):247S$55 S$.

2. Ritz E. The history of salt - aspects of interest to the nephrologist. Nephrol Dial Transplant. 1996;11(6):969-75.

3. Eaton SB, Eaton SB, 3rd, Konner MJ. Paleolithic nutrition revisited: a twelve-year retrospective on its nature and implications. Eur J Clin Nutr. 1997;51(4):207-16.

4. He FJ, MacGregor GA. A comprehensive review on salt and health and current experience of worldwide salt reduction programmes. J Hum Hypertens. 2009;23(6):363-84.

5. Morris RC, Jr., Schmidlin O, Frassetto LA, Sebastian A. Relationship and interaction between sodium and potassium. J Am Coll Nutr. 2006;25(3 Suppl):262S-70S.

6. Cordain L, Eaton SB, Sebastian A, Mann N, Lindeberg S, Watkins BA, et al. Origins and evolution of the Western diet: health implications for the 21st century. Am J Clin Nutr. 2005;81(2):341-54.

7. Cirillo M, Capasso G, Di Leo VA, De Santo NG. A history of salt. Am J Nephrol. 1994;14(4-6):426-31.

8. Charlton KE, Steyn K, Levitt NS, Jonathan D, Zulu JV, Nel JH. Development and validation of a short questionnaire to assess sodium intake. Public Health Nutr. 2008;11(1):83-94.

9. Bentley B. A review of methods to measure dietary sodium intake. J Cardiovasc Nurs. 2006;21(1):63-7.

10. Melse-Boonstra A, Rexwinkel H, Bulux J, Solomons NW, West CE. Comparison of three methods for estimating daily individual discretionary salt intake: 24 hour recall, duplicate-portion method, and urinary lithium-labelled household salt excretion. Eur J Clin Nutr. 1999;53(4):281-7.

11. Hashimoto T, Yagami F, Owada M, Sugawara T, Kawamura M. Salt preference according to a questionnaire vs. dietary salt intake estimated by a 
spot urine method in participants at a health check-up center. Intern Med. 2008;47(5):399-403.

12. Mattes RD, Donnelly D. Relative contributions of dietary sodium sources. J Am Coll Nutr. 1991;10(4):383-93.

13. Sarno F, Claro RM, Levy RB, Bandoni DH, Ferreira SR, Monteiro CA. Estimated sodium intake by the Brazilian population, 2002-2003. Rev Saude Publica. 2009;43(2):219-25.

14. Ferreira-Sae MC, Gallani MC, Nadruz W, Rodrigues RC, Franchini KG, Cabral PC, et al. Reliability and validity of a semi-quantitative FFQ for sodium intake in low-income and low-literacy Brazilian hypertensive subjects. Public Health Nutr. 2009;12(11):2168-73.

15. Leiba A, Vald A, Peleg E, Shamiss A, Grossman E. Does dietary recall adequately assess sodium, potassium, and calcium intake in hypertensive patients? Nutrition. 2005;21(4):462-6.

16. Wakai K. A review of food frequency questionnaires developed and validated in Japan. J Epidemiol. 2009;19(1):1-11.

17. World Health Organization. Reducing salt intake in populations : report of a WHO forum and technical meeting, 5-7 October 2006, Paris, France. 2007 [Acesso em 17/10/09]; Disponível em: http://www.who.int/dietphysicalactivity/Salt_Report_VC_april07.pdf.

18. Holbrook JT, Patterson KY, Bodner JE, Douglas LW, Veillon C, Kelsay $\mathrm{JL}$, et al. Sodium and potassium intake and balance in adults consuming selfselected diets. Am J Clin Nutr. 1984;40(4):786-93.

19. Parkington SR, Roussos S. Measuring salt consumption to guide behavior change in applied settings: a critical review. Am J Health Promot. 2008;23(2):101-7.

20. Salt Institute. The Salt Industry. [Acesso em 07/08/2010]; Disponível em: http://www.saltinstitute.org/Production-industry/Salt-industry.

21. Salt Institute. Wordl Salt Production. [Acesso em 07/08/2010]; Disponível em: http://www.saltinstitute.org/Production-industry/Factsfigures/World-salt-production. 
22. Brown IJ, Tzoulaki I, Candeias V, Elliott P. Salt intakes around the world: implications for public health. Int J Epidemiol. 2009;38(3):791-813.

23. Claro RM, Machado FMS, Bandoni DH. Evolução da disponibilidade domiciliar de alimentos no município de São Paulo no período de 1979 a 1999. Rev Nutr. 2007(5):483-90.

24. Anderson CA, Appel LJ, Okuda N, Brown IJ, Chan Q, Zhao L, et al. Dietary sources of sodium in China, Japan, the United Kingdom, and the United States, women and men aged 40 to 59 years: the INTERMAP study. J Am Diet Assoc. 2010;110(5):736-45.

25. Moraes RS, Fuchs FD, Dalla Costa F, Moreira LB. Familial predisposition to hypertension and the association between urinary sodium excretion and blood pressure in a population-based sample of young adults. Braz $\mathrm{J}$ Med Biol Res. 2000;33(7):799-803.

26. Molina M, Cunha R, Herkenhoff L, Mill J. Hipertensão arterial e consumo de sal em população urbana. 2003(6):743-50.

27. Michelia E, Rosa A. Estimation of sodium intake by urinary excretion and dietary records in children and adolescents from Porto Alegre, Brazil: a comparision of two methods. Nutrition Research. 2003:1477-87.

28. Pavan L, Casiglia E, Pauletto P, Batista SL, Ginocchio G, Kwankam MM, et al. Blood pressure, serum cholesterol and nutritional state in Tanzania and in the Amazon: comparison with an Italian population. J Hypertens. 1997;15(10):1083-90.

29. Joffres MR, Campbell NR, Manns B, Tu K. Estimate of the benefits of a population-based reduction in dietary sodium additives on hypertension and its related health care costs in Canada. Can J Cardiol. 2007;23(6):437-43.

30. Weinberger MH, Miller JZ, Luft FC, Grim CE, Fineberg NS. Definitions and characteristics of sodium sensitivity and blood pressure resistance. Hypertension. 1986;8(6 Pt 2):II127-34.

31. Weinberger $\mathrm{MH}$. Salt sensitivity of blood pressure in humans. Hypertension. 1996;27(3 Pt 2):481-90. 
32. de Boer MP, ljzerman RG, de Jongh RT, Eringa EC, Stehouwer CD, Smulders YM, et al. Birth weight relates to salt sensitivity of blood pressure in healthy adults. Hypertension. 2008;51(4):928-32.

33. Beeks E, Kessels AG, Kroon AA, van der Klauw MM, de Leeuw PW. Genetic predisposition to salt-sensitivity: a systematic review. J Hypertens. 2004;22(7):1243-9.

34. Sanders PW. Dietary salt intake, salt sensitivity, and cardiovascular health. Hypertension. 2009;53(3):442-5.

35. Morris RC, Jr., Sebastian A, Forman A, Tanaka M, Schmidlin O. Normotensive salt sensitivity: effects of race and dietary potassium. Hypertension. 1999;33(1):18-23.

36. Alberti KG, Eckel RH, Grundy SM, Zimmet PZ, Cleeman JI, Donato KA, et al. Harmonizing the metabolic syndrome: a joint interim statement of the International Diabetes Federation Task Force on Epidemiology and Prevention; National Heart, Lung, and Blood Institute; American Heart Association; World Heart Federation; International Atherosclerosis Society; and International Association for the Study of Obesity. Circulation. 2009;120(16):1640-5.

37. Yanai H, Tomono $\mathrm{Y}$, Ito K, Furutani N, Yoshida H, Tada N. The underlying mechanisms for development of hypertension in the metabolic syndrome. Nutr J. 2008;7:10.

38. Sarafidis PA, Bakris GL. The antinatriuretic effect of insulin: an unappreciated mechanism for hypertension associated with insulin resistance? Am J Nephrol. 2007;27(1):44-54.

39. Sociedade Brasileira de Hipertensão, Sociedade Brasileira de Cardiologia, Sociedade Brasileira de Endocrinologia e Metabologia, Sociedade Brasileira de Diabetes, Sociedade Brasileira de Estudos da Obesidade. I Brazilian guidelines on diagnosis and treatment of metabolic syndrome. Arq Bras Cardiol. 2005;84 Suppl 1:1-28.

40. Baxter AJ, Coyne T, McClintock C. Dietary patterns and metabolic syndrome--a review of epidemiologic evidence. Asia Pac J Clin Nutr. 2006;15(2):134-42. 
41. Lawes CM, Vander Hoorn S, Rodgers A. Global burden of bloodpressure-related disease, 2001. Lancet. 2008;371(9623):1513-8.

42. Lewington S, Clarke R, Qizilbash N, Peto R, Collins R. Age-specific relevance of usual blood pressure to vascular mortality: a meta-analysis of individual data for one million adults in 61 prospective studies. Lancet. 2002;360(9349):1903-13.

43. Appel LJ, Anderson CA. Compelling evidence for public health action to reduce salt intake. N Engl J Med. 2010;362(7):650-2.

44. Strazzullo P, D'Elia L, Kandala NB, Cappuccio FP. Salt intake, stroke, and cardiovascular disease: meta-analysis of prospective studies. BMJ. 2009;339:b4567.

45. Bibbins-Domingo K, Chertow GM, Coxson PG, Moran A, Lightwood JM, Pletcher MJ, et al. Projected Effect of Dietary Salt Reductions on Future Cardiovascular Disease. N Engl J Med. 2010;362:590-9.

46. Cook NR, Cutler JA, Obarzanek E, Buring JE, Rexrode KM, Kumanyika SK, et al. Long term effects of dietary sodium reduction on cardiovascular disease outcomes: observational follow-up of the trials of hypertension prevention (TOHP). BMJ. 2007;334(7599):885.

47. Instituto Brasileiro de Geografia e Estatística (IBGE). Pesquisa Nacional por Amostra de Domicílios, 2007 [Acesso em 28/8/10]; Disponível em: http://www.ibge.com.br/brasil_em_sintese/default.htm.

48. Fleming S, Kelleher C, O'Connor M. Eating patterns and factors influecing likely change in the workplace in Ireland. Health Promotion International. 1997;12(3):187-96.

49. Glanz K, Patterson RE, Kristal AR, Feng Z, Linnan L, Heimendinger J, et al. Impact of work site health promotion on stages of dietary change: the Working Well Trial. Health Educ Behav. 1998;25(4):448-63.

50. Goetzel RZ, Ozminkowski RJ. The health and cost benefits of work site health-promotion programs. Annu Rev Public Health. 2008;29:303-23.

51. Ambard L, Beaujard E. Causes de 1'hypertension arterielle. Arch Gen Méd. 1904;1:520-33. 
52. Kempner W. Treatment of hypertensive vascular disease with rice diet. Am J Med. 1948;4(4):545-77.

53. He FJ, MacGregor GA. Effect of modest salt reduction on blood pressure: a meta-analysis of randomized trials. Implications for public health. J Hum Hypertens. 2002;16(11):761-70.

54. He FJ, MacGregor GA. Effect of longer-term modest salt reduction on blood pressure. Cochrane Database Syst Rev. 2004(3):CD004937.

55. Brunner EJ, Rees K, Ward K, Burke M, Thorogood M. Dietary advice for reducing cardiovascular risk. Cochrane Database Syst Rev. 2007(4):CD002128.

56. Appel LJ, Moore TJ, Obarzanek E, Vollmer WM, Svetkey LP, Sacks FM, et al. A clinical trial of the effects of dietary patterns on blood pressure. DASH Collaborative Research Group. N Engl J Med. 1997;336(16):1117-24.

57. Sacks FM, Svetkey LP, Vollmer WM, Appel LJ, Bray GA, Harsha D, et al. Effects on blood pressure of reduced dietary sodium and the Dietary Approaches to Stop Hypertension (DASH) diet. DASH-Sodium Collaborative Research Group. N Engl J Med. 2001;344(1):3-10.

58. Alderman $\mathrm{MH}$. Reducing dietary sodium: the case for caution. JAMA. 2010;303(5):448-9.

59. McCarron DA, Geerling JC, Kazaks AG, Stern JS. Can dietary sodium intake be modified by public policy? Clin J Am Soc Nephrol. 2009;4(11):1878-82.

60. Cook NR, Sacks F, MacGregor G. Public policy and dietary sodium restriction. JAMA. 2010 May 19;303(19):1917-8.

61. He FJ, de Wardener HE, MacGregor GA. Salt intake and cardiovascular mortality. Am J Med. 2007 Jan;120(1):e5-e7.

62. Pickering TG, Hall JE, Appel LJ, Falkner BE, Graves J, Hill MN, et al. Recommendations for blood pressure measurement in humans and experimental animals: part 1: blood pressure measurement in humans: a statement for professionals from the Subcommittee of Professional and Public Education of the American Heart Association Council on High Blood Pressure Research. Circulation. 2005;111(5):697-716. 
63. Buyck JF, Blacher J, Kesse-Guyot E, Castetbon K, Galan P, Safar M, et al. Differential associations of dietary sodium and potassium intake with blood pressure: a focus on pulse pressure. J Hypertens. 2009;27(6):1158-64. 64. Midgley JP, Matthew AG, Greenwood CM, Logan AG. Effect of reduced dietary sodium on blood pressure: a meta-analysis of randomized controlled trials. JAMA. 1996;275(20):1590-7.

65. Graudal NA, Galloe AM, Garred P. Effects of sodium restriction on blood pressure, renin, aldosterone, catecholamines, cholesterols, and triglyceride: a meta-analysis. JAMA. 1998;279(17):1383-91.

66. He FJ, Markandu ND, MacGregor GA. Importance of the renin system for determining blood pressure fall with acute salt restriction in hypertensive and normotensive whites. Hypertension. 2001;38(3):321-5.

67. Beckmann SL, Os I, Kjeldsen SE, Eide IK, Westheim AS, Hjermann I. Effect of dietary counselling on blood pressure and arterial plasma catecholamines in primary hypertension. Am J Hypertens. 1995;8(7):704-11.

68. Jurgens G, Graudal NA. Effects of low sodium diet versus high sodium diet on blood pressure, renin, aldosterone, catecholamines, cholesterols, and triglyceride. Cochrane Database Syst Rev. 2004(1):CD004022.

69. Townsend RR, Kapoor S, McFadden CB. Salt intake and insulin sensitivity in healthy human volunteers. Clin Sci (Lond). 2007;113(3):141-8.

70. Meland E, Laerum E, Aakvaag A, Ulvik RJ, Hostmark AT. Salt restriction: effects on lipids and insulin production in hypertensive patients. Scand J Clin Lab Invest. 1997;57(6):501-5.

71. Heer M, Frings-Meuthen P, Titze J, Boschmann M, Frisch S, Baecker N, et al. Increasing sodium intake from a previous low or high intake affects water, electrolyte and acid-base balance differently. $\mathrm{Br} J$ Nutr. 2009;101(9):1286-94.

72. Sarno F, Jaime PC, Ferreira SR, Monteiro CA. Sodium intake and metabolic syndrome: a systematic review. Arq Bras Endocrinol Metabol. 2009;53(5):608-16.

73. Flegel K, Magner P. Get excess salt out of our diet. CMAJ. 2009;180(3):263. 
74. Meneton $P$, Jeunemaitre $X$, de Wardener HE, MacGregor GA. Links between dietary salt intake, renal salt handling, blood pressure, and cardiovascular diseases. Physiol Rev. 2005;85(2):679-715.

75. He FJ, Marrero NM, Macgregor GA. Salt and blood pressure in children and adolescents. J Hum Hypertens. 2008;22(1):4-11.

76. Tekol Y. Maternal and infantile dietary salt exposure may cause hypertension later in life. Birth Defects Res B Dev Reprod Toxicol. 2008;83(2):77-9.

77. Dall TM, Fulgoni VL, 3rd, Zhang Y, Reimers KJ, Packard PT, Astwood JD. Potential health benefits and medical cost savings from calorie, sodium, and saturated fat reductions in the American diet. Am J Health Promot. 2009;23(6):412-22.

78. Asaria P, Chisholm D, Mathers C, Ezzati M, Beaglehole R. Chronic disease prevention: health effects and financial costs of strategies to reduce salt intake and control tobacco use. Lancet. 2007;370(9604):2044-53.

79. Mohan S, Campbell NR, Willis K. Effective population-wide public health interventions to promote sodium reduction. CMAJ. 2009;181(9):605-9. 


\section{CURRÍCULO LATTES - PROFESSOR TITULAR CARLOS AUGUSTO MONTEIRO}

\section{Carlos Augusto Monteiro}

Bolsista de Produtividade em Pesquisa do CNPq - Nível 1A

A formação acadêmica do Professor Monteiro inclui graduação em Medicina, Residência e Mestrado em Medicina Preventiva, Doutorado em Saúde Pública, todos cursados na USP, e pós-doutorado no Instituto de Nutrição Humana da Columbia University. Sua carreira de pesquisador e orientador (já formou 10 mestres e 11 doutores, vários deles hoje ocupando posição de liderança na área da epidemiologia nutricional) foi feita no Depto.de Nutrição da Faculdade de Saúde Pública da USP, desde o ingresso como auxiliar de ensino em 1975 até o concurso para Professor Titular em 1990. Entre 1990 e 1992, trabalhou na Unidade de Nutrição da OMS em Genebra e foi professor visitante de duas universidades européias (Bonn e Genebra). É coordenador científico do Núcleo de Pesquisas Epidemiológicas em Nutrição e Saúde da Universidade de São Paulo NUPENS/USP e suas linhas de pesquisa incluem métodos para avaliação nutricional de populações, tendência secular e determinantes biológicos e socioeconômicos de doenças relacionadas à nutrição e avaliação de programas de alimentação e nutrição. De dezenas de projetos nessas linhas, realizados com o apoio de agências de fomento nacionais e internacionais e em colaboração com pesquisadores brasileiros e estrangeiros, resultaram 7 livros e monografias, mais de 200 publicações científicas, incluindo artigos, editoriais e capítulos de livros, mais de 100 artigos indexados no Medline e 1099 citações no ISI (H index: 18). É bolsista de produtividade científica do CNPq desde 1981 e pesquisador nível IA desde 1989. São destaques de sua produção científica voltada para o país e publicada na forma de livros e artigos: inquéritos populacionais sobre saúde e nutrição infantil realizados no município de São Paulo nas décadas de 70, 80 e 90, cujos resultados foram essenciais para redefinir o enfoque e o conteúdo dos programas nutricionais nas unidades básicas de saúde de 
São Paulo e, posteriormente, de todo o país; projeto temático interdisciplinar FAPESP de resgate e interpretação das tendências temporais das condições de saúde e nutrição da população brasileira na segunda metade do século $\mathrm{XX}$, do qual resultou obra de fôlego ganhadora do prêmio Jabuti de melhor livro do ano na categoria Ciências Naturais e Medicina; análise de dados da Pesquisa de Orçamentos Familiares do IBGE de 2002-2003, que trouxe nova e crítica visão para o problema da segurança alimentar no país; projeto de desenvolvimento e validação de sistema nacional de monitoramento de fatores de risco para doenças crônicas baseado em entrevistas telefônicas, ganhador do Prêmio de Incentivo em Ciência e Tecnologia para o SUS de 2005 e inspirador de sistema implantado em 2006 pelo Ministério da Saúde nas 26 capitais de estados brasileiros e distrito federal. Como parte de sua produção científica de impacto universal (publicada em revistas como BMJ, WHO Bull, Am J Pub Health, A J Cl Nut, Eur J Cl Nut, Int J Obes, Trans R Soc Trop Med Hyg, Ann Hum Biol, entre outras) destacam-se estudos publicados no final dos anos 80 sobre determinantes da tendência secular do aleitamento materno e da mortalidade infantil em países em desenvolvimento; contribuições metodológicas para a criação de novos indicadores para a avaliação antropométrica do estado nutricional de populações publicadas entre 1991 e 1997; e uma dezena de artigos sobre o fenômeno da transição nutricional nos países em desenvolvimento publicados entre 1995 e 2005 e que já receberam mais de 600 citações no ISI. É co-chairman do comitê sobre transição nutricional da International Union of Nutritional Sciences, Editor Científico da Revista de Saúde Pública, Editor Associado da Public Health Nutrition e membro do Conselho Editorial da EDUSP e das revistas International Journal of Obesity e Epidemiologic Reviews. Integra, ainda, o comitê de experts da OMS para implementação da Global Strategy on Diet, Physical Activity and Health e a força tarefa da OPS para eliminação das gorduras trans nas Américas. 


\section{CURRÍCULO LATTES - FLÁVIO SARNO}

\section{Flávio Sarno}

Médico graduado pela Universidade de São Paulo (USP), com especialização em Endocrinologia e Metabologia também pela USP. Atuou por vários anos no atendimento médico de pacientes nas áreas de Clínica Médica e Endocrinologia. Em 2001, passa a se dedicar ao estudo da saúde coletiva, com atenção voltada às doenças crônicas não transmissíveis (DCNT), e em 2005 obtém o título de Mestre em Saúde Pública pela Faculdade de Saúde Pública da USP. Dando continuidade aos seus estudos, atualmente é doutorando em Nutrição em Saúde Pública pela mesma Faculdade. Participa de pesquisas nas áreas de epidemiologia e saúde pública voltadas à prevenção de obesidade e hipertensão arterial e intervenções para redução do consumo excessivo de sal. 